\title{
Influencing Kidney Health and Function in Young Female Rats Through Dietary Alterations
}

Joseph Christopher Gigliotti

West Virginia University

Follow this and additional works at: https://researchrepository.wvu.edu/etd

\section{Recommended Citation}

Gigliotti, Joseph Christopher, "Influencing Kidney Health and Function in Young Female Rats Through Dietary Alterations" (2011). Graduate Theses, Dissertations, and Problem Reports. 4720.

https://researchrepository.wvu.edu/etd/4720

This Dissertation is protected by copyright and/or related rights. It has been brought to you by the The Research Repository @ WVU with permission from the rights-holder(s). You are free to use this Dissertation in any way that is permitted by the copyright and related rights legislation that applies to your use. For other uses you must obtain permission from the rights-holder(s) directly, unless additional rights are indicated by a Creative Commons license in the record and/ or on the work itself. This Dissertation has been accepted for inclusion in WVU Graduate Theses, Dissertations, and Problem Reports collection by an authorized administrator of The Research Repository @ WVU.

For more information, please contact researchrepository@mail.wvu.edu. 


\title{
Influencing Kidney Health and Function in Young Female Rats Through Dietary Alterations
}

\author{
Joseph Christopher Gigliotti
}

Dissertation submitted to the Davis College of Agriculture, Natural Resources and Design in partial fulfillment of the requirements for a degree of

\author{
Doctor of Philosophy \\ in \\ Animal and Food Sciences \\ Janet C. Tou, PhD., Chair \\ Jacek Jaczynski, PhD. \\ Kenneth Blemings, PhD. \\ Kimberly Barnes, PhD. \\ Randall W. Bryner, Ed.D.
}

Division of Animal and Nutritional Sciences

Morgantown, West Virginia

2011

Keywords: diet; omega-3 fatty acids; kidney; nephrocalcinosis 


\section{ABSTRACT \\ Influencing Kidney Health and Function in Young Female Rats Through Dietary Alterations}

\section{Joseph C. Gigliotti}

The occurrence of kidney failure in the US has drastically increased over the past decade. The decline in health associated with chronic kidney disease can be prevented if detected early in disease progression. However, substantial damage has often occurred before detection of renal disease is possible. Therefore, disease prevention (as in all diseases) is the optimal treatment.

In regards to the kidneys, dietary habits can have a profound influence on the function and overall kidney health. This is particularly evident in female rats due to their susceptibility to diet induced renal disease. In female rats, the initiation of chronic kidney disease typically involves nephrocalcinosis (NC). NC is characterized by increased renal calcium $(\mathrm{Ca})$ content, and involves the pathological deposition of mineral deposits in renal tissue. Fluctuations in dietary $\mathrm{Ca}$ and phosphorus $(\mathrm{P})$ content are the major consideration in managing NC. However, other dietary components can mediate the development and severity of this disease in rats.

Based on our study results, the source of dietary protein and lipid can influence the development of $\mathrm{NC}$ in female rats. Our initial study compared the nutritional quality of a novel protein source derived from krill to the milk protein, casein. Rats fed krill protein concentrate (KPC) had lower kidney weights $(P<0.001)$, lower kidney Ca content $(P=0.002)$, and lower incidence of renal damage than rats fed casein based diets. These changes occurred in the absence of fluctuating urinary mineral content, which is a major cause of NC. Further analysis showed that KPC contained residual krill oil, which is rich in omega-3 polyunsaturated fatty acids ( $\omega$-3 PUFAs). The next study involved isolation and characterization of krill oil. Krill oil is a unique lipid with high $(>65 \%)$ polar lipid content including phospholipids, whereas other dietary sources of $\omega-3$ PUFAs were found to be predominately triacyglyceride. In the final study, the characterized oils were added to casein-based diets and fed to female rats to determine if lipid content influences the development of NC. While rats fed KPC appeared to be protected from NC, rats fed the high fat diet as krill oil were the only rats who developed NC. The high inclusion of krill oil resulted in elevated dietary $\mathrm{P}$ content due to its high phospholipid content. Aside from $\mathrm{NC}$, the renal fatty acid content was influenced by the diet and lead to an apparent decrease in urinary prostaglandin production in all rats consuming the long-chain $\omega-3$ polyunsaturated fatty acids ( $\omega$-3 LCPUFAs) eicosapentaenoic (EPA) and docosahexaenoic acid (DHA). The consumption of the different $\omega$-3 PUFA sources also resulted in reduced activity of the proinflammatory transcription factor $\mathrm{NF} \kappa \mathrm{B}$, and expression of the proinflammatory cyclooxygenase -2 (COX-II) and transforming growth factor-beta (TGF- $\beta$ ). Despite these observed results, no differences were noted in serum measures of kidney function. We concluded that changing the source of dietary protein and lipid can mediate renal health in female rats. It appears that $\omega-3$ PUFAs do not influence the nephrocalcigenic nature of casein. However, providing dietary $\omega-3$ PUFAs resulted in decreased renal inflammatory activity as compared to rats fed corn oil. This 
supports the benefit of $\omega$-3 PUFA supplementation in reducing the onset of diseases caused by inflammatory processes, and suggests that different dietary sources of $\omega$ PUFAs vary in regards to biological activity. 


\section{Acknowledgements}

First, I would like to thank God for the many gifts he has presented me with throughout my life. In life there are things you can plan for and those you cannot, and I am eternally grateful for the way all things have turned out. I am grateful for meeting my beautiful wife Kristen, and having the opportunity to marry into a wonderful family. I am grateful to have learned from my parents; some through lectures and some through hardships. I have wonderful friends that make life and work very enjoyable, and for that I am also grateful.

I believe that the Davis College is a wonderful division of the college, with wonderful faculty and support staff. I have learned so much from various faculty members, information pertaining to both my future career and life in general. My supervisor Dr. Janet Tou has displayed both excellent professionalism and compassion throughout my work as both an undergraduate and graduate student. Through her guidance I feel that I have been able to flourish as a graduate student. Overall, I have

obtained excellent training here at the Davis College; training that I will use for rest of my life. Those listed above are just a few of the many people whom have assisted me to what success I have and will accomplish. Thank you all. 


\section{TABLE OF CONTENTS}

\begin{tabular}{|c|c|c|c|}
\hline & Page \\
\hline \multicolumn{3}{|c|}{ ABSTRACT } & ii \\
\hline \multicolumn{3}{|c|}{ ACKNOWLEDGEMENTS } & iv \\
\hline \multicolumn{3}{|c|}{ TABLE OF CONTENTS } & $\mathrm{V}$ \\
\hline \multicolumn{3}{|c|}{ LIST OF TABLES } & vii \\
\hline \multicolumn{3}{|c|}{ LIST OF FIGURES } & viii \\
\hline \multirow[t]{7}{*}{1.0 . } & \multicolumn{2}{|c|}{ LITERATURE REVIEW } & 1 \\
\hline & & THE BIOCHEMISTRY OF OMEGA-3 & 1 \\
\hline & & \multicolumn{2}{|l|}{ POLYUNSATURATED FATTY ACIDS } \\
\hline & 1.2 & RENAL PHYSIOLOGY & 9 \\
\hline & 1.3 & THE INFLUENCE OF DIETARY COMPONENTS & 20 \\
\hline & \multicolumn{3}{|c|}{ ON NEPHROCALCINOSIS IN RATS } \\
\hline & 1.4 & REFERENCES & 24 \\
\hline 2.0 . & \multicolumn{2}{|c|}{ STUDY OBJECTIVES } & 37 \\
\hline \multirow[t]{7}{*}{3.0 . } & \multicolumn{2}{|c|}{ CHAPTER 1} & 38 \\
\hline & 3.1 & BACKGROUND & 39 \\
\hline & 3.2 & INTRODUCTION & 39 \\
\hline & 3.3 & MATERIALS AND METHODS & 41 \\
\hline & 3.4 & RESULTS & 47 \\
\hline & 3.5 & DISCUSSION & 50 \\
\hline & 3.6 & REFERENCES & 56 \\
\hline
\end{tabular}


$\begin{array}{lll}\text { 4.0. } & \text { CHAPTER } 2 & 70\end{array}$

$\begin{array}{lll}4.1 & \text { BACKGROUND } & 71\end{array}$

$\begin{array}{lll}4.2 & \text { INTRODUCTION } & 72\end{array}$

4.3 MATERIALS AND METHODS 75

$\begin{array}{lll}4.4 & \text { RESULTS AND DISCUSSION } & 87\end{array}$

4.5 REFERENCES 93

$\begin{array}{lll}\text { 5.0. CHAPTER } 3 & 110\end{array}$

$\begin{array}{lll}5.1 & \text { BACKGROUND } & 111\end{array}$

$\begin{array}{lll}5.2 & \text { INTRODUCTION } & 111\end{array}$

5.3 MATERIALS AND METHODS 113

$\begin{array}{lll}5.4 & \text { RESULTS } & 120\end{array}$

$\begin{array}{lll}5.5 & \text { DISCUSSION } & 123\end{array}$

$\begin{array}{lll}5.6 & \text { REFERENCES } & 128\end{array}$

6.0. DISSERTATION RESULTS AND CONCLUSIONS 149 


\section{LIST OF TABLES}

3.0 CHAPTER 1

$\begin{array}{ll}\text { TABLE } 1 . & 62\end{array}$

TABLE 2. 63

TABLE 3. 64

$\begin{array}{ll}\text { TABLE } 4 . & 65\end{array}$

TABLE 5. 66

4.0 CHAPTER 2

$\begin{array}{ll}\text { TABLE } 1 . & 109\end{array}$

5.0 CHAPTER 3

TABLE 1.

$\begin{array}{ll}\text { TABLE } 2 . & 143\end{array}$

$\begin{array}{ll}\text { TABLE } 3 . & 144\end{array}$

$\begin{array}{ll}\text { TABLE } 4 . & 145\end{array}$

$\begin{array}{ll}\text { TABLE 5. } & 147\end{array}$

TABLE $6 . \quad 148$ 


\section{LIST OF FIGURES}

1.0 LITERATURE REVIEW

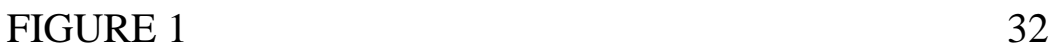

FIGURE 2

$\begin{array}{ll}\text { FIGURE } 3 & 34\end{array}$

$\begin{array}{ll}\text { FIGURE } 4 & 35\end{array}$

3.0 CHAPTER 1

$\begin{array}{ll}\text { FIGURE } 1 & 67\end{array}$

$\begin{array}{ll}\text { FIGURE } 2 & 68\end{array}$

$\begin{array}{ll}\text { FIGURE CAPTIONS } & 69\end{array}$

4.0 CHAPTER 2

$\begin{array}{ll}\text { FIGURE } 1 & 100\end{array}$

$\begin{array}{ll}\text { FIGURE } 2 & 101\end{array}$

$\begin{array}{ll}\text { FIGURE } 3 & 102\end{array}$

$\begin{array}{ll}\text { FIGURE } 4 & 103\end{array}$

$\begin{array}{ll}\text { FIGURE } 5 & 104\end{array}$

$\begin{array}{ll}\text { FIGURE } 6 & 105\end{array}$

$\begin{array}{ll}\text { FIGURE } 7 & 106\end{array}$

$\begin{array}{ll}\text { FIGURE CAPTIONS } & 107\end{array}$

5.0 CHAPTER 3

$\begin{array}{ll}\text { FIGURE } 1 & 134\end{array}$

$\begin{array}{ll}\text { FIGURE } 2 & 135\end{array}$

$\begin{array}{ll}\text { FIGURE } 3 & 136\end{array}$ 
FIGURE 4

FIGURE 5

138

FIGURE 6

139

FIGURE CAPTIONS

140 


\subsection{Literature Review}

\subsection{The Biochemistry of Omega-3 Polyunsaturated Fatty Acids ( $\omega$-3 PUFAs)}

\subsubsection{Essential Fatty Acids}

Mammalian hepatocytes and adipocytes are able to synthesize a variety of fatty acids, which serve primarily as a metabolic energy source. However, $\alpha$ -

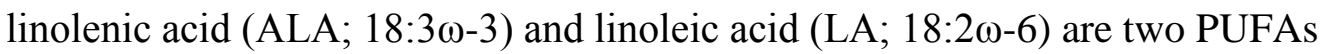
which cannot be synthesized de novo. Mammals do not have delta $(\Delta) 12$ and $\Delta 15$ desaturases, therefore double bonds cannot be placed beyond the $\Delta 9$ carbon during fatty acid synthesis. The double bonds found in LA are at carbons $\Delta 9$ and $\Delta 12$, and carbons $\Delta 9, \Delta 12$, and $\Delta 15$ in ALA. Therefore, ALA and LA are termed essential fatty acids (EFAs) and must be obtained from the diet.

Currently, it is recommended for women to consume $\sim 1.1$ and men $\sim 1.6$ $\mathrm{g} / \mathrm{d}$ of ALA. LA requirements are $\sim 12 \mathrm{~g} / \mathrm{d}$ for women and $\sim 17 \mathrm{~g} / \mathrm{d}$ for men [1]. Rodent EFA recommendations consist of $1.2 \mathrm{~g} \mathrm{LA} / \mathrm{kg}$ diet and $2 \mathrm{~g} \mathrm{ALA} / \mathrm{kg}$ [2]. However, these requirements were based on tissue $\omega-6$ and $\omega-3$ concentrations as opposed to tissue functionality. Therefore, the recommendations for EFAs may change once the relationship between tissue fatty acid content and tissue function is better understood. 


\subsubsection{Conversion of EFAs to long-chain polyunsaturated fatty acids (LCPUFAs )}

Despite being termed essential, little biological activity has been directly attributed to ALA and LA. Instead, the essential fatty acids are elongated and desaturated to form their respective LCPUFAs. The formation of LCPUFAs from EFAs involves a series of steps, which occur primarily at the endoplasmic reticulum of hepatocytes (Figure 1).

The action of $\Delta 6$ desaturase is the committed step in EFA conversion to LCPUFAs [3]. Subsequent elongation and another desaturation by $\Delta 5$ desaturase

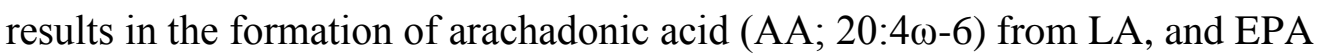

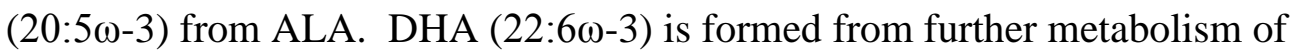
EPA, which includes: two elongation reactions, another desaturation by $\Delta 6$ desaturase, and relocation to the peroxisome for a single round of $\beta$-oxidation [4]. In mammalian tissues, AA predominates as the major $\omega-6$ LCPUFA, while EPA and DHA are the primary $\omega-3$ LCPUFAs [5].

Despite the biological importance attributed to these LCPUFAs, the conversion of the $\omega-3$ EFA ALA into EPA and DHA appears to be limited. Factors limiting this conversion include: competition and substrate specificity for common elongation and desaturation enzymes [6], preference for ALA as a metabolic fuel [7], and LCPUFA induced suppression of liver desaturase enzyme expression [8]. The competition between LA and ALA is supported by a study in females subjects provided formulas consisting of constant LA ( $4 \%$ total energy) and variable ALA content ( $0-16 \%$ of total energy). The EPA content in 
circulating lipid fractions increased from 0.2 to $~ 1.8 \%$ of total fatty acids with increasing ALA consumption. Despite the increasing presence of ALA, numerical increases in plasma AA were still observed [9] Previous studies in men have shown that the oxidation of fatty acids is influenced by both the length of the ingested fatty acid and degree of saturation. By measuring the exhalation of

${ }^{13} \mathrm{CO}_{2}$ in men fed radiolabeled fatty acids, it was determined that the preference for fatty acid oxidation is $\mathrm{C} 12: 0>\mathrm{C} 18: 3(\omega-3)>18: 1 t(\omega-9)>18: 1 c(\omega-9)>$ 18:2( $\omega-6)>16: 0>18: 0$ [10]. Increased oxidation of ALA explains why only $15 \%$ of ALA is used to synthesize EPA and DHA in humans; with ALA derived DHA being undetectable in some studies $[5,11]$. Similar results were found in rodent studies, suggesting that mammalian $\omega$-3 LCPUFA synthesis is limited and should be obtained in the diet [12].

\subsubsection{Dietary sources of $\omega-3$ PUFAs}

Research and health claims have promoted increased consumption of PUFAs. Plant oils are the richest source of the essential fatty acids LA and ALA, with flaxseed oil reported to be one of the richest sources of ALA [13]. However, the low mammalian de novo synthesis of the $\omega$-3 LCPUFAs EPA and DHA from ALA has led to the recommendation to increase dietary consumption of these LCPUFAs.

Recently, it has been suggested that healthy individuals should consume 400-500 mg $\omega$-3 LCPUFAs per day to decrease the risk for mortality associated with cardiovascular disease. This level of $\omega$-3 LCPUFA intake can be achieved in 
the diet by following the American Heart Association's recommendation to consume two servings of fatty fish per week [14]. The recommended types of fish include tuna, salmon, and menhaden which are normally harvested from colder waters. Fatty fish are high in the $\omega-3$ LCPUFAs EPA and DHA because their diets consist of various marine algae and planktonic crustaceans such as algae and krill. These planktonic organisms have a high capability for de novo $\omega$ 3 LCPUFAs synthesis, and depletion of fish stocks and concern of heavy metal contamination have led to an interest in the nutritional value of krill and algae [15, 16].

\subsubsection{Cellular activities of LCPUFAs}

Despite the host of benefits associated with $\omega-3$ LCPUFA consumption, the cellular mechanisms behind their biological effects are still not fully understood. Originally, fatty acid trafficking was believed to be a relatively random and somewhat passive event. Information discovered during the past two decades suggests that fatty acid metabolism and cellular activity is tightly regulated [17], and that PUFAs are crucial components in cellular biology.

\section{$\underline{\text { PUFAs and biological membranes }}$}

Fatty acids are typically cycled through several cellular compartments upon acquisition. The cellular fate of fatty acids depends on both the needs of the cell as well as the type of fatty acid present. As mentioned above, the oxidation of fatty acids depends on the length and desaturation of the fatty acid. However, 
fatty acid oxidation typically accounts for less than $40 \%$ of detectable fatty acid utilization [10]. This suggests that storage as triglycerides and membrane incorporation are the major metabolic fates of dietary fatty acids.

A clear response to changes in dietary LCPUFA content is the resultant influence it has on cellular membrane fatty acid composition. While the saturated and monounsaturated fatty acid content of membranes remain constant (approximately 50 and 30\%, respectively), the $\omega-6$ and $\omega-3$ PUFA content appears to be the most variable. This has important implications in cellular biology, since membrane fatty acid content influences membrane physiochemistry and subsequent cellular functions $[18,19]$.

The fatty acid content of the membrane can have profound influence on cellular activity and tissue function. A classic example for this interaction involves the activation of phospholipases. While several forms of phospholipases exist, all perform the similar action of cleaving membrane phospholipids upon stimulation by intracellular calcium. Phospholipase $\mathrm{A}_{2}$ specifically targets the $s n$ 2 position of membrane phospholipids, and results in the liberation of the AA or EPA that commonly resides there. Therefore, changing the membrane $\omega-6$ and $\omega-$ 3 PUFA content can influence which species of LCPUFA are released upon phospholipase activation. The activation of phospholipase $\mathrm{A}_{2}$ during certain disease states suggests that liberated fatty acids play a key role in inflammatory processes [20]. 
The influence of PUFAs on NFkB activity

During the past 15 years, it has become evident that fatty acids influence gene expression through mediating the activity of various transcription factors [21]. Most studies addressing the influence of PUFAs on transcription factor activity is focused on metabolic processes. However, recent data suggests that PUFAs can also modulate the activity of transcription factors involved in inflammatory processes.

Nuclear factor kappa-light-chain-enhancer of activated B cells (NFкB) is considered a key regulator of cell viability and inflammatory pathways. Activated $\mathrm{NF \kappa B}$ upregulates the expression of various proinflammatory proteins in various cell types [22]. Therefore, $\mathrm{NF \kappa B}$ is considered a master regulator of the inflammatory response and is a common target for steroidal anti-inflammatory drugs [24, 24].

Interestingly, fatty acids appear to play a role in NFkB activity. DHA supplementation, but not EPA, resulted in $60 \%$ decrease in NFkB activity, $50 \%$ reduction in COX-II expression [25], and greater than $25 \%$ reduction in vascular cellular adhesion molecule-1 (VCAM-1) expression in cultured endothelial cells [26]. In contrast, cultured immune cells and adipocytes display an increased NFkB activity when cultured with AA or palmitate [27, 28]. Therefore, the cellular and biological response depends on the species of fatty acid present and supports the recommendation to increase $\omega-3$ LCPUFA consumption. 


\section{PUFAs and eicosanoid synthesis}

As mentioned above, PUFAs influence the expression of COX-II through mediating NFאB activation. The COX enzymes initiate the formation of prostaglandins, which are hormone like signaling compounds involved in virtually all aspects of physiology.

AA is the typical substrate for prostaglandin production. Activated phospholipase $\mathrm{A}_{2}$ can result in liberated AA or EPA, which provides substrates for COX (which is located on the endoplasmic reticulum and nuclear envelope). COX converts AA to prostaglandin $\mathrm{H} 2\left(\mathrm{PGH}_{2}\right)$, which is an intermediate in the production of the 2 -series prostaglandins $\left(\mathrm{PGE}_{2}, \mathrm{PGI}_{2}, \mathrm{TXA}_{2}, \mathrm{PGF}_{2 \alpha}\right.$ etc.) by a respective synthase. Once produced, prostaglandins mediate various physiological responses by binding to select 7-transmembrane domain, G-protein coupled receptors. The physiological outcome is based upon the species of prostaglandin produced, as well as the nature of the prostaglandin receptor present on the target cells. The species of prostaglandin produced depends on the LCPUFA used as a substrate. The 2-series is derived from the $\omega-6$ LCPUFA AA, while the 3-series of prostaglandins are derived from the $\omega$-3 LCPUFA EPA. The 3- series of prostaglandins typically display different affinities for prostaglandin receptors as compared to the 2 -series prostaglandins. Therefore, different cellular and physiological responses may occur to similar prostaglandins that differ in species. For example, $\mathrm{PGE}_{3}$ differed from $\mathrm{PGE}_{2}$ in inducing proliferation of cultured fibroblasts. $\mathrm{PGE}_{2}$ resulted in fibroblast proliferation at $50 \mathrm{ng} / \mathrm{ml}$, while similar $\mathrm{PGE}_{3}$ concentrations resulted in no difference in cell number. $\mathrm{PGE}_{3}$ also 
resulted in decreased expression of proinflammatory protein expression in both fibroblasts and macrophages as composed to cells exposed to $\mathrm{PGE}_{2}$ [29].

\section{Conclusion}

LCPUFAs are important cellular compounds, as evident by the essential nature of their 18 carbon precursors. The reduction in inflammatory transcription factor activity and prostaglandin production supports the importance of $\omega-3$ LCPUFAs in ameliorating inflammatory conditions. However, it is unclear if LCPUFAs influence non-pathological processes. Aside from mediating inflammatory processes, prostaglandins are involved in all aspects of physiology. For example, kidneys are heavily reliant on prostaglandin production while NFkB mediates several forms of renal disease. Therefore, the dietary PUFA content may heavily influence renal physiology. 


\subsection{Renal Physiology}

In general, the kidneys are viewed solely as excretory organs. While a major function of the kidneys is to filter wastes out of the circulation, the kidneys also play key roles in various physiological processes [30].

\subsubsection{Renal Anatomy and Vasculature}

The kidneys are bean shaped organs located between the $12^{\text {th }}$ thoracic and the third lumbar vertebrae in humans. Each kidney (left and right) receives arterial blood from the descending aorta via the left or right renal artery, which enters the kidneys through the renal hilum (which is also the site of renal innervation). Inside the kidney the renal artery undergoes a series of divisions to form the segmental, interlobular, arcuate, and intralobular arteries as well as the afferent and efferent arterioles. The efferent arterioles further divide to form the peritubular capillaries and vesa recta, which adjoin to form venuoles and eventually merge to form the renal vein.

\subsubsection{The nephron}

The vasculature of the kidney provides necessary nutrients and gases to the surrounding tissue. In addition, the primary functions of the kidney are accomplished within specialized regions of the renal vasculature, and include regulation of blood volume, waste content, $\mathrm{pH}$, electrolyte and mineral concentrations, and nutrient concentrations. By regulating these components of the blood, the kidneys are the primary organ responsible for maintaining a 
constant composition of all extracellular fluids. In humans, it has been estimated that 1700 liters of fluid flow through the kidney each day.

To accomplish this work load, each human kidney is composed of around 1 million nephrons ( 2 million in total). The nephron is composed of vascular and tubular portions which are involved in filtering the blood (Figure 2). Healthy individuals have around 2 million nephrons; yet, only $\sim 10 \%$ of this capacity is needed to support life. Despite this large reserve capacity, millions of Americans suffer from inadequate renal function each year [31].

The structure and functions of the glomerulus

The primary structure of the nephron is the glomerulus. The glomerulus includes a number of cells / tissues that together perform the filtering responsibility of the kidney (as well as other processes). The glomerulus is composed of an afferent arteriole, Bowman's capsule, tubular capillaries (including the vesa recta), podocytes, and mesangium (Figure 3). Glomerular diseases (glomerulonephritis) are the primary cause of renal failure in the U.S., which suggests that this is a key structure in renal physiology [31].

The physiology of the glomerulus begins with the entry of blood into the glomerulus via the afferent arterioles. The afferent arteriole branches to form a "knot" of capillaries, which are completely encased by a structure called Bowman's capsule. These capillaries are extremely "leaky" due to the presence of fenestrations, which are porous structures in the walls of the capillaries (Figure 4). Fenestrations allow approximately $20 \%$ of the fluid portion of blood (plasma) 
to be forced out of the capillaries into Bowman's capsule. This filtered fluid is termed filtrate since this is the portion of blood that was filtered. The remaining $80 \%$ of the blood not filtered leaves the capillaries via the efferent arteriole, and branches to form capillaries which surround the rest of the nephron [30].

The capillary structure inside Bowman's capsule appears as a "knot" due to the presence of podocytes and the mesangium (Figure 3). These components are considered pericapillary structures, since they are found amongst (mesangium) and/or physically attached to (podocytes) the capillaries. The podocytes "coat" the capillaries and assist with the filtering process, whereas the mesangium is a complex tissue with an undefined role in renal physiology. The mesangium is a matrix consisting of various collagens (and other structural components), the mesangial cells (which produce the matrix), and resident immune cells. Although the role of the mesangium in renal physiology is not completely understood, mesangial expansion is a common finding in glomerular diseases [32]. Mesangial expansion results in interference of normal glomerular processes, and is termed glomerular scarring (or glomerulosclerosis) upon histological evaluation.

Glomerular filtration occurs by only allowing a portion of the plasma to escape the capillaries and enter into Bowman's space (Figures 3 and 4). Normally the filtrate and blood have equal concentrations of small solutes such as organic nutrients and minerals, while the cell and protein content of the filtrate is negligible. This suggests that large plasma components such as cells and albumin are unable to escape the capillary lumen. Early research described that the glomerulus discriminates not only by size, but also by the charge of a molecule. 
This filtering capacity appears to be largely mediated by the charge characteristics of the glomerular basement membrane. Loss of charge discrimination has been associated with renal disease in animal models, resulting in proteinuria and deposition of immune complexes within the glomerulus [33].

\section{Reabsorption along the tubular portion of the nephron}

Upon exiting the glomerular capillaries, the plasma filtrate is now subject to the biochemical processes of the tubular portion of the nephron. Small organic nutrients, such as glucose and amino acids, and minerals are as concentrated in the filtrate as found in the plasma. With 1700 liters of blood flowing through the kidney daily, deficiencies of these solutes would quickly arise if they were not

reabsorbed in the kidneys. Almost $100 \%$ of the sodium, glucose, amino acids, Ca, and water is reabsorbed from the filtrate by the kidneys. Aside from nutrient reabsorption, the kidneys play a key role in the maintenance of the $\mathrm{pH}$ and electrolyte content of the blood. Maintenance of these and other compounds can include reabsorptive and secretory processes, both of which are accomplished within the tubular portion of the nephron [30].

Upon leaving the glomerulus, the solute rich filtrate enters into the proximal convoluted tubule. The proximal convoluted tubule is where the majority of the glucose and amino acids are reabsorbed along with a majority of the sodium, chloride, and water. Reabsorption of glucose and amino acids is mediated by sodium-dependent cotransporters located on the apical membrane of the tubular epithelial cells. The organic nutrient transported from the tubular 
lumen into the epithelial cell along with sodium. Since this process is continually occurring, the concentration of organic nutrients within the epithelial cell increases. High concentrations drive the diffusion of these nutrients out of the epithelial cell and into the peritubular capillaries, which allow for reentry into the general circulation [30].

\section{$\underline{\mathrm{Ca} \text { and } \mathrm{P} \text { reabsorption }}$}

The reabsorption of $\mathrm{Ca}$ and $\mathrm{P}$ also occurs predominately in the proximal tubule. Tubular P is reabsorbed in a sodium dependent cotransport mechanism, while Ca reabsorption primarily occurs via paracellular pathway [48]. However, renal handling of $\mathrm{Ca}$ and $\mathrm{P}$ can also be influenced by hormonal signaling.

The major hormones involved in $\mathrm{Ca}$ and $\mathrm{P}$ metabolism are parathyroid hormone, vitamin D, and calcitonin [30]. Generally, parathyroid hormone and vitamin $\mathrm{D}$ are involved in increasing serum $\mathrm{Ca}$ levels by influencing release of $\mathrm{Ca}$ and $\mathrm{P}$ from bone, increasing intestinal absorption of $\mathrm{Ca}$, and decreasing urinary excretion of $\mathrm{Ca}$. Increased urinary reabsorption of $\mathrm{Ca}$ is mediated by parathyroid hormone induced increase in $\mathrm{Ca}$ channels in the distal nephron. Due to the toxic effects of elevated serum $\mathrm{P}$, parathyroid hormone also stimulates the urinary excretion of $\mathrm{P}$ to counteract the increase in serum $\mathrm{P}$ induced by bone resorption. Calcitonin, on the other hand, is released from the thyroid gland in the presence of high serum Ca. The release of calcitonin triggers a general hypocalcemic response, which primarily involves decreased Ca release from bone. 
After losing a large portion of the solutes (i.e. organic nutrients, $\mathrm{Ca}, \mathrm{P}$, etc.) in the proximal tubule, the remaining filtrate eventually descends from the cortex of the kidney (cortex includes the glomerulus and both the proximal and distal convoluted tubules) into the medullary tissue (medulla includes both the descending and ascending Loops of Henle and the collecting ducts). As the filtrate leaves the proximal tubule, it descends into the medulla via the descending limb of the Loop of Henle. The Loop of Henle has varying properties which contribute to the development and maintenance of the medullary characteristics. The descending limb is water permeable. Therefore, water diffuses out of the tubular lumen in response to the loss of solutes within the proximal tubule. The filtrate then continues through the ascending limb, where sodium-chloride is actively pumped out of the lumen and into the interstitial space and associated capillaries. The increased interstitial salinity is the driving force for water reabsorption from the kidney tubules. This provides an ability to regulate water excretion, which is a key function of the kidneys [30].

The Renin-Angiotensin-Aldosterone-System in Sodium and Water Reabsorption

Variable hydration states occur daily; yet extracellular volume remains relatively constant. This is accomplished by fluctuating the amount of water excreted or retained in urine. When there is an excess of water (overhydrated), then water reabsorption in the kidney is minimized and results in increased urinary volume (diuresis). The opposite occurs in states of dehydration, where the kidneys reabsorb water and urinary volume decreases (antidiuresis). This process 
is initiated and carried out within the nephron and is referred to as the reninangiotensin-aldosterone system (RAAS). RAAS's primary function is to maintain efficient blood flow through the kidney by modulating plasma hemodynamics [30].

The initiation of RAAS occurs with the juxtaglomerular apparatus, which is a structure composed of the afferent and efferent arterioles of the glomerulus and the ascending limb of Henle (Figure 5). Within the juxtaglomerular apparatus are a set of specialized cells which respond to changes in extracellular fluid components by releasing the protease renin. Angiotensinogen is continuously secreted by the liver and has little biological activity. The activation of angiotensinogen involves proteolytic cleavage by renin to produce angiotensin I. This proteolytic cleavage is the rate limiting step in the activation of the RAAS. Once angiotensin I is formed, it is rapidly converted to angiotensin II in pulmonary capillaries by angiotensin converting enzyme. The primary effects of angiotensin II include the secretion of aldosterone from the adrenal cortex, constriction of the efferent arterioles, and peripheral vasoconstriction. Taken together, the goal of the RAAS is to increase fluid flow through the kidney by increasing Na resorption, and redirecting blood flow through the glomerulus. The importance of the RAAS in whole body fluid content becomes evident when the mechanisms behind renin release are understood.

In the vasculature portion of juxtaglomerular apparatus, specialized granule cells act as baroreceptors which respond to changes in blood pressure. These cells produce and store renin, which is secreted in response to a drop in 
blood flow. While renin is produced and secreted from the granule cells, other cells / tissues can also induce the secretion of renin. Within the ascending limb of Henle, which is in close proximity to the granule cells, are a group of cells known as the macula densa (Figure 5). While the granule cells were baroreceptors which were sensitive to changes in blood flow in the vasculature, the macula densa cells are sensitive to the $\mathrm{NaCl}$ content of the tubular fluid. These chemoreceptive cells induce a release of renin from the granule cells in response to a drop in $\mathrm{NaCl}$. The activation of the granule cells appears to be largely mediated by the production of prostaglandins by the stimulated macula densa. Rats fed a salt restricted diet have higher renal COX-II expression, which occurred specifically in the macula densa [34]. Furthermore, cultured mouse granule cells had increased renin mRNA and renin secretion when cultured with $\mathrm{PGI}_{2}$ and $\mathrm{PGE}_{2}$ [35]. Finally, neural stimulation can also induce the release of renin. The granule cells are innervated by the sympathetic nerves. The peripheral baroreceptors induce sympathetic nerve activity during hypotension, and results in an increase in renin excretion. The association of renal blood flow, tubular $\mathrm{NaCl}$ content, and systemic hypotension further supports the importance of the kidney in maintaining and regulating both renal and peripheral blood flow.

The distal portion of the nephron, starting with the ascending Loop of Henle, is water-impermeable. Therefore, the increased salinity outside of the tubule generates an osmotic gradient that can be utilized to reabsorb more water from with filtrate. In the presence of antidiuretic hormone (ADH), the distal portion becomes water permeable by the addition of aquaporins. This allows 
water to leave the tubule due to the large interstitial sodium chloride concentration and reenter circulation via the peritubular capillaries / vesa recta. Therefore, this region of the nephron is where variable water excretion is controlled.

Tubular Secretion is Another Method to Remove Substances from the Blood

At this stage, the filtrate has lost much of its osmolarity due to solute reabsorption,(in the proximal tubule) and a portion of its water content (descending Loop of Henle). Another process begins in the distal convoluted tubule, and includes regulation of the unfiltered blood in the peritubular capillaries. By the process of tubular secretion, unwanted substances can stil be removed despite not undergoing glomerular filtration. The plasma present in the peritubular capillaries are closely associated with the nephron tubules, as indicated in the process of reabsorption. In the distal tubule, plasma components such as potassium and protons can be pumped out of the capillaries and into the filtrate for excretion. This occurs due to the location of specific channels in the distal tubule epithelial cells. In the proximal tubule (where reabsorption occurs), the solutes were pumped into the cell and then diffused through channels located on the basolateral membrane facing the capillaries. These substances diffuse back into the circulation; however, the channels for potassium and protons in the distal tubule are located on the apical membrane. Therefore, potassium and protons secreted from the capillaries diffuse into the tubular lumen for excretion. The secretion of protons and the presence of bicarbonate transporters suggests that the kidneys are also involved in acid-base balance. 
The fluid and solutes remaining in the filtrate at the end of the distal tubule are destined for excretion. The filtrate leaves the distal tubule and enters into a collecting duct. The collecting ducts route the filtrate from numerous nephrons to be collected in a calyx, which later empties into the ureter which leaves the kidney at the renal hilum. The ureter transports the filtrate to the bladder, where the urine is stored until excreted [30].

\section{Typical measurements of renal function}

Given the role of the kidney in maintaining blood composition, insufficient renal activity can influence multiple organ systems. Therefore, monitoring renal function is of great importance in both clinical and research settings.

Serum markers of renal function include creatinine, blood urea nitrogen (BUN), uric acid, total protein, albumin, Ca, and P. Serum creatinine levels can be combined with urinary excretion of creatinine to estimate glomerular filtration rate (GFR). Estimating GFR provides insight into the amount of fluid that is filtered by the kidney over a given time $(\mathrm{ml} / \mathrm{min})$. In humans, reduction in GFR allows for the severity of renal disease to be determined and is the standard method used to assess renal function. BUN is another common measurement, and also provides insight into the filtrating ability of the kidney. Urea is a waste product derived from the metabolism of amino acids, and is removed from the circulation through renal filtration. Therefore, increases in BUN signify renal deficiency. The remaining serum measures (total protein, albumin, $\mathrm{Ca}$, and $\mathrm{P}$ ) are 
not specific to renal function. For example, alterations in serum protein and albumin could result from liver abnormalities and not glomerular damage resulting in increased excretion of albumin. Likewise, changes in serum $\mathrm{Ca}$ and $\mathrm{P}$ could result in pathologies associated with bone and or mineral metabolism (such as hyperparathyroidism).

Estimating GFR is by far the most common measure of renal function used. However, less than $10 \%$ of the nephrons present in healthy individuals are required to maintain blood composition [30]. This large renal capacity makes detection of early renal damage difficult using serum measurements. To address this issue, urinary composition can also be measured to determine renal health. The urinary markers are similar to those measured in serum and typically include albumin, $\mathrm{pH}, \mathrm{Ca}$, and $\mathrm{P}$. Urinary albumin is a powerful measurement, because elevated urinary albumin (or total protein content) suggests damage has occurred to the filtrating apparatus of the kidney (i.e. glomerulus). As in the case of serum measures, urinary $\mathrm{Ca}, \mathrm{P}$, and $\mathrm{pH}$ could be the result of dysfunction in other organ systems. However, elevated urinary Ca (hypercalciuria), P (hyperphosphouria), and acidity are implicated in the etiology of certain renal diseases. Dietary components can influence the excretion of these compounds, and suggests that diet can have a profound influence on renal health. 


\subsection{The influence of dietary components on nephrocalcinosis in rats}

\subsubsection{Defining nephrocalcinosis}

Nephrocalcinosis (NC) is a form of kidney disease that refers to the accumulation of $\mathrm{Ca}$ deposits in kidney tissue. $\mathrm{NC}$ has been documented in several animal species (including humans), however there may be differences in the etiology. Due to their sensitivity for NC, the female rat is a common animal model. NC can be induced in female rats with simple changes in dietary mineral, protein, and lipid content. NC has been shown to induce inflammatory processes that result in nephron damage and fibrosis, which are involved in the initiation of other forms of renal diseases. Therefore, $\mathrm{NC}$ is considered an initiating factor for the development of chronic renal disease and renal failure [36, 37].

NC typically develops within the tubular lumen, and appears to be dependent upon filtrate concentrations. It is believed that urinary compounds typically involved in $\mathrm{NC}$ (such as $\mathrm{Ca}, \mathrm{P}$, and oxalate) must become insoluble before deposition (or nucleation) can occur. In vitro studies have shown that Cabased crystals adhere to anionic glycoproteins on the surface of tubular epithelial cells [38]. After a given exposure time, the epithelial cell engulfs the crystal as a clearance mechanism. However, free radical production and cytokine expression accompany this process, and leads to the formation of a site for nucleation [39, 40]. 


\subsubsection{Dietary components and NC}

The etiology of NC involves the precipitation of filtrate components followed by their attachment to the tubular epithelial cells. Therefore, factors influencing the solubility of urinary components (such as $\mathrm{Ca}, \mathrm{P}$, and oxalate) mediate the development of NC. These factors originate from the diet, and suggest that dietary alterations influence urinary composition and NC. This is expected since the main function of the kidney is to maintain blood composition through the production of urine.

\section{Dietary mineral content}

Variable consumption of $\mathrm{Ca}, \mathrm{P}$, and $\mathrm{Mg}$ can results in concomitant changes in their respective excretion. Surprisingly, increased consumption of dietary $\mathrm{Ca}$ is not directly associated with urinary $\mathrm{Ca}$ excretion and associated $\mathrm{NC}$ [41]. However, elevated dietary intake of $\mathrm{P}$ is tightly associated with both urinary P excretion [42] and severity of NC [43]. Several studies have also addressed the interaction of dietary $\mathrm{Ca}$ and $\mathrm{P}$ in $\mathrm{NC}$, and reported that a dietary $\mathrm{Ca}: \mathrm{P}$ ratio less than 1 is nephrocalcigenic [41]. However, it appears that the absolute amount of $\mathrm{Ca}$ and $\mathrm{P}$ is important and not just the ratio. Cockell et al., [44] found that the severity of $\mathrm{NC}$ increased with dietary $\mathrm{Ca}$ and $\mathrm{P}$ content despite a Ca:P ratio of 1.3.

\section{$\underline{\text { Dietary protein content }}$}

Dietary protein has also been shown to influence urinary characteristics. In fact, Meyer et al., [45] concluded that changing the source of dietary protein 
had a greater effect on NC than manipulations in dietary mineral content. This finding was later supported by Zhang and Beynen [46], who fed female rats diets varying in protein source (casein, soybean, or codmeal) and amount (18, 35, and 53\%). They noted significant fluctuations in both urinary and renal content, with rats fed casein having the highest $\mathrm{P}$ excretion, most acidic urine, and highest kidney Ca content. Urinary acidification is a common finding in rats with high urinary $\mathrm{P}$ content $[42,47]$. Urinary acidification could influence NC by decreasing proximal tubule $\mathrm{P}$ reabsorption and result in increased urinary $\mathrm{P}$ excretion $[48,49]$.

\section{$\underline{\text { Dietary lipid content }}$}

Few publications exist studying the influence of lipids on diet induced NC. Schmiedl et al. [50] fed rats a hyperlipidemic-EFA deficient diet high in (1\%) cholesterol and neutral fat (10\%). As compared to rats fed a standard chow diet (5\% lipid), rats fed the hyperlipidemic diet had more calcifications (mean of 2840 vs 392), and higher renal Ca and $\mathrm{P}$ content. Unlike urinary profiles mentioned above, the rats with $\mathrm{NC}$ did not excrete more $\mathrm{P}$ or an acidic urine. Instead, rats fed the hyperlipidemic diet had a more basic urine and higher excretion of oxalate leading to development of calcium oxalate $(\mathrm{CaOx})$ deposition. $\mathrm{CaOx}$ is another Ca precipitate that can form in basic urine containing elevated oxalate concentrations [49]. $\mathrm{CaOx}$ is a common form of $\mathrm{NC}$ in humans and has potent proinflammatory signaling potential [39]. However, $\mathrm{CaOx}$ stone formation is typically associated with liver or GI dysfunction. The authors noted that the 
hyperoxaluria reported was due to changes in liver oxalate synthesis, presumably due to the poor quality of the high fat diet.

Dietary PUFAs may also mediate NC through their proposed antiinflammatory actions (Section 1.1.4). Furthermore, residual $\omega$-3 PUFAs may explain why certain protein sources differ in their nephrocalcigenic ability [46]. $\omega$-3 PUFA supplementation has shown beneficial effects in rodent models of hypercalcemic NC. Burgess et al., [51] and Schlemmer et al. [52] both reported decreased renal $\mathrm{Ca}$ content in $\mathrm{Ca}$ glubonate injected rats supplemented with EPA. However, Ca gluconate injections are hypercalcemic and induce NC by sustained hypercalciuria (a different mechanism than that normally occurring in rats). Additionally, no urinary values or serum values were given to determine if the observed NC was specific to the kidney. Therefore, it is unclear if PUFAs can mediate diet induced NC. Furthermore, different sources of $\omega-3$ PUFAs exist and each may differ in ability to modulate the NC induced by feeding different dietary protein sources. Given their role in inflammatory processes and prostaglandin production, consuming diets differing in PUFA content may influence renal health and the development of NC. 


\subsection{References}

1. Institute of Medicine of the National Academies. (2002). Dietary reference intakes for energy, carbohydrate, fiber, fat, fatty acids, cholesterol, protein, and amino acids. Washington Academies Press, Washington, D.C.

2. National Research Council. (1993). Composition of Feed Ingredients (pp. 64-71). Washington, DC: National Academy Press.

3. Williams, C.M., and Burdge, G. (2006). Long-chain n-3 PUFA: plant v. marine sources. Proceedings of the Nutrition Society, 65, 42-50.

4. Sprecher, H. (2002). The roles of anabolic and catabolic reactions in the synthesis and recycling of polyunsaturated fatty acids. Prostaglandins Leukot. Essent. Fatty Acids. 67, 79-83.

5. Arterburn, L.M.m Hall, E.B., and Oken, H. (2006). Distribution, interconversion, and dose response of n-3 fatty acids in humans. Am J Clin Nutr, 83, 1467S-1476S.

6. Brenner, R.R. (1971). The desuration step in the animal biosynthesis of polyunsaturated fatty acids. Lipids, 6, 567-575.

7. Nettleton, J.A. (1991). Omega-3 fatty acids: comparison of plant and seafood sources in human nutrition. J Am Diet Assoc., 91, 331-337.

8. Wang, Y., Botolin, D., Xu, J., Christian, B., Mitchell, E., Jayaprakasam, B., Nair, M., Peters., J.M., Busik, J., Olson, L.K., and Jump, D.B. (2005). Regulation of hepatic fatty acid elongase and desaturase expression in diabetes and obesity. Lipid Research, 47, 2028-2041. 
9. Adam, O., Wolfram, G., and Zollner, N. (1986). Effect of $\alpha$-linoleni acid in the human diet on linoleic acid metabolism and prostaglandin biosynthesis. J Lipid Res, 27, 421-426.

10. DeLany, J.P., Windhauser, M.M., Champagne, C.M., and Bray, G.A. (2000). Differential oxidation of individual dietary fatty acids in humans. Am J Clin Nutr, 72, 905-911.

11. Davis, B.C. (2003). Achieveing optimal essential fatty acid status in vegetarians: current knowledge and practical implications. Am J Clin Nutr., 78, S640-S646.

12. Lin, Y.H. and Salem Jr., N. (2005). In vivo conversion of 18- and 20-C essential fatty acids in rats using the multiple simultaneous stable isotope method. J Lipid Res, 46, 1962-1973.

13. Prasad, K. (2000). Flaxseed: a source of hypocholesterolemic and antiatherogenic agents. Drug News Perspct, 13, 99.

14. Harris, W.S., Kris-Etherton, P.M., and Harris, K.A. (2008). Intakes of long-chain omega-3 fatty acid associated with reduced risk for death from coronary heart disease in healthy adults. Current Athereosclerosis Reports, 10 .

15. Tou, J.C., Jaczynski, J., and Chen, Y.C. (2007). Krill for human consumption: nutritional value and potential health benefits. Nutrition Reviews, 65, 63-77.

16. Gigliotti, J.C., Jaczynski, J., \& Tou, J.C. (2008). Determination of the nutritional value, protein quality, and safety of krill protein concentrate 
isolated using an isoelectric solubilization/precipitation technique. Food Chemistry, 111, 209-214.

17. Hajri, T. and Abumrad, N.A. (2002). Fatty acid transport across membranes: relevance to nutrition and metabolic pathology. Annual Review of Nutrition, 22, 383-415.

18. Stillwell, W. and Wassall, S.R. (2003). Docosahexaenoic acids: membrane properties of a unique fatty acid. Chemistry and Physics of Lipids, 126, 1-27.

19. Hulbert, A.J., Turner, N., Storlien, L.H., and Else, P.L. (2005). Dietary fats and membrance function: implications for metabolism and disease.

20. Gijon, M.A. and Leslie, C.C. (1994). Regulation of arachidonic acid release and cytosolic phospholipase $\mathrm{A}_{2}$ activation. Journal of Leukocyte Biology, 65, 330-336.

21. Sampath, H. and Ntambi, J.M. (2004). Polyunsaturated fatty acid regulation of gene expression. Nutrition Reviews, 62, 333-339.

22. Barnes, P.J. and Karin, M. (1997). Nuclear factor-KB - a pivotal transcription factor in chronic inflammatory diseases. NEJM, 336, 10661071.

23. Katzung, B.G. (2007). Basic and clinical pharmacology. McGraw-Hill, NY.

24. Simmonds, R.E. and Foxwell, B.M. (2008). NF-kB and its relevance to arthritis and inflammation. Rheumatology, 47, 584-590. 
25. Massaro, M., Habib, A., Lubrano, L., Del Turco, S., Lazzerini, G., Bourcier, T., Weksler, B.B., and De Caterina, R. (2006). The omega-3 fatty acid docosahexaenoate attenuates endothelial cyclooxygenaseinduction through both $\mathrm{NADP}(\mathrm{H})$ oxidase and $\mathrm{PKC} \varepsilon$ inhibition. PNAS, $103,15184-15189$.

26. De Caterina, R., Cybulsky, M.I., Clinton, S.K., Gimbrone Jr., M.A., and Libby, P. (1994). The omega-3 fatty acid docosahexaenoate reduces cytokine-induced expression of proatherogenic and proinflammatory proteins in human endothelial cells. Arterioscler Thromb, 14, 1829-1836.

27. Camandola, S., Leonarduzzi, G., Musso, T., Varesio, L., Carini, R., Scavazza, A., Chiarpottto, E., Baeuerle, P.A., and Poli, G. (1996). Nuclear factor $\kappa \mathrm{B}$ is activated by arachidonic acid but not by eicosapentaenoic acid. Biochem Biophys Res Commun, 229, 643-647.

28. Ajuwon, K.M. and Spurlock, M.E. (2005). Palmitate activates the NF-kB transcription factor and induces IL-6 and TNF $\alpha$ expression in 3T3-L1 adipocytes. J Nutr, 135, 1841-1846.

29. Bagga, D., Wang, L., Farias-Eisner, R., Glaspy, J.A., amd Reddy, S.T. (2003). Differential effects of prostaglandin derived from $\omega-6$ and $\omega-3$ polyunsaturated fatty acids on COX-2 expression and IL-6 secretion. PNAS, 100, 1751-1756.

30. Sherwood, L., Klandorf, H., and Yancey, P. (2012). Animal physiology: from genes to organisms, $2^{\text {nd }}$ edition. Brookes/Cole, KY. 
31. Porth, C.M. (2010). Essentials of pathophysiology: concepts of altered health states. Lippincott Williams \& Wilkins, PA.

32. Kashgarian, M. and Sterzel, R.B. (1992). The pathobiology of the mesangium. Kidney International, 41, 524-529.

33. Brenner, B.M., Hostetter, T.H., Humes, H.D. (1978). Glomerular permselectivity: barrier function based on discrimination of molecular size and charge. Am J Physiol, 234, F455-F460.

34. Harris, R.C., McKanna, J.A., Akai, Y., Jacobson, H.R., Dubois, R.N., and Breyer, M.D. (1994). J Clin Invest, 94, 2504-2510.

35. Jensen, B.L., Schmid, C., and Kurtz, A. (1996). Prostaglandins stimulate renin secretion and renin mRNA in mouse renal juxtaglomerular cells. Am J Physiol, 271, F659-F669.

36. Schmidt, R.E., Hubbard, G.B., Booker, J.L., \& Gleiser, C.A. (1980). Dietary induction of renal mineralization in dogs. Can. J. comp. Med., 44, 459-465.

37. Jara A, Chacon C, Ibaceta M, Valdivieso A, and Felsenfeld A (2004) Effect of ammonium chloride and dietary phosphorus in the azotaemic rat. Part II-kidney hypertrophy and calcium deposition. Nephrol Dial Transpl 19: 1993-1998.

38. Asselman, M., Verhulst, A., De Broe, M.E., \& Verkoelen, C.F. (2003). Calcium oxalate crystal adherence to hyaluronan-, osteopontin-, and CD44-expressing injured/regerating tubular epithelial cells in rat kidneys. 
39. Umekawa, T., Chegini, N., \& Khan, S.R. (2003). Increased expression of monocyte chemoattractant protein-1 (MCP-1) by renal epithelial cell in culture on exposure to calcium oxalate, phosphate and uric acid crystals. Nephrol Dial Transplant, 18, 664-669.

40. Verkoelen, C.F., \& Herhulst, A. (2007). Proposed mechanism in renal tubular crystal retention. Kidney International, 72, 13-18.

41. Al-Modhefer, A.K.J., Atherton, J.C., Garland, H.O., Singh, H.J., and Walker, J. (1986). Kidney function in rats with corticomedullary nephrpcalcinosis: effects of alterations in dietary calcium and phosphorus. J Physiol, 380, 405-414.

42. Ritkes-Hoitinga, J., Lemmens, A.G., Danse, L.H.J.C., \& Beynen, A.C. (1989). Phosphorus induced nephrocalcinosis and kidney function in female rats. J Nutr, 119, 1423-1431.

43. Haut, L.L., Alfrey, A.C., Guggenheim, S., Buddington, B., \& Schrier, N. (1980). Renal toxicity of phosphate in rats. Kidney Int, 17, 722-731.

44. Cockell, K.A., Abbe, M.R., and Belonje, B. (2002). The concentration and ratio of dietary calcium and phosphorus influence development of nephrocalcinosis in female rats. $J$ Nutr, 132, 252-256.

45. Meyer, O., Blom, L., and Sondergaard, D. (1982). The influence of minerals and protein on the nephrocalcinosis potential for rats of semisynthetic diets. Lab Anim, 16, 271-273. 
46. Zhang, X., \& Beynen, A. (1992). Increasing intake of soybean protein or casein, but not cod meal, reduces nephrocalcinosis in female rats. J Nutr, $122,2218-2225$.

47. Ritkes-Hoitinga, J., Mathot, J.N.J.J., Danse, L.H.J.C., \& Beynen, A.C. (1991). Commercial rodent diets and nephrocalcinosis in weanling female rats. Laboratory Animals, 25, 126-132.

48. Gmaj, P. and Murer, H. (1986). Cellular mechanisms of inorganic phosphate transport in kidney. Physiol Rev, 66, 36-70.

49. Bushinsky, D.A., Grynpas, M.D., Asplin, J.R. (2001). Effect of acidosis on urine supersaturation and stone formation in genetic hypercalciuric stone-forming rats. Kidney International, 59, 1415-1423.

50. Schmiedl, A., Schwille, P.O., Bonucci, E., Erben, R.G., Grayczyk, A., and Sharma, V. (2000). Nephrocalcinosis and hyperlipidemia in rats fed a cholesterol- and fat-rich diet: association with hyperoxaluria, altered kidney and bone minerals, and renal tissue phospholipid-calcium interaction. Urol Res, 28, 404-415.

51. Burgess, S.A., Reynolds, T.M., Williams, A.P., and Smith, S. (1995). Evaluation of four animal models of intrarenal calcium deposition and assessment of the influence of dietary supplementation with essential fatty acids on calcification. Urol Res, 23, 239-242.

52. Schlemmer, C.K., Coetzer, H., Claassen, N., Kruger, M.C., Rademeyer, C., van Jaarsveld, L., \& Smuts, C.M. (1998). Ectopic calcification of rat 
aortas and kidneys is reduced with n-3 fatty acid supplementation.

Prostaglandins Leukot Essent Fatty Acids, 59, 221-227. 
Figure 1.

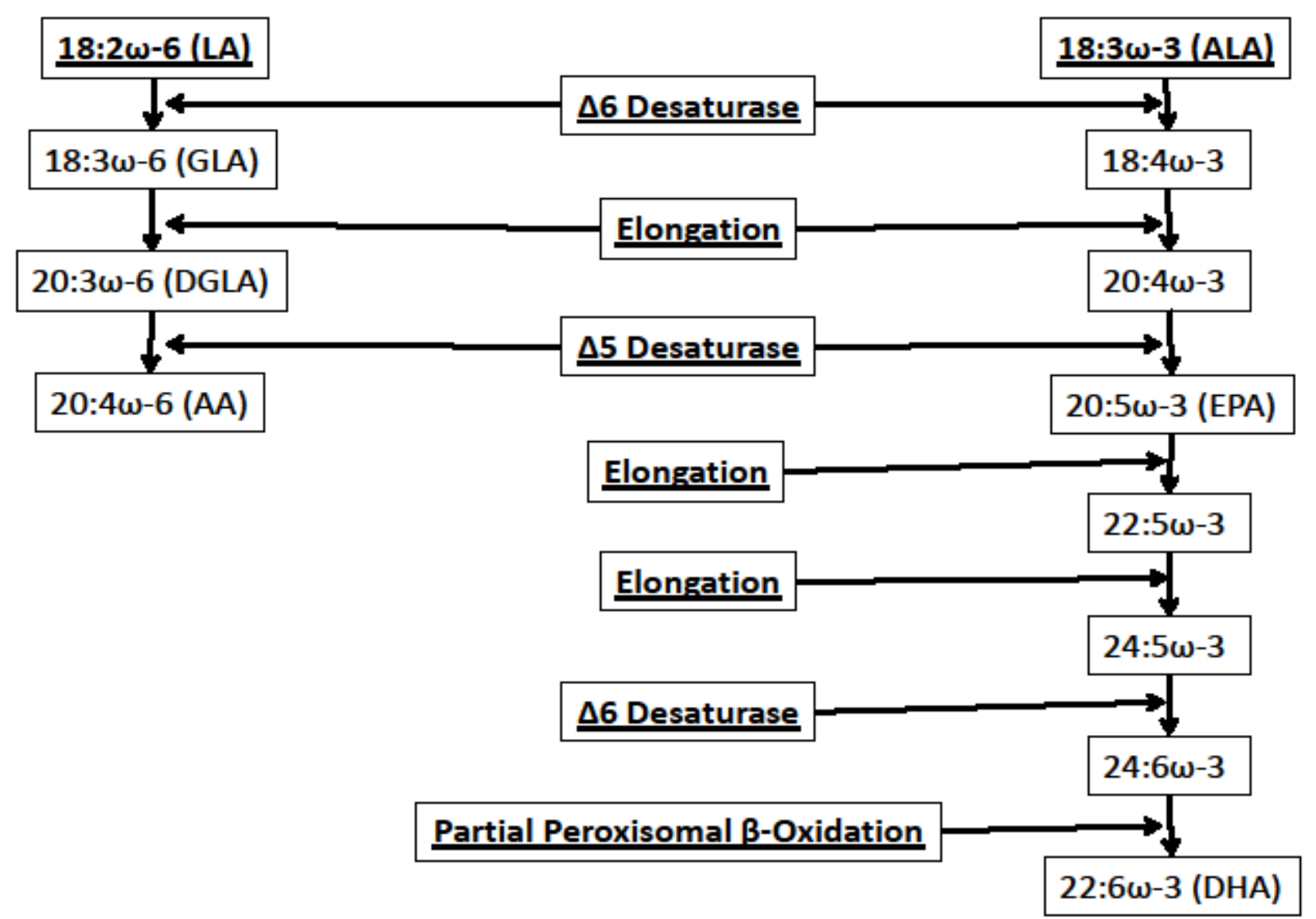


Figure 2.

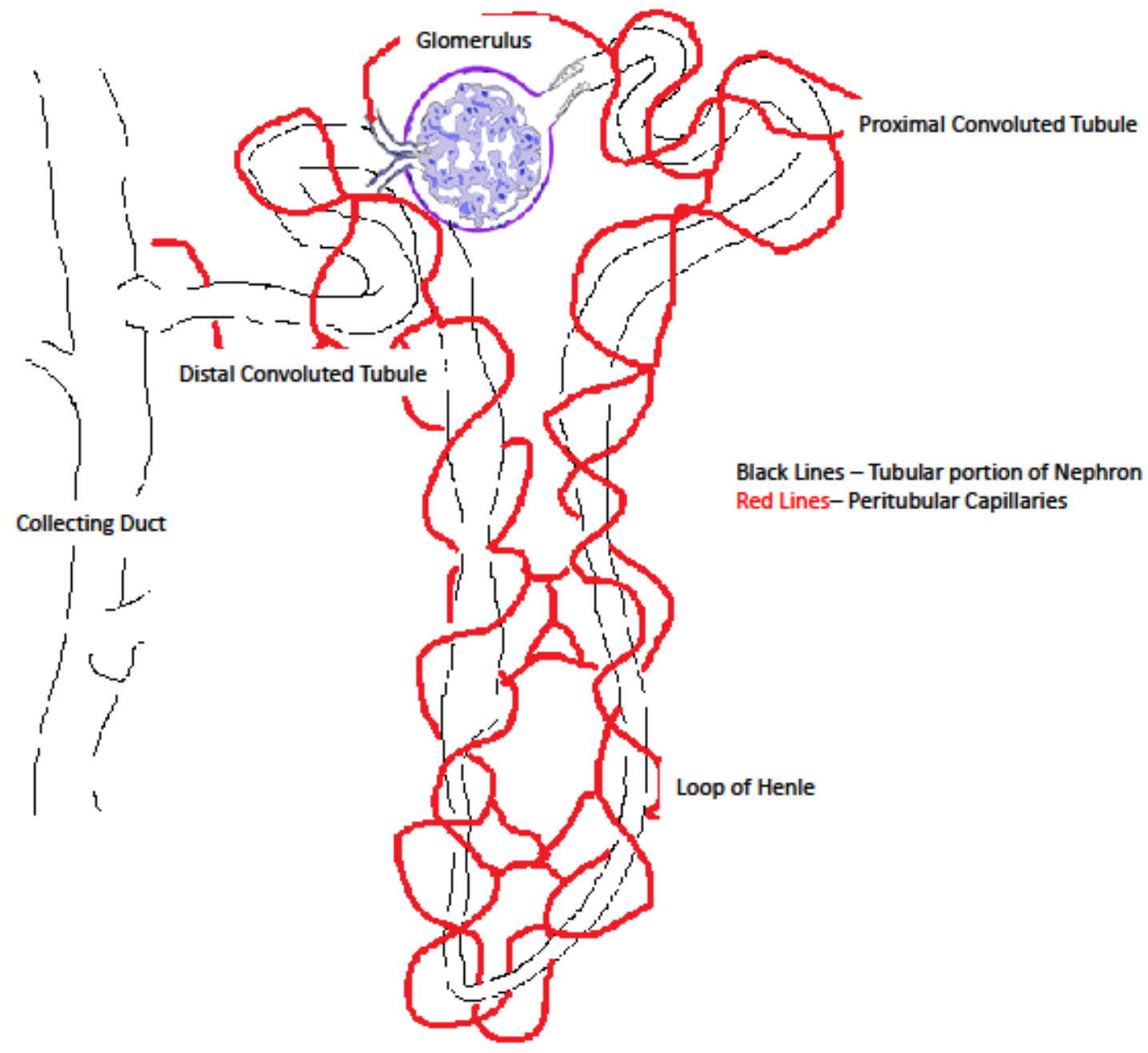


Figure 3.

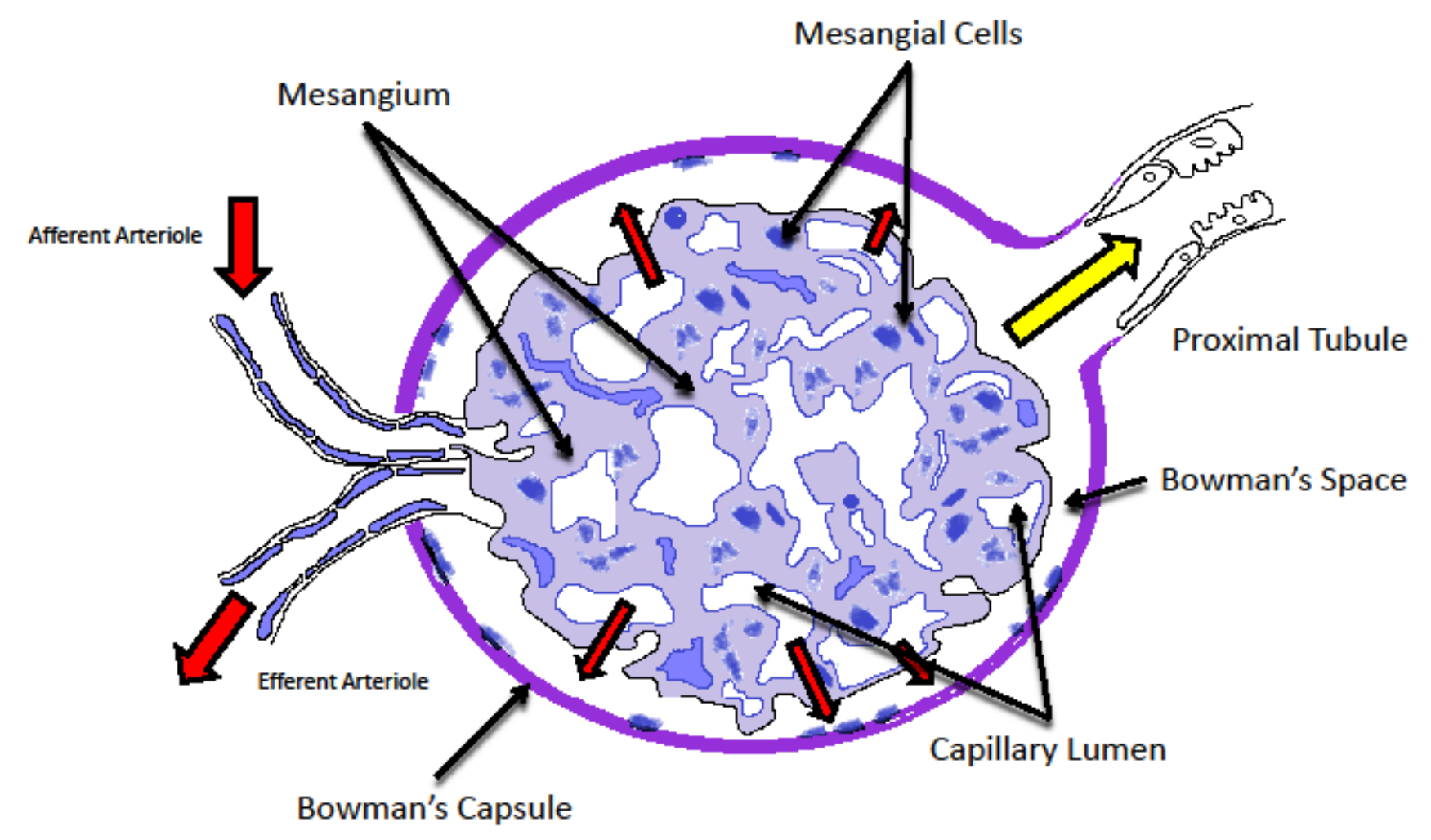


Figure 4.

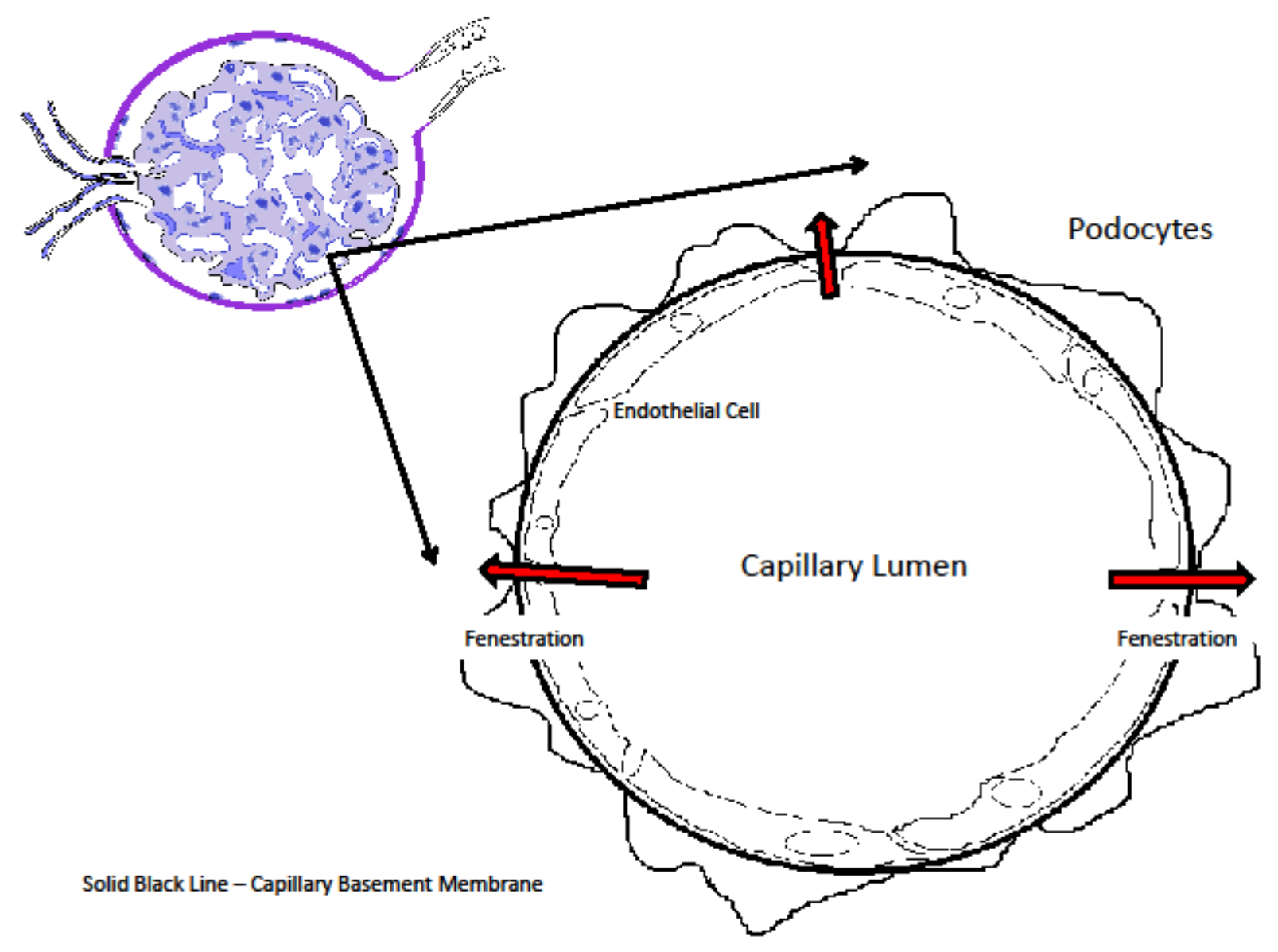


Figure 5.

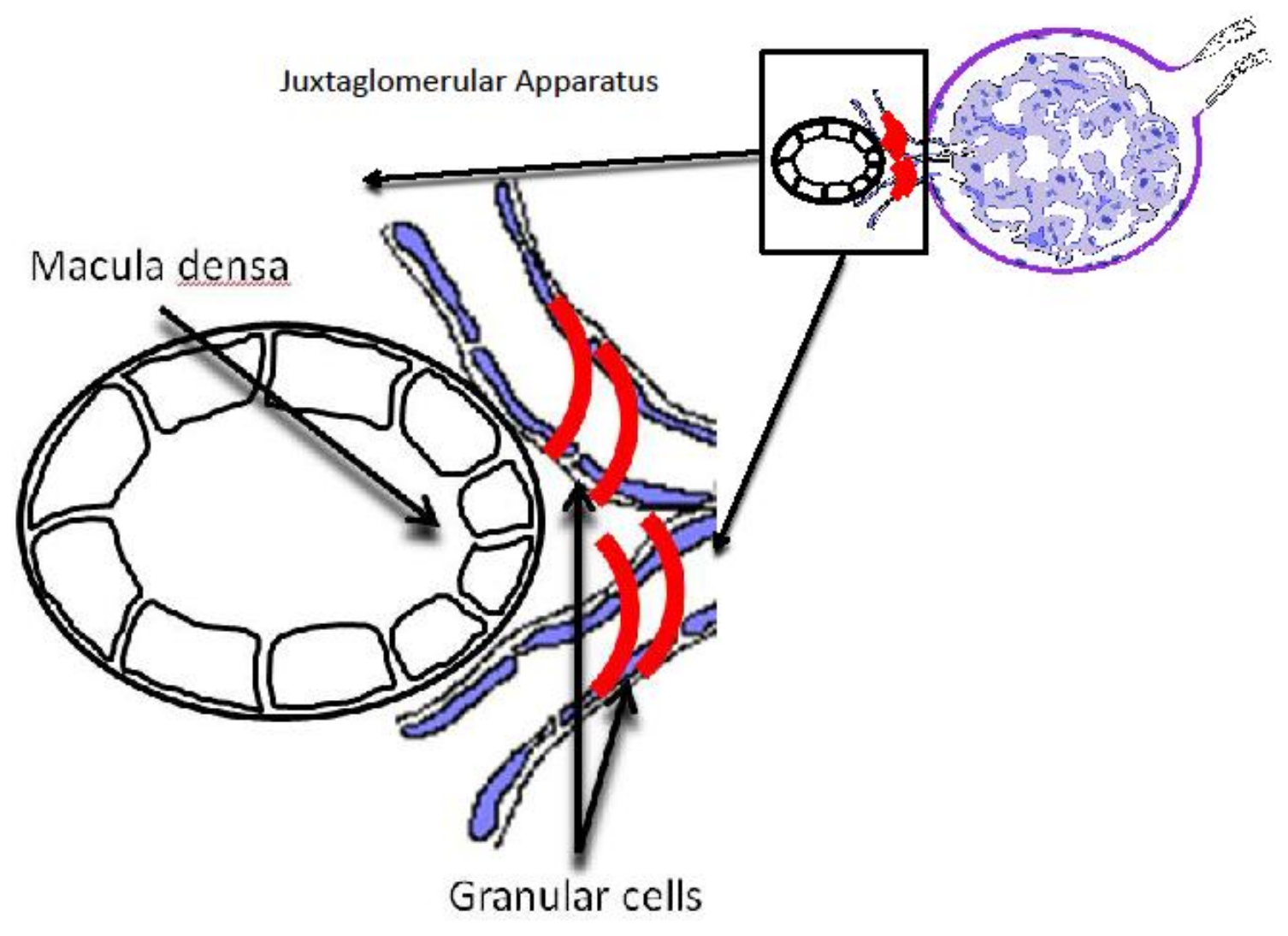




\subsection{Study Objectives}

Objective 1. To investigate the effect of consuming krill protein concentrate on renal and bone health.

Objective 2. To characterize krill oil that has been isolated using different processing methods.

Objective 3. To determine how different dietary sources of $\omega-3$ PUFAs influence kidney health and function in female rats. 
Gigliotti, J.C., Smith, A.L., Jaczynski, J., \& Tou, J.C. (2011).

Consumption of Krill Protein Concentrate Prevents Early Renal Injury and Nephrocalcinosis in Female Sprague-Dawley Rats

Journal of Urological Research, (2011), 39, 59-67 


\subsection{Background}

We have previously shown that krill protein concentrate (KPC) has nutritional potential for human consumption [1]. However, these rats also had significantly lower kidney weights compared to rats fed casein, the standard protein source used in semipurified diets. Changes in kidney weight have been correlated with renal disease, and include potential alterations in mineral metabolism [2]. Therefore, the objective of this study was to address this change in body weight, and determine if changing the dietary protein source can influence measures of mineral metabolism and bone health.

\subsection{Introduction}

Diet-induced alterations in kidney health are common in female rats, with renal calcification (nephrocalcinosis) being a prime example $[3,4,5]$. The transition of nephrocalcinosis to kidney stones (nephrolithiasis) has been implicated in nephropathy and subsequent renal failure in rats [5]. Diet-induced alterations in the kidney function has been attributed to manipulating various components of the diet, including the dietary calcium:phosphorus ratio $[6,7,8,9$, $10]$, and the dietary protein content $[11,12,13]$. Diets rich in phosphorus $(\mathrm{P})$ or leading to increased $\mathrm{P}$ excretion have been reported as being an underlying cause of nephrocalcinosis [14]. However, Meyer et al. [11] reported that changing the source of dietary protein fed to female Wistar rats reduced calcium $(\mathrm{Ca})$ deposition in the kidneys to a greater extent than manipulating dietary minerals. Together the study results suggest that the amount, as well as the source, of 
dietary protein influences the development of nephrocalcinosis and nephrolithiasis $[12,13]$. Additionally, different protein sources are associated with different fatty acids. The role of lipids in nephrocalcinosis and nephrolithiasis should be considered because fatty acids have been shown to differentially influence inflammatory pathways, and inflammation has also been implicated as an initiating factor in tissue calcification $[15,16,17]$.

Nephrocalcinosis is commonly associated with increased urinary $\mathrm{Ca}$ excretion (hypercalcuria), and dietary proteins also influence the excretion of $\mathrm{Ca}$. It has been proposed that higher consumption of dietary protein increases intestinal $\mathrm{Ca}$ absorption and this may increase urinary $\mathrm{Ca}$ excretion $[18,19]$. The consumption of dietary protein has also been correlated with an increase in urinary acid excretion $[20,21,22]$, which has been shown to reduce renal $\mathrm{Ca}$ reabsorption and possibly promote hypercalciuria [23]. These potential changes in kidney function may influence mineral balance and in turn, bone health. Calvo et al., [24] reported hypercalciuria in male Sprague-Dawley rats fed high protein diets; however, there was no effect on bone mineral content. Female rats display a higher sensitivity to alterations in renal handling of $\mathrm{Ca}[6]$ and therefore, in the present study female rats were used since they may provide a more sensitive model for mineral and subsequent bone loss.

In our study, female Sprague-Dawley rats fed protein derived from a pelagic source were compared to rats fed casein, a standard protein source used in commercial semi-purified rodent diets. Fish contain high-quality protein as well as other nutrients with potential health benefits. However, depletion of existing 
fish stocks and environmental contaminants has raised public concern regarding fish consumption. A potential alternative is to promote consumption of underutilized species such as krill. Based on body size, krill has the largest amount of protein (over 65\% dry weight) among all organisms worldwide. Analysis of lipid content showed $\sim 27 \%$ of total fatty acids in Antarctic krill (Euphausia superba) consists of the health benefiting omega-3 polyunsaturated fatty acids ( $\omega-3$ PUFAs) $[1,25]$. Krill offers a promising high quality and sustainable source of protein for human consumption. Therefore, the objective of this study was to evaluate the effects of consuming KPC in regards to renal and bone health.

\subsection{Materials and Methods}

\subsubsection{Diets and animal feeding study}

All animal procedures were conducted in accordance with the guidelines set forth by the Institute of Laboratory Animal for the Care and Use of Laboratory Animals [26], and were approved by the Animal Care and Use Committee at West Virginia University.

Immature (age $28 \mathrm{~d}$ ) female Sprague-Dawley rats $(\mathrm{n}=20)$ were purchased from Taconic Farms (Rockville, MD). Female rats were used due to their higher susceptibility to nephrocalcinosis compared to male rats [4]. Upon arrival, rats were individually housed in metabolic cages. All animals were maintained in a room at $21^{\circ} \mathrm{C}$ with a $12 \mathrm{~h}$ light/dark cycle. During a $14 \mathrm{~d}$ acclimation period, animals were given ad libitum access to deionized distilled water $\left(\mathrm{ddH}_{2} \mathrm{O}\right)$ and AIN-93G diet (Harklan Teklad, IN). Following the $14 \mathrm{~d}$ acclimation period, rats 
were randomly assigned ( $\mathrm{n}=10$ per group) to be fed ad libitum a low protein diet consisting of $10 \%$ crude protein supplied as casein or KPC for 4 weeks. KPC was isolated from whole frozen Antarctic krill (Euphausia superba) purchased from Krill Canada (Langley, BC, Canada) using an isoelectric solubilization / precipitation method described previously in Gigliotti et al. [1]. The recovered KPC was $77.7 \%$ crude protein, $8.1 \%$ total lipid, and $4.4 \%$ total ash on a dry basis by proximate analysis. Freeze-dried KPC was stored at $-20^{\circ} \mathrm{C}$ until mixed into the diet. Replacement of the protein as either KPC or casein at a level of $10 \%$ in AIN-93G diet was corrected for protein and lipids so that the diets were isocaloric and isonitrogenous. $\mathrm{Ca}$ and $\mathrm{P}$ contents of the diets were also matched to provide a 1.2 ratio (Table 1). Diets were kept stored at $5^{\circ} \mathrm{C}$. Food consumption and $\mathrm{ddH}_{2} \mathrm{O}$ intake were measured and replaced with fresh $\mathrm{ddH}_{2} \mathrm{O}$ and assigned diet every $2 \mathrm{~d}$.

\subsubsection{Kidney mineral content}

At the end of 4 weeks, rats were euthanized by $\mathrm{CO}_{2}$ inhalation, and both kidneys excised. Kidneys were trimmed, decapsulated, and weighed separately. No statistical differences were found between the right and left kidney weights. Therefore, the left kidneys were assayed for mineral content and the right kidneys used for histological evaluation.

To determine kidney mineral concentrations, the left kidneys were dried overnight at $110^{\circ} \mathrm{C}$ in an oven and then ashed at $550^{\circ} \mathrm{C}$ in a muffle furnace (Lindberg 515A2, WI) for $24 \mathrm{~h}$. To determine specific minerals, ashed samples 
were dissolved in $70 \%$ nitric acid $(2 \mathrm{~mL})$ and neutralized in $\mathrm{ddH}_{2} \mathrm{O}(5 \mathrm{~mL})$. Samples were then filtered through Whatman no. 1 paper, diluted to volume (50 $\mathrm{mL}$ ), and renal $\mathrm{Ca}$ and $\mathrm{P}$ content in the kidneys were measured using inductively coupled plasma spectrometry (ICP) (model P400, Perkin Elmer, Shelton, CN).

\subsubsection{Kidney histology}

The right kidneys $(n=4)$ were dissected and immediately fixed in $10 \%$ formalin solution overnight and then transferred to $70 \%$ ethanol. Tissues were dehydrated through a series of increasing ethanol concentrations (70-100\% in $\mathrm{ddH}_{2} \mathrm{O}$ ) to xylene, embedded in paraffin, and serially cut in $8 \mu \mathrm{m}$ thick sections using a microtome (American Optical Company, NY). Paraffin embedded sections were placed on moist glass slides and dried for mounting. Mounted sections were then deparaffinized in xylene, and rehydrated through a series of decreasing ethanol concentrations (100-70\%) prior to staining.

Renal morphology and microtubular calcification was examined by standard hematoxylin and eosin (H\&E) and periodic acid-Schiff (PAS) staining. PAS staining was performed following a commercially available protocol (SigmaAldrich, MO). Briefly, hydrated slides were incubated in Periodic Acid Solution for 5 minutes. After rinsing in $\mathrm{ddH}_{2} \mathrm{O}$, slides were immersed in Schiff's reagent for 15 minutes, washed in water, and then counterstained in Gill Hematoxylin solution for 90 seconds and cover slipped. All slides were analyzed under a Nikon TE 2000-S light microscope (Nikon Instruments, NY) at 4X magnification 
by three trained individuals, and images captured using a PC interfaced with QCapture imaging software (Quantitative Imaging Corporation, BC, Canada).

\subsubsection{Urinary assays of renal function and damage}

Rats were individually housed in metabolic cages to collect urine for determination of renal function and damage. Urine samples were collected and centrifuged at $1,500 \mathrm{~g}$ for $10 \mathrm{~min}$ at $4^{\circ} \mathrm{C}$ to remove any debris. Urine samples were aliquoted into fresh tubes and stored at $-80^{\circ} \mathrm{C}$ until assayed. Baseline urine consisted of pooled samples collected over $7 \mathrm{~d}$ of the first week of treatment. Final urine consisted of pooled samples collected over the final $7 \mathrm{~d}$ of the 4 week feeding study.

To determined renal function, urinary total protein and creatinine were determined using commercially available colorimetric assays (Cayman Chemical, MI). Serum creatinine concentrations were determined enzymatically using a commercially available Vet-16 rotor (Hemagen Diagnostics Inc., Columbia, MD). Glomerular filtration rate (GFR) was determined based on creatinine clearance $(\mathrm{CrC})$ calculated as: $\mathrm{CrC}=(\mathrm{UC} / \mathrm{SC}) \mathrm{X} \mathrm{V}$, where $\mathrm{UC}$ is urinary creatinine concentration, $\mathrm{V}$ is the volume of measured urine excreted per minute, and $\mathrm{SC}$ is serum creatinine concentration. Renal damage was determined by measuring urinary n-acetyl glucosaminidase (NAG) activity, an early indicator of renal damage, using a commercially available colorimetric kit (Diazyme, CA). The optical densities of the urinary samples were determined at wavelength $505 \mathrm{~nm}$ in a Beckman DU530 spectrophotometer (Beckman Coulter, CA). Urinary sodium 
(Na) was determined by diluting the urine 1:40 (v/v) in $\mathrm{ddH}_{2} \mathrm{O}$ and measuring the mineral concentration using the ICP. Urinary $\mathrm{pH}$ was determined using a standard $\mathrm{pH}$ meter (Beckman, CA).

\subsubsection{Mineral balance}

Mineral balance studies were performed by individually housing rats in metabolic cages to determined food intake and to collect feces and urine samples. Ca apparent absorption was calculated as (Ca intake - fecal Ca excretion) / $\mathrm{Ca}$ intake x 100. Calcium retention was determined by calculating Ca intake - (fecal $\mathrm{Ca}$ excretion + urinary $\mathrm{Ca}$ excretion). $\mathrm{P}$ apparent absorption was calculated as $(\mathrm{P}$ intake - fecal P excretion) / P intake x 100 and $\mathrm{P}$ retention was determined by calculating $\mathrm{P}$ intake - (fecal $\mathrm{P}$ excretion + urinary $\mathrm{P}$ excretion).

$\mathrm{Ca}$ and $\mathrm{P}$ intake was calculated by multiplying the amount of diet consumed and the dietary concentration of $\mathrm{Ca}(6 \mathrm{mg} / \mathrm{g}$ diet $)$ or $\mathrm{P}(5 \mathrm{mg} / \mathrm{g}$ diet $)$ as provided by diet manufacturer and confirmed by ICP. Urine and fecal samples consisted of pooled samples collected during the final $7 \mathrm{~d}$ of the 4 week feeding study. To determine urinary minerals, samples were diluted 1:40 in $\mathrm{ddH}_{2} \mathrm{O}$ and $\mathrm{Ca}$ and $\mathrm{P}$ concentration measured by ICP. To determine fecal minerals, the fecal samples were freeze-dried for $48 \mathrm{~h}$. Feces were ashed overnight in a muffle furnace (Lindberg 515A2, WI), dissolved in 70\% nitric acid, diluted to 1:50 in $\mathrm{ddH}_{2} \mathrm{O}$ and then $\mathrm{Ca}$ and $\mathrm{P}$ concentration determined by ICP. 


\subsubsection{Bone measurements}

Both femurs were dissected and defleshed with care being taken not to damage the periosteum. Each femur was wrapped in saline soaked gauze, and frozen at $-20^{\circ} \mathrm{C}$ until assayed. For analysis each bone was brought to room temperature. Bone morphology was determined by measuring length, width, and depth using a vernier caliper (Bel-Art Products, NJ). Bones were dried at $110^{\circ} \mathrm{C}$ for $48 \mathrm{~h}$ and dry weights measured using an analytical balance (Mettler Toledo, $\mathrm{OH}$ ). The dried femurs were ashed at $600^{\circ} \mathrm{C}$ in a muffle furnace (Lindberg $515 \mathrm{~A} 2$, WI) for $24 \mathrm{~h}$ and total bone mineral content (BMC) determined by the weight of the bone ash. Ashed femur samples were dissolved in 70\% nitric acid, diluted to $1: 50 \mathrm{ddH}_{2} \mathrm{O}$ and femoral $\mathrm{Ca}$ and $\mathrm{P}$ content measured by ICP.

Femoral strength was determined on a TA.HDi Texture Analyzer (Texture Technologies Corp, NY) outfitted with a three-point bending apparatus. The femur was placed on supports ( $1 \mathrm{~mm}$ width at tip) and bent until broken by lowering a centrally placed blade $(1 \mathrm{~mm}$ width) at constant crosshead speed $(0.1$ $\mathrm{mm} / \mathrm{s})$. The load-deflection data collected by a PC interfaced with the TA.HDi Texture Analyzer was used to determine the bone strength measurement of peak force. Bone morphometry, $\mathrm{BMC}, \mathrm{Ca}, \mathrm{P}$, and bone strength results of the bone pairs were averaged after no differences between right and left femurs were determined by paired t-test with significance level set at $P<0.05$. 


\subsubsection{Statistical analysis}

The animal feeding study was a completely randomized design, with $n=10$ rats per diet treatment. The t-test was used to compare differences between treatment groups, and Mann-Whitney Rank Sum test was performed on data not normally distributed. The t-test and the Mann-Whitney Rank test were both performed using Sigma Stat 3.1 (Systat Software Inc., San Jose, CA). Differences were considered significant at $P<0.05$.

\subsection{Results}

\subsubsection{Kidney mineral content}

Figure 1 shows the relative weights (g/g body weight*100) of the kidneys, kidney total mineral (ash), $\mathrm{Ca}$, and $\mathrm{P}$ content of rats fed $\mathrm{KPC}$ relative to rats fed casein. Kidney weights of rats fed KPC were lower $(P<0.001)$ compared to the kidney weights of rats fed casein. Rats fed KPC had decreased $(P<0.001)$ kidney total mineral content compared to rats fed casein. Measurements of specific minerals showed that rats fed KPC also had lower $(P=0.002)$ kidney $\mathrm{Ca}$ concentrations, and lower $(P<0.001)$ kidney $\mathrm{P}$ concentrations compared to rats fed casein.

\subsubsection{Kidney histology}

H\&E and PAS stains were used to detect renal calcium deposits, with more than 115 renal tissue sections of $n=4$ rats / diet used. All slides containing the cortico-medullary junction from rats fed casein displayed extensive 
microtubular calcification (Figures A and B, top). Interestingly, only one (Figure C) of the four rats fed KPC (Figures C and D) used for histological evaluation showed renal calcification in the same region of renal tissue and this was comparatively mild compared to casein fed rats. Focal areas of tubular atrophy were also observed, however no distinction between the diets could be made. There were no indications of fibrosis or other glomerular abnormalities in rats fed casein or KPC.

\subsubsection{Urinary assays of renal function and damage}

To determine kidney damage and function, various biomarkers were determined in urine collected during the final week of the 4 week study. Table 2 shows NAG concentrations were lower $(P=0.03)$ in rats fed KPC compared to casein. Although not significant, rats fed KPC tended to have higher $\mathrm{CrC}$ $(P=0.055)$ and lower total urinary protein $(P=0.057)$ than rats fed casein. Rats fed KPC had a more basic $(P=0.004)$ urinary $\mathrm{pH}$ values compared to rats fed casein. The urine of rats fed KPC also had higher urinary $\mathrm{Na}(P<0.001)$ concentrations compared to rats fed casein (Table 2).

\subsubsection{Mineral Balance}

Table 3 shows that rats fed KPC had higher a $(P=0.02)$ urinary output after the initiation of the diet. Despite the higher urinary output, there was no difference in urinary $\mathrm{Ca}$ excretion between rats fed casein and KPC. There was no effect on Ca homeostasis indicated by no significant differences in Ca intake, 
absorption, retention, or fecal excretion between rats fed KPC or casein at the initiation of the diet. During the final week, rats fed KPC had greater $(P<0.001)$ Ca intake than the rats fed casein. However, there were no differences in measures of total $\mathrm{Ca}$ intake, absorption, retention, or fecal $\mathrm{Ca}$ concentrations between rats fed KPC and rats fed casein (Table 3).

Table 4 shows that consumption of KPC had no effect on P homeostasis at the initiation of the diet as indicated by no differences in $\mathrm{P}$ intake, absorption, retention, urinary, or fecal output between rats fed KPC and rats fed casein. During the final week, there was no effect on $\mathrm{P}$ homeostasis as indicated by no differences in $\mathrm{P}$ intake, absorption, retention, urinary or fecal $\mathrm{P}$ concentrations between rats fed KPC and rats fed casein.

\subsubsection{Bone measurements}

Table 5 shows there were no significant differences in femur morphometry measurements of weight, length, width or depth between rats fed KPC and rats fed casein. There were no significant differences in femur total BMC of rats fed KPC compared to rats fed casein. Similarly, measurements of the major bone minerals indicated no significant difference in either the femoral $\mathrm{Ca}$ or $\mathrm{P}$ content of rats fed KPC compared to rats fed casein. Measurement of bone strength as determined by peak force in the femur showed no significant difference between rats fed KPC and rats fed to casein. 


\subsection{Discussion}

Protein quality of KPC is similar to that of casein, a standard protein source, used in commercial semi-purified rodent diets [1]. However, female rats fed KPC had lower $(P<0.001)$ kidney weights compared to rats fed casein. To investigate the effect of KPC compared to casein on kidney health, NAG was measured as an early marker of renal injury. Despite being provided a low (10\% $\mathrm{g} / \mathrm{kg}$ diet) protein diet, urinary NAG concentrations were higher $(P=0.03)$ in rats fed casein compared to KPC, indicating that protein source is an important factor to consider in renal health. Similarly, NAG excretion was greater in male Munich-Wistar rats consuming casein compared to a soy protein based diet. The authors suggested that casein induced renal injury through increased acidification of the kidney filtrate [27]. Ritskes-Hoitinga et al., [28] reported that high urinary $\mathrm{pH}$ values were associated with low degree of nephrocalcinosis indicated by a negative correlation $(\mathrm{r}=0.68, \mathrm{p}<0.05)$ between urinary $\mathrm{pH}$ and the severity of nephrocalcinosis. Therefore, in our study higher $(P=0.004)$ urinary $\mathrm{pH}$ in rats fed KPC compared to rat fed casein may be responsible for preventing early renal injury.

The pathogenesis of nephrolithiasis has been proposed to involve renal injury followed by deposition of calcium crystals to the site of injury [29]. In our study, kidney mineral content $(P<0.01), \mathrm{Ca}(P<0.001)$, and $\mathrm{P}(P<0.001)$ concentrations were lowered in rats fed KPC compared to casein. Furthermore, histological evaluation of the kidneys showed that rats fed casein had extensive renal calcification, whereas mild to absent renal calcification was observed in the 
kidneys of rats fed KPC. Similarly, Zhang and Benyen [13] reported that female Wistar rats fed cod meal had lower kidney Ca content compared to rats fed casein or soybean protein isolate. Together, the study results suggest that pelagic protein sources may provide protection against mineral deposition in the kidneys.

After an initial renal injury, kidney function often declines [30].

Determination of urinary total protein excretion provides an estimation of kidney filtrating ability with proteinuria considered a risk factor for progressive loss of kidney function. $\mathrm{CrC}$ provides an estimation of glomerular filtration rate with reduced $\mathrm{CrC}$ used as a clinical diagnosis for renal disease [31]. Although not significant, rats fed KPC for 4 weeks tended to have lower $(P=0.057)$ urinary total protein excretion and higher $(P=0.055) \mathrm{CrC}$ compared to rats fed casein.

Similarly, male Wistar rats fed soy protein had lower urinary total protein and higher $\mathrm{CrC}$ compared to rat fed casein [32]. These study results indicate that the protein source influences renal function. In the current study, urinary output was higher $(P=0.02)$ in rats fed KPC compared to casein-fed rats. This may have been the result of a tendency $(P=0.10)$ for rats fed KPC to consume more $\mathrm{ddH}_{2} \mathrm{O}(970.3$ $\mathrm{ml} / 28 \mathrm{~d})$ than rats fed casein $(620 \mathrm{ml} / 28 \mathrm{~d})$. Increased urinary output in rats fed KPC may have contributed to the observed decreased kidney mineral content and deposition. Promoting increased urinary output is a common recommendation for individuals suffering from kidney mineralization [33]. However, in a study comparing different dietary proteins and development of nephrocalcinosis, Zhang and Benyen [13] reported that the rats with the lowest kidney mineral content did not have the highest urinary outputs. Therefore, decreased mineralization of the 
kidneys in rats fed KPC in the current study was likely not the result of an increased urinary output alone.

The tendency for higher glomerular filtration rates and lower urinary total protein excretion, accompanied by lower kidney calcification, in KPC compared to casein fed rats suggested that consumption of KPC had beneficial effects on kidney function. Furthermore, lower urinary NAG concentration and renal tissue Ca deposition suggested that KPC consumption prevented kidney injury. However, these beneficial effects may not be due to the protein alone, since KPC also contains minerals and lipids that may affect the kidneys.

KPC is composed of $4.4 \%$ minerals by weight [1]. Alterations in dietary Ca:P ratio has been reported to play an important role in the development of nephrocalcinosis [7]. Increasing the Ca:P ratio to greater than 1.0 has been reported to prevent nephrocalcinosis [8]. In our study the KPC and casein diets were formulated to have matching $\mathrm{Ca}$ and $\mathrm{P}$ concentrations which resulted in a Ca:P ratio of 1.2. Therefore, it appears that decreased kidney mineralization in rats fed KPC was not due to differences in dietary $\mathrm{Ca}$ and $\mathrm{P}$ content.

Common urinary abnormalities associated with nephrocalcinosis and nephrolithiasis are hypercalciuria and/or hyperphosphouria. In our study there were no differences in urinary $\mathrm{Ca}$ and $\mathrm{P}$ concentrations between rats fed KPC and casein. Unexpectedly, rats fed KPC had a 4 fold increase in urinary Na compared to rats fed casein. Subsequent analysis of diets showed that KPC had twice the Na content of the casein diet. Increased Na was likely due to the processing method used to obtain KPC. As a result rats fed KPC consumed twice the amount of Na 
compared to rats fed casein. Higher Na consumption in rats fed KPC may explain their tendency $(P=0.10)$ to consume more $\mathrm{ddH}_{2} \mathrm{O}$, and in turn, their increased urinary output. High urinary $\mathrm{Na}$ has been suggested to interfere with tubular $\mathrm{Ca}$ reabsorption leading to hypercalciuria, a risk factor for nephrocalcinosis and nephrolithiasis $[34,35]$. In the current study, the increased urinary $\mathrm{Na}$ in rats fed KPC did not appear to affect urinary Ca excretion compared to rats fed casein. Furthermore, Mattson et al., [36] concluded that dietary composition significantly influenced the development of renal disease in salt sensitive rodent models independent of the $\mathrm{NaCl}$ content. Taken together these data suggest that the mineral content of the diet is not the sole determinant of urinary mineral excretion, a risk factor for developing nephrocalcinosis. This finding is supported by Meyer et al., [11] who reported that changing the source of protein in semisynthetic diets reduced mineral deposits, and this exceeded the effects of changing the mineral composition of the diet.

KPC also contains a lipid component that may benefit renal health. Gigliotti et al. [1] reported that KPC consists of $8.1 \%$ lipid by weight. The lipids in KPC are rich ( $27 \%)$ in the $\omega-3$ PUFAs, eicosapentaenoic acid (EPA) and docosahexaenoic acid (DHA). EPA and DHA have anti-inflammatory properties that potentially contributed to renal health. Rats fed cod meal, a potential source of EPA and DHA, were reported to have reduced kidney Ca concentrations compared to rats fed casein or soy isolate [13]. Furthermore, Schlemmer et al. [37] reported that rats supplemented with $\omega-3$ PUFAs had decreased calcification of the renal tubules. Consuming KPC as a source of protein provides a high 
quality protein with the added benefit of $\omega$-3 PUFAs, whereas other high quality protein foods tend to be high in saturated fatty acids.

In addition to renal injury, changes in renal function may negatively affect $\mathrm{Ca}$ and $\mathrm{P}$ balance, which can lead to compromised bone health [38]. Protein source appears to affect $\mathrm{Ca}$ and $\mathrm{P}$ absorption and retention. Van Dael et al. [39] reported that replacing casein with whey protein diets resulted in higher absorption of $\mathrm{Ca}$ and higher absorption and retention of $\mathrm{P}$. In our study, there were no differences between $\mathrm{Ca}$ and $\mathrm{P}$ absorption and retention in rats fed KPC compared to casein. Furthermore, bone measurements showed no differences in femoral total bone mineral content, $\mathrm{Ca}, \mathrm{P}$ or bone strength between rats fed KPC and casein. Similarly, the lower urinary $\mathrm{pH}$ observed in rats fed casein had no effect on bone mass or strength measurements. It is likely that extracellular $\mathrm{pH}$ was not lowered sufficiently to activate bone resorption in rats fed casein, a proposed mechanism for protein induced bone loss [40]. Studies addressing bone loss due to lower $\mathrm{pH}$ commonly use high protein diets of up to $50 \%$ protein. It was unlikely that our diet consisting of $10 \%$ protein would promote the metabolic acid load required to affect bone health. Recent evidence suggests that dietary protein may be as important as dietary $\mathrm{Ca}$ in preventing bone loss [41, 42]. Bone tissue is formed by the mineralization of the collagen, a protein-derived connective tissue. Thus, dietary protein may contribute to bone density and strength by promoting complete bone matrix formation.

In conclusion, early renal injury and Ca deposits were influenced by the protein source fed to young female Sprague-Dawley rats, even with a low protein 
$\operatorname{diet}(10 \% \mathrm{~g} / \mathrm{kg}$ diet $)$. Therefore, it is important not only to consider the amount, but also the source of dietary protein. Compared to rats fed casein, the consumption of KPC prevented early renal injury. This was indicated by the lower urinary NAG, reduced kidney mineralization, and a tendency for higher glomerular filtration rates and lower proteinuria. Other nutrients associated with KPC, particularly the $\omega-3$ PUFA rich lipids, may also have contributed to reduced kidney injury and $\mathrm{Ca}$ deposition. In addition to the beneficial effect on the kidney, KPC consumption had no effect on bone mass or strength. Based on the study results, KPC is a novel and sustainable protein source which appears to attenuate the development of diet-induced alterations in renal health and associated bone loss in rats. 


\subsection{References}

1. Gigliotti JC, Jaczynski J, and Tou JC (2008) Determination of the nutritional value, protein quality, and safety of krill protein concentrate isolated using an isoelectric solubilization/precipitation technique. Food Chem 111: 209-214.

2. Ritskes-Hoitinga J, Lemmens AG, and Beynen AC (1989) Nutrition and kidney calcification in rats. Lab Anim 23: 313-318.

3. Woodard JC (1971) A morphologic and biochemical study of nutritional nephrocalcinosis in female rats fed semipurified diets. Am J Pathol 65: 253-264.

4. Rao GN (2002) Diet and kidney diseases in rats. Toxicol Pathol 30: 651656.

5. Jara A, Chacon C, Ibaceta M, Valdivieso A, and Felsenfeld A (2004) Effect of ammonium chloride and dietary phosphorus in the azotaemic rat. Part II-kidney hypertrophy and calcium deposition. Nephrol Dial Transpl 19: 1993-1998.

6. Clapp MJL, Wade JD, and Samuels DM (1982) Control of nephrocalcinosis by manipulating the calcium: phosphorus ratio in commercial rodent diets. Lab Anim 16: 130-132.

7. Reeves PG (1989) AIN-76 diet: Should we change the formulation? J. Nutr 119: 1081-1082.

8. Reeves PG, Rossow KL, and Lindlauf J (1993) Development and testing of the AIN-93 purified diets for rodents: results on growth, kidney 
calcification and bone mineralization in rats and mice. J Nutr 123: 19231931.

9. Cockell KA, L'Abbe MR, and Belonje B (2002) The concentrations and ratio of dietary calcium and phosphorus influence development of nephrocalcinosis in female rats. J Nutr 132: 252-256.

10. Cockell KA, and Belonje B (2004) Nephrocalcinosis caused by dietary calcium:phosphorus imbalance in female rats develops rapidly and is irreversible. J Nutr 134: 637-640.

11. Meyer O, Blom L, and Sondergaard D (1982) The influence of minerals and protein on the nephrocalcinosis potential for rats of semisynthetic diets. Lab Anim 16: 271-273.

12. Kunkel ME, Lopez H, Punyasingh J. and Navia JM (1984) Development of nephrocalcinosis in rats fed caries-promoting diets with different protein sources. Nutr Rep Int 30: 339-346.

13. Zhang X, and Beynen A (1992) Increasing intake of soybean protein or casein, but not cod meal, reduces nephrocalcinosis in femals rats. J.Nutr 122: $2218-2225$.

14. Matsuzaki H, Katsumata S, Uehara M, Suzuki K, and Miwa M (2007) High-phosphorus diet induces osteopontin expression of renal tubules in rats. J Clin Biochem Nutr 41: 179-183.

15. Ajuwon KM, and Spurlock ME (2005) Palmitate activates the NF- $\kappa B$ transcription factor and induces TNF $\alpha$ expression in 3T3-L1 adipocytes. J Nutr, 135: 1841-1846. 
16. Massaro M, Habib A, Lubrano L, Del Turco S, Lazzerini G, Bourcier T, Weksler B, and De Caterina R (2006) The omega-3 fatty acid docosahexanoate attenuates endothelial cyclooxygenase- 2 induction through both $\mathrm{NADP}(\mathrm{H})$ oxidase and PKC (varepsilon) inhibition. P Natl Acad Sci USA 103: 15184-15189.

17. Tsirpanlis G (2007) Is inflammation the link between atherosclerosis and vascular calcification in chronic kidney disease? Blood Purificat 25: 179182.

18. Ferraretto A, Signorile A, Gravaghi C, Fiorilli A, and Tettamanti G (2001) Casein phosphopeptides influence calcium uptake by cultured human intestinal HT-29 tumor cells. J. Nutr 131: 1655-1661.

19. Zhao Y, Martin BR, Wastney ME, Schollum L, and Weaver CM (2005) Acute versus chronic effects of whey proteins on calcium absorption in growing rats. Exp Biol Med 230: 536-542.

20. Schuette SA, Zemel MB, and Linkswiler HM (1980) Studies on the mechanism of protein-induced hypercalciuria in older men and women. $\mathbf{J}$ Nutr 110: 305-315.

21. Whiting SJ and Draper HH (1980) The role of sulfate in the calciuria of high protein diets in adult rats. J. Nutr 110: 212-222.

22. Zemel MB, Schuette SA, Hegsted M, and Linkswiler HM (1980) Role of the sulfur containing amino acids in protein-induced hypercalciuria in men. J Nutr 111: 545-552. 
23. Sutton RAL, Wong NLM, and Dirks JH (1979) Effects of metabolic acidosis and alkalosis on sodium and calcium transport in the dog kidney. Kidney Int 15: 520-533.

24. Calvo MS, Bell RR, and Forbes RM (1982) Effect of protein-induced calciuria on calcium metabolism and bone status in adult rats. J Nutr 112: 1401-1413.

25. Kolakowska A, Kolakowska E, and Szcygielski M (1994) Winter season krill (Euphausia superba Dana) as a source of n-3 polyunsaturated fatty acids. Die Nahrung 38: 128-134.

26. Institute of Laboratory Animal Resources Commission on Life Sciences. Guide for the care and use of laboratory animals. National Academy Press, Washington D.C. 1996.

27. Wesson DE, Nathan T, Rose T, Simoni J. and Tran RM (2007) Dietary protein induced endothelin-mediated kidney injury through enhanced intrinsic acid production. Kidney Int 71: 210-217.

28. Ritskes-Hoitinga J, Mathot JNJJ, Danse LHJC, and Beynen AC (1991) Commercial rodent diets and nephrocalcinosis in weanling female rats. Lab Anim 25: 126-132.

29. Verkoelen CF, and Verhulst A (2007) Proposed mechanisms in renal tubular crystal retention. Kidney Int. 72: 13-18.

30. Levey AS, Coresh J, Balk E, Kausz AT, Levin A, Steffes MW, Hogg RJ, Perrone RD, Lau J, and Eknoyan G (2003) National Kidney Foundation 
practice guidelines for chronic kidney disease: Evaluation, classification, and stratification. Ann Intern Med 139: 137-147.

31. National Kidney Foundation. (2008) Glomerular filtration rate (GFR). 〈http://www.kidney.org/kidneydisease/ckd/knowGFR.cfm>

32. Yang HY, Chen JR, and Chang LS (2008) Effects of soy protein hydrolysate on blood pressure and angiotensin-converting enzyme activity in rats with chronic renal failure. Hypertens Res 31: 957-963.

33. Curhan GC (2004) Diet and the prevention of kidney stones. Nephrology Rounds, 2, Iss. 4.

34. Muldowney FP, Freaney R, and Moloney MF (1982) Importance of dietary sodium in the hypercalciuria syndrome. Kidney Int 22: 292-296.

35. Creedon A and Cashman KD (2000) The effect of high salt and high protein intake on calcium metabolism, bone composition and bone resorption in the rat. Brit $\mathrm{J}$ of Nutr 84: 49-56.

36. Mattson RL, Kunert MP, Kaldunski ML, Greene AS, Roman RJ, Jacob HJ, and Cowley Jr. AW (2004) Influence of diet and genetics on hypertension and renal disease in Dahl salt-sensitive rats. Physiol Genomics 16: 194-203.

37. Schlemmer CK, Coetzer H, Claassen N, Kruger MC, Rademeyer C, Jaarsfeld L, and Smuts CM (1998) Ectopic calcification of rat aortas and kidneys is reduced with n-3 fatty acid supplements. Prostag Leukotr Ess 59: 221-227. 
38. London G, Marty C, Marchais S, Guerin A, Metivier F, and Vernejoul M (2004) Arterial calcifications and bone histomorphometry in end-stage renal disease. J Am Soc Nephrol 15: 1943-1951.

39. Van Dael P, Kastenmayer P, Clough J, Jarret AR, Barclay DV, and Maire JC (2005) Substitution of casein by $\beta$-casein or of whey protein isolate by $\alpha$-lactalbumin does not affect mineral balance in growing rats. J Nutr 135: 1438-1443.

40. Arnett TR and Spowage M (1996) Modulation of the resorptive activity of rat osteoclasts by small changes in extracellular $\mathrm{pH}$ near the physiological range. Bone 18: 277-279.

41. Kerstetter JE, O’Brien KO, and Insogna KL (2003) Dietary protein, calcium metabolism, and skeletal homeostasis revisited. Am J Clin Nutr 78: 584S-592S.

42. Heaney RP, and Layman DK (2008) Amount and type of protein influences bone health. Am J Clin Nutr 87: 1567S-1570S. 
Table 1. Diet Composition

\begin{tabular}{|c|c|c|}
\hline Ingredients (g/kg diet) & 10\% Casein & $10 \% \mathrm{KPC}^{\mathrm{b}}$ \\
\hline Casein & 115 & 0 \\
\hline DL-Methionine & 1.5 & 0 \\
\hline KPC & 0 & 128 \\
\hline Sucrose & 531.8 & 609.8 \\
\hline Corn Starch & 200 & 229.4 \\
\hline Corn Oil & 53.5 & 49.9 \\
\hline Cellulose & 52 & 59.6 \\
\hline Vitamin Mix $^{\mathrm{a}}$ & 10 & 11.5 \\
\hline Ethoxyquin & 0.01 & 0.01 \\
\hline Mineral Mix ${ }^{\mathrm{a}}$ & 13.4 & 15.3 \\
\hline Calcium Phosphate & 20.2 & 20.9 \\
\hline Calcium Carbonate & 2.6 & 3.6 \\
\hline Gross Energy (kcal/g) & 4.3 & 4.3 \\
\hline
\end{tabular}

KPC, krill protein concentrate

${ }^{a}$ Based on the AIN-93G vitamin and mineral mixes [7].

${ }^{\mathrm{b}}$ Diet formulated for $872 \mathrm{~g}$ of diet $+128 \mathrm{~g}$ addition of KPC 
Table 2. Urinary assays for kidney damage and function in female Sprague-Dawley rats fed different dietary sources of protein.

\begin{tabular}{lccc}
\hline Biomarkers $^{\mathbf{a}}$ & Casein $^{\mathbf{b}}$ & KPC $^{\mathbf{b}}$ & $\boldsymbol{P}^{\text {value }}$ \\
\hline Urinary NAG (IU/L) & $22.9 \pm 6.9$ & $3.9 \pm 1.0$ & 0.005 \\
$\mathrm{CrC}(\mathrm{ml} / \mathrm{min})$ & $1.7 \pm 0.7$ & $5.5 \pm 2.1$ & 0.055 \\
Total Urinary Protein $(\mu \mathrm{g} / \mathrm{ml})$ & $0.6 \pm 0.02$ & $0.5 \pm 0.03$ & 0.057 \\
Urinary pH & $7.5 \pm 0.5$ & $9.0 \pm 0.02$ & 0.004 \\
Urinary Na (mg/7d) & $81.3 \pm 10.4$ & $246.2 \pm 40.1$ & $<0.001$ \\
\hline
\end{tabular}

$\mathrm{CrC}$ - creatinine clearance; NAG - n-acetyl glucosaminidase; $\mathrm{Na}$ - sodium

${ }^{a}$ Rats were individually housing in metabolic cages. Urine samples consisted of pooled samples collected during the final $7 \mathrm{~d}$ of the 4 week feeding study.

${ }^{b}$ Values are expressed as the mean $\pm S E M$ of $n=10$ rats/group. The $t$-test was used to compare differences between treatment groups, Differences were considered significant at $P<0.05$. 
Table 3. Calcium balance of female Sprague-Dawley rats fed different dietary sources of protein

\begin{tabular}{llll}
\hline Measurements $^{\mathbf{a}}$ & Casein & KPC & $\boldsymbol{P}$ val \\
\hline Total Ca Intake & $3.16 \pm 0.08$ & $3.23 \pm 0.08$ & 0.5 \\
First Week & & & \\
Urinary Output (ml/d) & $6.05 \pm 3.5$ & $13.9 \pm 3.4$ & 0.02 \\
Fecal Output (mg/d) & $1.9 \pm 0.1$ & $2.03 \pm 0.1$ & 0.7 \\
Ca Intake (mg/d) & $82.0 \pm 2.7$ & $82.6 \pm 3.7$ & 0.9 \\
Ca Apparent Absorption (\%) & $40.2 \pm 4.4$ & $46.6 \pm 3.7$ & 0.6 \\
Fecal Ca Excretion (mg/d) & $43.0 \pm 5.6$ & $44.1 \pm 3.7$ & 0.7 \\
Urinary Ca Excretion (mg/d) & $0.67 \pm 0.2$ & $1.01 \pm 0.3$ & 0.4 \\
Ca Retention (mg/d) & $22.3 \pm 2.8$ & $26.3 \pm 2.4$ & 0.6
\end{tabular}

Final Week

$\begin{array}{llll}\text { Urinary Output (ml/d) } & 6.7 \pm 2.9 & 13.6 \pm 3.6 & 0.03 \\ \text { Fecal Output (mg/d) } & 2.2 \pm 0.134 & 2.2 \pm 0.113 & 0.9 \\ \text { Ca Intake (mg/d) } & 111.0 \pm 4.4 & 133.0 \pm 2.7 & <0.001 \\ \text { Ca Apparent Absorption (\%) } & 23.8 \pm 5.1 & 31.1 \pm 6.4 & 0.7 \\ \text { Fecal Ca Excretion (mg/d) } & 83.7 \pm 4.3 & 79.9 \pm 11.4 & 0.7 \\ \text { Urinary Ca Excretion (mg/d) } & 3.3 \pm 0.7 & 3.6 \pm 1.7 & 0.3 \\ \text { Ca Retention (mg/d) } & 19.1 \pm 4.1 & 31.4 \pm 6.6 & 0.2 \\ \text { Serum Ca (mg/dl) } & 11.5 \pm 0.4 & 11.4 \pm 0.8 & 0.6\end{array}$

\footnotetext{
${ }^{\bar{a}}$ Values are expressed as the mean \pm SEM of $\mathrm{n}=10$ rats/group. The $\mathrm{t}$-test was used to compare differences between treatment groups, Differences were considered significant at $P<0.05$.
} 
Table 4. Phosphorus balance of female Sprague-Dawley rats fed different dietary sources of protein

\begin{tabular}{llll}
\hline Measurements $^{\mathbf{a}}$ & Casein & KPC & $\boldsymbol{P}$ value \\
\hline Total P Intake (mg/28d) & $2.44 \pm 0.06$ & $2.50 \pm 0.06$ & 0.5
\end{tabular}

First Week

$\begin{array}{lccc}\text { P Intake (mg/d) } & 89.7 \pm 3.0 & 90.9 \pm 4.1 & 0.8 \\ \text { P Apparent Absorption (\%) } & 71.3 \pm 2.4 & 74.8 \pm 1.7 & 0.5 \\ \text { Fecal P Excretion (mg/d) } & 25.1 \pm 1.9 & 23.1 \pm 2.0 & 0.8 \\ \text { Urinary P Excretion (mg/d) } & 18.2 \pm 3.7 & 13.7 \pm 1.1 & 0.3 \\ \text { P Retention (mg/d) } & 30.3 \pm 3.4 & 37.9 \pm 2.5 & 0.3\end{array}$

Final Week
P Intake (mg/d)
$87.6 \pm 3.4 \quad 91.3 \pm 1.9 \quad 0.4$
P Apparent Absorption (\%) $\quad 47.4 \pm 3.9 \quad 51.2 \pm 4.6 \quad 0.8$
Fecal P Excretion $(\mathrm{mg} / \mathrm{d}) \quad 45.1 \pm 2.3 \quad 42.2 \pm 3.3 \quad 0.4$
Urinary P Excretion $(\mathrm{mg} / \mathrm{d}) \quad 15.6 \pm 1.4 \quad 13.5 \pm 0.8 \quad 0.2$
P Retention $(\mathrm{mg} / \mathrm{d}) \quad 19.9 \pm 3.6 \quad 25.5 \pm 3.2 \quad 0.4$
Serum P $(\mathrm{mg} / \mathrm{dl}) \quad 11.3 \pm 0.4 \quad 10.7 \pm 0.5 \quad 0.4$
${ }^{\mathrm{a}}$ Values are expressed as the mean \pm SEM of $n=10$ rats/group. The t-test was used to compare differences between treatment groups, Differences were considered significant at $P<0.05$.


Table 5. Bone measures in female Sprague-Dawley rats fed different dietary sources of protein

\begin{tabular}{|c|c|c|c|}
\hline Measurements $^{\text {a }}$ & Casein & KPC & $P$ value \\
\hline Femoral Weight (g) & $0.53 \pm 0.02$ & $0.55 \pm 0.02$ & 0.4 \\
\hline Femoral Length (mm) & $27.2 \pm 0.22$ & $27.3 \pm 0.33$ & 0.9 \\
\hline Femoral Width (mm) & $3.8 \pm 0.09$ & $3.7 \pm 0.14$ & 0.5 \\
\hline Femoral Depth (mm) & $3.00 \pm 0.03$ & $2.98 \pm 0.04$ & 0.7 \\
\hline Femoral BMC (g) & $0.54 \pm 0.03$ & $0.52 \pm 0.01$ & 0.2 \\
\hline Femoral Ca (mg/g) & $41.4 \pm 4.6$ & $39.0 \pm 1.7$ & 0.7 \\
\hline Femoral P (mg/g) & $55.0 \pm 8.8$ & $67.5 \pm 7.9$ & 0.5 \\
\hline Femoral Strength $(\mathrm{N})$ & $159.0 \pm 6.5$ & $174.6 \pm 9.1$ & 0.2 \\
\hline Values are expressed as & 0 & ip. The $t-1$ & used to \\
\hline
\end{tabular}


Figure 1.

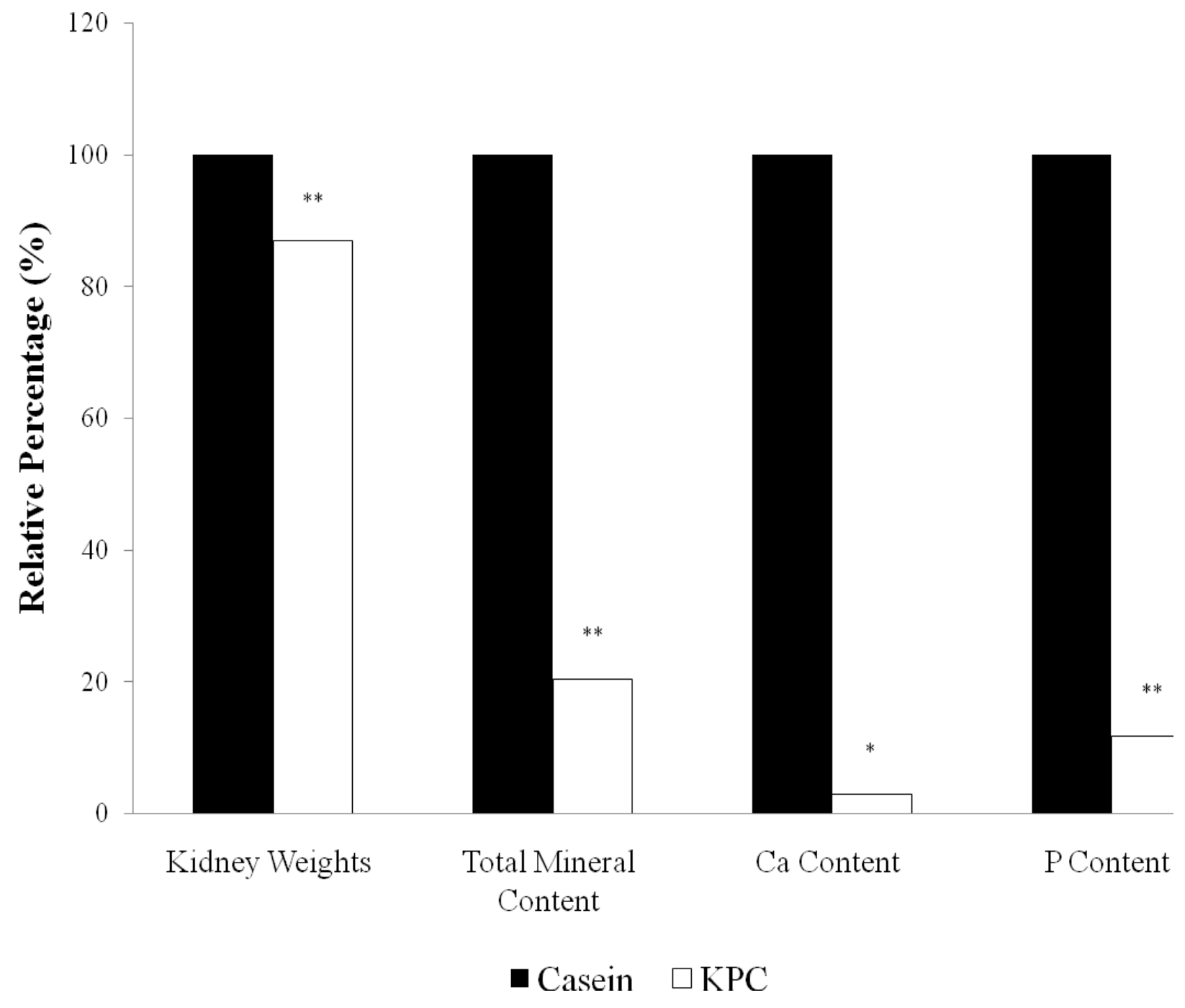


Figure 2.

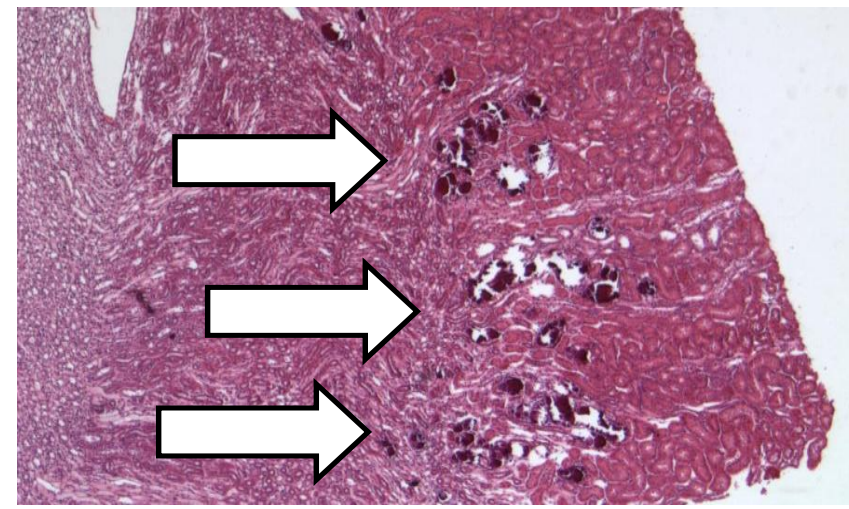

$\mathrm{A}$

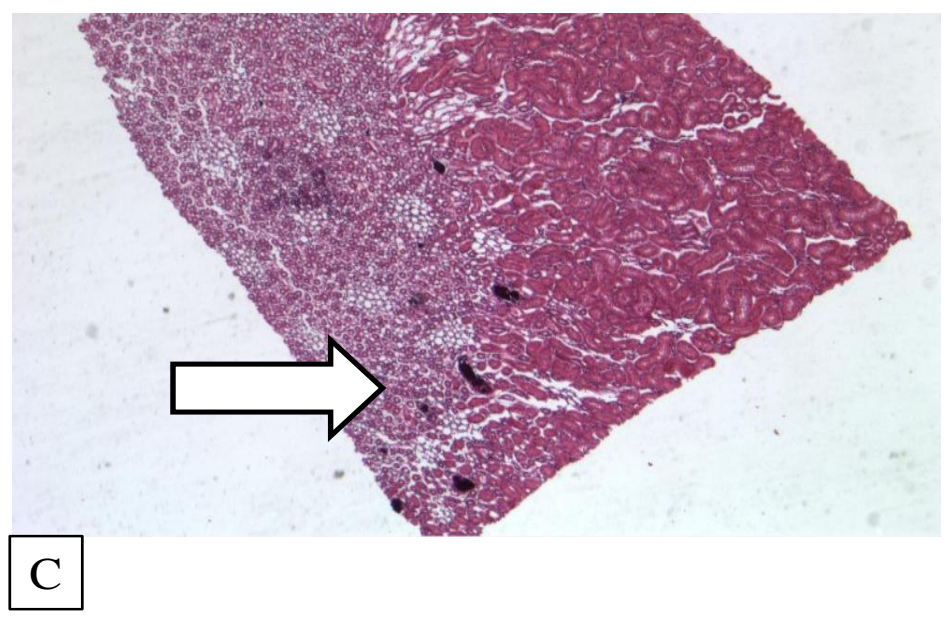

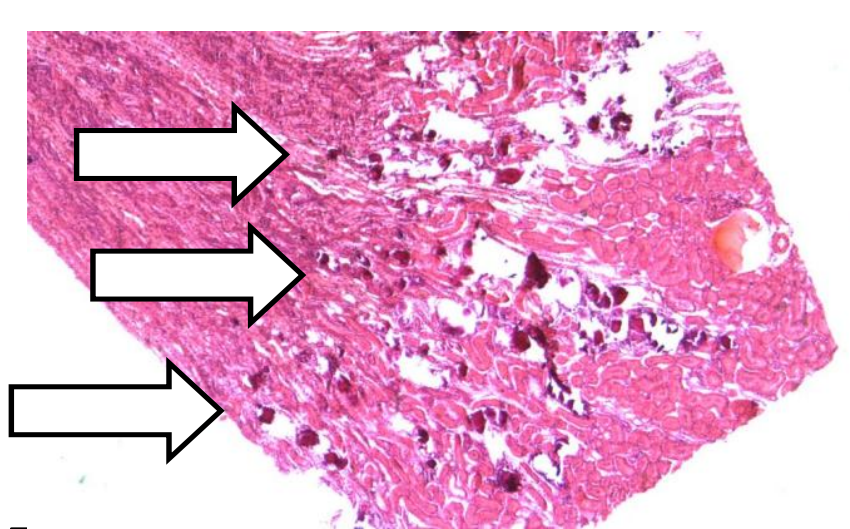

B

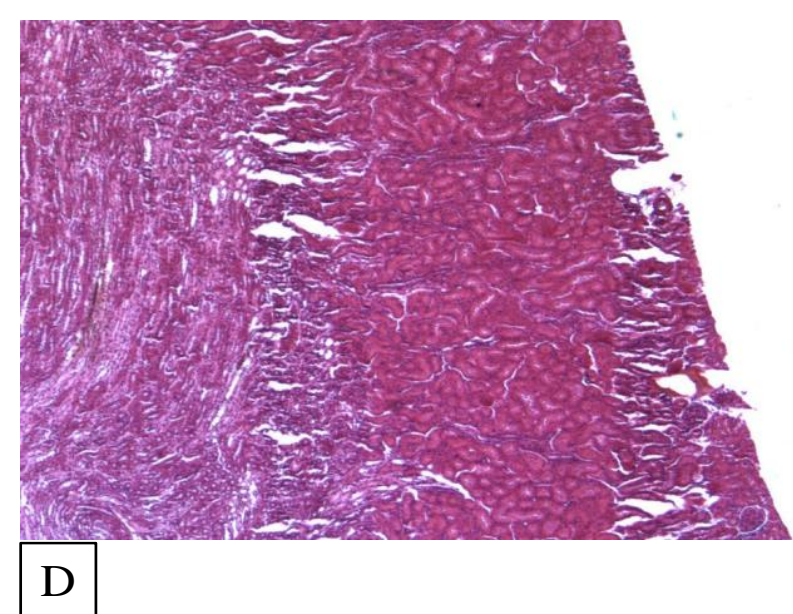


Figure 1. Weights and total mineral, $\mathrm{Ca}$, and $\mathrm{P}$ content of kidneys from rats fed $10 \%$ protein diets consisting of either casein or KPC for 4 weeks. Data presented as percent relative to casein. Symbols indicate significant difference of $P=0.002$ (*) or $P<0.001$ $(* *)$ by t-test.

KPC, krill protein concentrate.

Figure 2. Hematoxylin and eosin $(\mathrm{H} \& \mathrm{E})$ stained renal tissue from rats fed $10 \%$ protein diets consisting of either casein (A \& B) or KPC (C \& D) for 4 weeks. Arrows highlight mineral deposition observed at $4 \mathrm{X}$ magnification. KPC, krill protein concentrate. 
Gigliotti, J.C., Davenport, M., Beamer, S., Tou, J.C., \& Jaczynski, J. (2011)

\section{Extraction and characterization of lipids from}

Antarctic krill (Euphausia superba)

Food Chemistry, (2011), 125, 1028-1036 


\subsection{Background}

Results from Chapter 1 (Section 3) indicated that nephrocalcinosis and associated kidney injury was lower in rats fed KPC as compared to casein.

Similar results have been reported elsewhere. Replacing casein with soybean, flaxseed, or codmeal also resulted in decreased kidney Ca content, suggesting that casein is nephrocalcigenic [1]. However, why different proteins have varying influence on kidney health remains unclear.

It is understood that changing the source of dietary protein also changes the dietary lipid content. In some animal studies, the protein sources used have commonly contained residual lipid content $[1,2]$. This could explain how different protein sources differentially influence kidney health, since soybean, flaxseed, codmeal, and KPC are known sources of $\omega-3$ PUFAs. Rodent models of kidney disease have benefitted from $\omega-3$ PUFAs supplementation [3, 4].

Therefore, the residual $\omega-3$ PUFA content of KPC may be responsible for the decreased nephrocalcinosis.

Conumsption of $\omega-3$ PUFAs has been associated with multiple health benefits, and therefore has become a well-recognized nutritional supplement. Krill oil is an available $\omega-3$ PUFA supplement and it is advertised as being a superior $\omega$-3 supplement due to its high phospholipid content [5]. Health claims

state that there are nutritional benefits of consuming phospholipids as opposed to triglycerides; however little compelling evidence exists supporting these claims.

The unique composition of krill oil also has manufacturing implications. This unique lipid composition can pose difficulties during the processing of krill 
oil, resulting in inefficient usage of the nutritional properties of krill. Given the vital role of krill in its ecosystem, and its valuable nutritional potential, efficient usage of this resource is vital. Therefore, the objective of the next study is to determine the composition of krill oil isolated using different processing methods.

\subsection{Introduction}

Antarctic krill (Euphausia superba) are small, shrimp-like planktonic crustaceans found predominately in the Southern ocean. Despite their small size, the Antarctic krill is estimated to be one of the most numerous multicellular organisms on the planet [6]. A sustainable harvest of krill has been estimated at 70-200 million tons (MT) [7]), whereas the total annual capture of all fisheries has been approximately 130 MT since 2000 [8]. Although it is difficult to accurately determine the fluctuating krill biomass [9], the harvest of krill alone could be comparable to the biomass of all other aquatic species currently harvested by humans. Nicol and Foster [10] estimated a potential annual krill capture to be 0.1 MT, making krill an underutilized species given proper harvest managment [11, $12,13]$

Despite this large biomass, the use of krill as a human food source has been limited [7]. The interest in using krill as a food source stems from its nutrient composition, where krill was reported to contain $77.9-83.1 \%$ moisture, 11.9-15.4\% protein, 0.4-3.6\% lipids, and $\sim 2 \%$ chitin and glucides [14]. Krill protein has been shown to be high quality, making krill a large potential source of valuable dietary protein [15]. In addition, krill oil is currently marketed as a 
valuable dietary supplement, due to its unique lipid composition. Traditionally, triglycerides (TRIGs) are the largest component of dietary oils and can represent over $60 \%$ of the lipid by TLC and densitometry analysis (unpublished data). However, krill oil has been cited as having around 40\% phospholipid by weight [5]. In addition, Kolakowska et al. [16] reported that krill oil is rich in the omega3 polyunsaturated fatty acids ( $\omega-3$ PUFAs) eicosapentaenoic acid (EPA) and docosahexaenoic acid (DHA). Intakes of EPA and DHA are associated with decreased risk of cardiovascular disease [17]. Furthermore, krill oil is also rich in the carotenoid astaxanthin, which is a potent antioxidant and provides additional neutraceutical value [18]. Together, these multiple bioactive components have resulted in various clinical benefits associated with krill oil consumption [19, 20, 21].

Given their role in Antarctic ecosystems, it is crucial to develop ways to efficiently utilize harvested krill. Currently, krill oil is extracted by a two-step solvent extraction using acetone and then ethanol in the first and second step, respectively $[21,22]$ However this extraction requires two separate processing steps and is preferably conducted overnight. This long incubation time could potentially result in the degradation of lipids and proteins due to the rapid autolysis that occurs in krill post-mortem [23]. Additionally, there is no mention about water removal from krill prior to oil extraction. Research has shown an improved extraction efficiency is obtained with krill dehydration prior to oil extraction [24]. Other popular processing methods use superctitical- $\mathrm{CO}_{2}$ entrained with up to $20 \%$ ethanol, and uses heat to inactivate endogenous krill 
lipases [25]. The heating process $\left(>50^{\circ} \mathrm{C}\right)$ is efficient at inactivating the endogenous lipases; however heating may also denature heat-labile krill proteins [26]. Denaturation of these proteins likely result in a low recovery, and the recovered proteins would unlikely be functional (i.e., gel-forming ability, waterholding-capacity, emulsification, etc). This process also does not require water removal prior to processing, despite lyophilized krill having a threefold increase in lipid extraction efficiency using the supercritical- $-\mathrm{CO}_{2}$ method.

Therefore, we hypothesize that one-step extraction with acetone:ethanol mixture for $2 \mathrm{~h}$ from freeze-dried whole krill will result in high extraction efficiency. The study objectives were to determine: (1) oil extraction efficiency from whole krill using different solvent systems, (2) lipid classes of extracted oils, (3) FA profile of the lipid classes, (4) antioxidant capacity and cholesterol content of extracted oils, and (5) composition of the residual spent krill following oil extraction. The residual protein in the spent krill could be recovered with established techniques, such as isoelectric solubilization/precipitation. If protein functionalities are retained, this protein could be used in human food products and would contribute to the efficient utilization of this tremendous resource $[27,28$, 29]. 


\subsection{Materials and methods}

\subsubsection{Sample preparation and oil extraction}

Whole frozen Antarctic krill (Euphausia superba) was obtained from Krill Canada (Langley, BC, Canada). The krill blocks were transported overnight to the West Virginia University food science laboratory in heavily insulated industrial strength boxes filled with dry ice. Upon arrival the boxes were immediately stored at $-80^{\circ} \mathrm{C}$ until use. Whole frozen krill was freeze-dried without thawing (VirTis Genesis 35SQ Super XL freeze-dryer, Virtis, Gardiner, NY, USA), vacuum-packed and stored at $-80^{\circ} \mathrm{C}$ until processed. A flow diagram of oil extraction from krill is shown in Figure 1.

In the one-step extraction oil was extracted from freeze-dried krill using 1:1 acetone:ethanol (v:v) solvent mixture (ACS grade acetone, Fisher Scientific, Fairlawn, NJ, USA; ACS grade 95\% ethanol, Pharmco, Brookfield, CT, USA). The following krill:solvent ratios were tested 1:6, 1:9, 1:12, and 1:30 (w:v). The weight of the initial freeze-dried krill was recorded in order to determine extraction efficiency (see below). The 1:30 ratio was used in the present study to mimic the 1:6 ratio of whole fresh krill as described by [21] and [22]. Fresh whole krill is currently used in commercial oil extraction [21, 22, 25]. However, in the present study freeze-dried krill was used [24] Therefore, 1:30 ratio (freezedried krill) used in the present study approximately corresponded to 1:6 ratio (fresh whole krill) during commercial krill oil extraction with respect to lipid content in relation to the solvent volume. Freeze-dried krill was dispersed in the solvent mixture (acetone:ethanol) by homogenization for $30 \mathrm{~s}$ using a laboratory 
blender (model 51BL31, Waring Commercial, Torrington, CT, USA). Oil extraction was conducted for $2 \mathrm{~h}$ at $4^{\circ} \mathrm{C}$ using a continuous shaker (model Excella E25R, New Brunswick Scientific, Edison, NJ, USA) followed by centrifugation at $10,000 \times \mathrm{g}$ for $20 \mathrm{~min}$ and $4^{\circ} \mathrm{C}$ (model Sorvall RC-5B Refrigerated Superspeed, Kendro Laboratory Products, Newtown, CT, USA). The supernatant (i.e., extracted krill oil) was decanted and dried under air at atmospheric pressure. The sediment (residual spent krill including protein, shell, etc.) was also dried under air at atmospheric pressure and analyzed for crude protein (Kjeldahl), total fat (Soxhlet), and ash content (see below).

In the two-step extraction oil was extracted from freeze-dried krill using two separate extractions. The weight of the initial freeze-dried krill was recorded in order to determine extraction efficiency (see below). The freeze-dried krill was first mixed with acetone at a 1:6 ratio (krill:acetone, w:v), centrifuged, and then the sediment was mixed with ethanol at a 1:6 ratio (krill:ethanol, w:v), followed by final centrifugation. Therefore, two separate extracts were obtained. Acetone extract was obtained in step 1 and ethanol extract in step 2. In step 1 freeze-dried krill was dispersed in acetone by homogenization for $30 \mathrm{~s}$ using the laboratory blender. Oil extraction in step 1 was conducted for $2 \mathrm{~h}$ at $4^{\circ} \mathrm{C}$ using the continuous shaker followed by centrifugation at $10,000 \mathrm{x} g$ for $20 \mathrm{~min}$ and $4^{\circ} \mathrm{C}$. The supernatant (i.e., acetone extract) was decanted and dried under air at atmospheric pressure; while the sediment was subjected to step 2 of the extraction. Step 2 was conducted in the same manner as step 1 except ethanol was used instead of acetone. Therefore, total extraction time (i.e., step 1 and 2) 
was $4 \mathrm{~h}$. Following step 2, final centrifugation at $10,000 \mathrm{x} g$ for $20 \mathrm{~min}$ and $4^{\circ} \mathrm{C}$ was applied. The supernatant (i.e., ethanol extract) was decanted and dried under air at atmospheric pressure. The sediment (residual spent krill including protein, shell, etc.) was analyzed for crude protein (Kjeldahl), total fat (Soxhlet), and ash content (see below).

Dry krill oils (i.e., krill oil from one-step extraction, acetone extract from two-step extraction, and ethanol extract from two-step extraction) were clarified in 2:1 chloroform:methanol (v:v) mixture (ACS grade chloroform, Fisher Scientific, Fairlawn, NJ, USA; HPLC grade methanol, Fisher Scientific, Fairlawn, NJ, USA) with $20 \mathrm{ml}$ of $10 \% \mathrm{NaCl}$ in water added to a separation funnel [30]. This clarification removed any residual water in the krill oil samples. Sufficient volume of the chloroform:methanol mixture was added until there was no visible separate layers. Following clarification, the krill oil samples were re-dried under air at atmospheric pressure. Dry clarified krill oils were weighed and compared to the initial weight of the freeze-dried krill subjected to extraction in order to determine extraction efficiency (see below). The lipid classes of the oils were determined by thin layer chromatography (TLC). Fatty acid profile (FAP) of the lipid classes was determined with gas chromatography (GC). In addition, cholesterol content and antioxidant capacity of the oils were determined. These analyses are described in the subsequent sections.

For comparison, oil was also extracted from freeze-dried krill using the Folch method and Soxhlet extraction [31]. In Folch method, 3g of freeze-dried krill were dispersed in $60 \mathrm{ml}$ of the 2:1 chloroform:methanol mixture by 
homogenization for $30 \mathrm{~s}$ using the laboratory blender, followed by filtration through Whatmann nr 40 paper (Whatman International, Maidstone, UK) in the separation funnel. An aliquot of $20 \mathrm{ml}$ of $10 \% \mathrm{NaCl}$ in water was added to the separation funnel and the mixture was manually shaken and allowed to stand until the phases had completely separated. The bottom organic solvent phase was removed and dried under air at atmospheric pressure. The drying resulted in solvent evaporation yielding krill oil. The weight of krill oil was recorded in order to determine extraction efficiency. In Soxhlet extraction, $3 \mathrm{~g}$ of freeze-dried krill were dispersed in petroleum ether (ACS grade petroleum ether, VWR International, Bridgeport, NJ, USA) [31]. The extraction was carried out in a standard Soxhlet apparatus for $18 \mathrm{~h}[32,33]$, followed by drying under air at atmospheric pressure. The drying resulted in evaporation of petroleum ether yielding krill oil. The weight of krill oil was recorded in order to determine extraction efficiency. The same set of analyses was performed for krill oil extracted with Folch method and Soxhlet extraction as described above for oils extracted with one- and two-step extractions (i.e., extraction efficiency, TLC, GC, cholesterol content, and antioxidant capacity).

In preliminary experiments, the above solvent systems were applied to extract oil from fresh krill and freeze-dried krill. The extraction efficiency was significantly lower $(\mathrm{P}<0.05)$ for all solvent systems using fresh krill when compared to freeze-dried krill. These preliminary experiments confirmed earlier reports [24]. Therefore, the data from preliminary experiments is not shown and oil extracted from fresh krill was not used for analyses described in the 
subsequent sections (i.e., TLC, GC, cholesterol content, and antioxidant capacity). This is also why only freeze-dried krill was used in the present study. All oil extractions were performed in triplicate $(\mathrm{n}=3)$ using the same batch of fresh and freeze-dried krill.

\subsubsection{Extraction efficiency}

The weight of the initial freeze-dried krill prior to the extraction with different solvent systems was recorded. Following extraction, the weight of extracted oils was also recorded. The weight of acetone extract and ethanol extract were combined in order to determine an overall extraction efficiency of the two-step extraction. The extraction efficiency was determined according to the following equation:

$$
\text { Extraction Efficiency }=\frac{\text { weight of extracted krill oil }(\mathrm{g})}{\text { weight of freeze }- \text { dried krill subjected to extraction }(\mathrm{g})} * 100
$$

Extraction efficiency is expressed as grams of extracted oil per 100 grams of freeze-dried krill subjected to the extraction. 


\subsubsection{Determination of lipid classes with thin layer chromatography (TLC) and densitometry analysis}

Thin layer chromatography (TLC) was applied to resolve lipid classes of the oils extracted with all extraction methods tested in the present study (i.e., onestep, two-step, Folch, and Soxhlet). For krill oil extracted with the two-step extraction, TLC and subsequent densitometry analysis were applied to acetone and ethanol extracts (Figure 4). An aliquot of $10 \mathrm{mg}$ of the oil extracted from krill was dissolved in 1:1 chloroform:methanol (v:v) and loaded onto TLC plates (Whatman K6F silica plates with 60 A pore sizes, P.J. Cobert Associates, St. Louis, MO). The TLC plates were developed using a 80:20:1.5 hexane:ether:acetic acid solution (v:v:v) as a mobile phase. Once developed, plates were air-dried for $5 \mathrm{~min}$.

Plate images were captured using a digital camera interfaced with a PC and spot densitometer using transluminating white light (Alpha Innotech Corp., San Leandro, CA). The images were analyzed using the Fluorchem software (ver. 1.0). Phospholipid (PL) and TRIG classes were identified using $R_{F}$ values obtained from triolein (Sigma-Aldrich, St. Louis, MO) and soybean lecithin (Fisher Scientific, Fairlawn, NJ) standards. Once identified, the bands corresponding to PL, TRIG, and polar non-PL class were extracted (i.e., scraped) from the TLC plates and suspended in 1:1 chloroform:methanol (v:v) for determination of fatty acid profile (FAP) by gas chromatography (GC).

Although at least three replicate TLC plates were run per each extraction method (one-step, two-step, Folch, and Soxhlet), only a representative image 
(three replicates) of the krill oil extracted with one-step extraction using 1:12 krill:solvent ratio (w:v) is shown in Figure 3. However, Figure 4 shows densitometry data for all extraction methods (one-step, two-step, Folch, and Soxhlet). The densitometry data was analyzed statistically; and therefore, the densitometry data in Figure 4 is quantitative; while the sample TLC image shown in Figure 3 is qualitative. The densitometry data are reported as mean values ( \pm standard deviation) of at least three replicates and the mean values are expressed as percent of lipid class in total krill oil.

\subsubsection{Determination of fatty acid profile (FAP) of phospholipids (PL) and triglycerides (TRIG) with gas chromatography (GC)}

TLC was applied to resolve lipid classes of the oils extracted with all extraction methods tested in the present study (i.e., one-step, two-step, Folch, and Soxhlet) (Figure 3 and 4). However, only phospholipids (PL) and triglycerides (TRIG) had detectable levels of FA (data not shown). Since PL was the major lipid class containing FA (PL - 20-33\% vs. TRIG - 1-3\%; Figure 4), preliminary experiments were conducted in order to determine if extraction methods (i.e., onestep, two-step, Folch, and Soxhlet) had an effect $(\mathrm{P}<0.05)$ on composition of FA (i.e., FAP). FAP for PL extracted with all extraction methods was determined (data not shown). However, the contents of major FA were not $(\mathrm{P}>0.05)$ different regardless of the extraction method. Therefore, extraction methods tested in the present study did not $(\mathrm{P}>0.05)$ affect FAP of the extracted oils. In addition, Figure 2 indicates that one-step extraction resulted in the highest $(\mathrm{P}<0.05)$ 
extraction efficiency for 1:12 and 1:30 krill:solvent ratio (w:v); while the extraction efficiency at 1:12 and 1:30 was similar $(\mathrm{P}>0.05)$. Therefore, only FAP for PL and TRIG extracted with one-step extraction using 1:12 krill:solvent ratio $(\mathrm{w}: \mathrm{v})$ is reported (Figure 5).

Lipid classes (i.e., PL and TRIG) were extracted (i.e., scraped) from the TLC plates. The PL and TRIG were separately extracted from the TLC scrapings according to [30] and FAP was determined as described elsewhere $[33,34,35$, 36]. FA were transmethylated by the addition of $4 \mathrm{ml}$ of $4 \%(\mathrm{w}: \mathrm{v})$ methanolic $\mathrm{H}_{2} \mathrm{SO}_{4}$ and heated in a water bath set at $90^{\circ} \mathrm{C}$ for $60 \mathrm{~min}$. The mixture was saponified by transferring through a $\mathrm{Na}_{2} \mathrm{SO}_{4}$-filled glass Pasteur pipette and subsequently dried under $\mathrm{N}_{2}$ in a water bath set at $60^{\circ} \mathrm{C}$ for $60 \mathrm{~min}$. The FA methyl esters (FAME) were re-suspended in filtered iso-octane (HPLC grade isooctane, Fisher Scientific, Fairlawn, NJ, USA). The FAME were analyzed by a GC (model CP-3800, Varian Analytical Instruments, Walnut Creek, CA, USA) using flame ionization detector fitted with a WCOT-fused silica capillary column (50 m length, $0.25 \mathrm{~mm}$ inside diameter; Varian Analytical Instruments, Walnut Creek, CA, USA). Injection and detection temperatures were maintained at $220^{\circ} \mathrm{C}$ and column temperature was $190^{\circ} \mathrm{C}$. The stationary phase was CP-Silica 88 (Varian Analytical Instruments, Walnut Creek, CA, USA). Nitrogen was the carrier gas and a split ratio of 10 to 1 was used. The FA were identified by comparing their retention times with those of known standards Peak area and the amount of each FA were computed by an integrator using the Star GC workstation version 6 software (Varian Analytical Instruments, Walnut Creek, 
CA, USA). The data are reported as mean values ( \pm standard deviation) of at least three replicates and the mean values are expressed as percent of a fatty acid in total fatty acids.

\subsubsection{Cholesterol content in extracted krill oils}

Due to the prevalence of polar, non-PL class (Figure 3), the TLC and densitometry analysis did not allow specific determination of cholesterol content. Cholesterol was probably contained within the polar, non-PL class. However, krill is a shellfish; and therefore, determination of cholesterol content in the oil extracted from krill in this study was of interest. However, two-thirds of the sterols in shellfish such as krill are non-cholesterol sterols interfering with cholesterol absorption $[37,38]$. Therefore, cholesterol content of oil extracted from krill with all extraction methods (i.e., one-step, two-step, Folch, and Soxhlet) was determined using a colorimetric assay (catalog number 428901, EMD Chemicals Inc., an affiliate of Merck, Darmstadt, Germany). For krill oil extracted with the two-step extraction, cholesterol content was separately determined for acetone and ethanol extracts (Figure 6). This cholesterol assay relies on the oxidation of cholesterol by added cholesterol oxidase and yielding $\mathrm{H}_{2} \mathrm{O}_{2}$. The resulting $\mathrm{H}_{2} \mathrm{O}_{2}$ interacts with a cholesterol probe to produce resorufin that is detected spectrophotometrically. The results are compared to a standard curve constructed with cholesterol standards.

Krill oil samples were prepared in a cholesterol reaction buffer. In a 96 well microplate, $50 \mu \mathrm{L}$ of the buffered krill oil samples were mixed with $50 \mu \mathrm{L}$ of 
reaction mix (containing cholesterol oxidase and cholesterol probe). Samples were covered and incubated at $37^{\circ} \mathrm{C}$ for $1 \mathrm{~h}$. Absorbance was read at $570 \mathrm{~nm}$ using a Spectramax Plus microplate reader (Molecular Devices, Sunnyvale, CA). In order to determine cholesterol content in krill oil, standard curve was constructed using cholesterol standards mixed with $50 \mu \mathrm{L}$ of the reaction mix. The cholesterol content is reported as mean values ( \pm standard deviation) of at least three replicates and the mean values are expressed as grams of cholesterol per 100 grams of krill oil.

\subsubsection{Antioxidant capacity (trolox equivalents - TE) of extracted krill oils}

The oil extracted from krill in a present study had a deep maroon red color. It has been reported that krill oil is rich in antioxidants, in particular astaxanthin $[7,16,39,40]$. These antioxidants were likely included in the polar non-PL class. Therefore, total antioxidant capacity for the oil extracted from krill with all extraction methods (i.e., one-step, two-step, Folch, and Soxhlet) was determined and compared to trolox equivalents (TE) according to a colorimetric antioxidant assay (catalog number 709001, Cayman Chemical Company, Ann Arbor, MI). For krill oil extracted with the two-step extraction, total antioxidant capacity was separately determined for acetone and ethanol extracts (Figure 7). This antioxidant assay relies on the ability of endogenous antioxidants in krill oil to inhibit the metmyoglobin-mediated oxidation of ABTS (2,2'-Azino-di-[3ethylbenzthiazoline sulphonate]) to $\mathrm{ABTS}^{+}$. ABTS and metmyoglobin were added to krill oil samples as reagents and the amount of $\mathrm{ABTS}^{+}$was determined 
spectrophotometrically. The capacity of the endogenous antioxidants in krill oil to prevent ABTS oxidation was compared with that of a water-soluble tocopherol analogue, trolox (6-Hydroxy-2,5,7,8-tetramethylchroman-2-carboxylic acid).

In a 96 well microplate, $10 \mu \mathrm{L}$ of krill oil samples were mixed with $10 \mu \mathrm{L}$ of metmyoglobin and $150 \mu \mathrm{L}$ of ABTS. To initiate the reaction, $40 \mu \mathrm{L}$ of $\mathrm{H}_{2} \mathrm{O}_{2}$ was added to each well. Samples were covered and incubated at room temperature on a shaker for $5 \mathrm{~min}$. Absorbance was read at $750 \mathrm{~nm}$ using a Spectramax Plus microplate reader (Molecular Devices, Sunnyvale, CA). In order to determine TE for krill oil, standard curve was constructed using trolox standards mixed with $10 \mu \mathrm{L}$ of metmyoglobin and $150 \mu \mathrm{L}$ of ABTS. The antioxidant capacity is reported as mean values ( \pm standard deviation) of at least three replicates and the mean values are expressed as micromols of TE per milliliter of krill oil.

\subsubsection{Crude protein (Kjeldahl), total fat (Soxhlet), and ash content of the residual spent krill following oil extraction}

The crude protein, ash content, and total fat were determined in the residual spent krill following oil extraction with one- and two-step extraction only (i.e., sediment in Figure 1). Crude protein was determined by Kjeldahl assay (AOAC, 1995). Ash content was performed by incinerating samples in a muffle furnace at $550^{\circ} \mathrm{C}$ for $24 \mathrm{~h}$ [31]. Residual fat content was determined according to the Soxhlet extraction method [31]. To determine proximate composition (i.e., crude protein, total fat, and ash content) on dry basis, the residual spent krill was 
analyzed for moisture content. A sample ( $2 \mathrm{~g})$ was placed on an aluminum dish (Fisher Scientific, Fairlawn, NJ, USA), spread evenly across the dish and ovendried $\left(105^{\circ} \mathrm{C}\right.$ for $\left.24 \mathrm{~h}\right)$ [31]. The proximate data are reported as mean values $( \pm$ standard deviation) of at least three replicates and the mean values are expressed as grams per 100 grams of the residual spent krill following oil extraction (dry weight basis).

\subsubsection{Statistical analysis}

The oil extraction experiments were triplicated $(n=3)$. For each triplicate, at least three measurements were performed. One-way independent measures analyses of variance (ANOVA) were used to examine the effects of all methods used. Post-hoc analysis was conducted only in the presence of significant population differences $(\mathrm{P}<0.05)$. ANOVA statistical comparisons were conducted using KYPlot (KyensLab, Tokyo, Japan) with a significance level of $\mathrm{P}<0.05$. Tukey's test $(\mathrm{P}<0.05)$ was used to determine individual differences between treatments except for the differences of FA content between TRIG and PL where Student's t-test was used (Figure 5).

\subsection{Results and Discussion}

\subsubsection{Extraction efficiency}

Extraction of krill oil using the 2-step procedure resulted in similar $(\mathrm{P}>0.05)$ efficiency as the 1-step procedure using a krill:solvent ratio of 1:6 (Figure 2). The extraction efficiency for the 1-step procedure increased $(\mathrm{P}<0.05)$ 
as the krill:solvent ratio increased, with 1:12 and 1:30 ratios having the greatest efficiencies. Although these two krill:solvent ratios resulted in the highest $(\mathrm{P}<0.05)$ efficiencies, they were similar $(\mathrm{P}>0.05)$. Therefore, krill:solvent ratio is a critical parameter for extraction efficiency. Likely, if the krill:solvent ratio were increased in the 2-step extraction, the extraction efficiency would similarly increase. However, 1-step extraction is simpler than the 2-step procedure; and therefore, 1-step extraction with acetone:ethanol (1:1, v:v) using 1:12 krill:solvent ratio is recommended.

\subsubsection{Determination of lipid classes with thin layer chromatography (TLC) and densitometry analysis}

Major lipid classes (triglycerides - TRIG, phospholipids - PL, and polar non-PL) of the extracted krill oils were identified using TLC (Figure 3), quantified by densitometry and presented as $\%$ of lipid class in total krill oil extracted (Figure 4). The extraction procedure did not $(\mathrm{P}>0.05)$ affect TRIG content in the extracted oils, which ranged 1.0-3.2\% (Figure 4). However, extraction procedure had an effect $(\mathrm{P}<0.05)$ on $\mathrm{PL}$ content, with Folch, Soxhlet, and 1-step (1:6 krill:solvent ratio) extractions having the highest $(\mathrm{P}<0.05)$ content of PL. The PL content ranged from 20.4-32.7\% (Figure 4). A high PL content in krill oil has been described previously, with total PL at approximately 40\% [5]. The high PL content makes krill oil unique as compared to other dietary lipids. The TRIG content in fish oils is approximately 60\% [39]. 
The major lipid class in all of the oils extracted from krill was the polar non-PL class $(>60 \%)$. This class consists of the following lipid classes:

cholesterol, mono- and di-glycerides, and the red pigment associated with krill oil (primarily astaxanthin). The association of the red pigment with the polar non-PL class on the TLC plates made quantifying each class individually difficult, thus these classes were combined and accounted for as the polar non-PL class. The 1step extraction with krill:solvent ratios greater than 1:6 and the acetone fraction from the 2-step extraction had the highest $(\mathrm{P}<0.05)$ content of the polar non-PL class. The densitometry results of the TLC plates coincided with the visual appearance of the oils. The extractions that resulted in the highest content of the polar non-PL also had a deeper red color. The differences in the polar non-PL class content should be of commercial interest. It is possible that the extraction procedure could yield oil with lower cholesterol content, but higher antioxidant capacity. Therefore, cholesterol content and total antioxidant capacity (as an indirect measure of astanxanthin content) were determined (see section 3.4 and 3.5 , respectively).

\subsubsection{Determination of fatty acid profile (FAP) of phospholipids (PL) and triglycerides (TRIG) with gas chromatography (GC)}

Following TLC analysis, TRIG and PL spots were scraped from the TLC plates and methylated for FAP by GC (Figure 5). The TRIG had a higher $(\mathrm{P}<0.05)$ content of myristic, palmitoleic, and oleic acid than PL (Figure 5A). Conversely, EPA and DHA were predominant $(\mathrm{P}<0.05)$ in $\mathrm{PL}$, contributing to 
much higher $(\mathrm{P}<0.05)$ content of total n-3 FA and unsaturated FA in PL than in TRIG (Figure 5B). Consequently, the ratios of $n 6 / n 3$ and saturated FA/unsaturated FA were lower $(\mathrm{P}<0.05)$ in PL (Figure 5C).

Consumption of $\omega-3$ FA in a form of PL or TRIG has different health and physiological effects [41, 42]. Therefore, having EPA and DHA esterified as PL in krill oil has significant implications for human health. The preferential esterification of EPA and DHA into PL is intriguing and has been noted previously [43]. However, available data comparing the benefits of consuming $\omega$ 3 FA as krill oil compared to other sources is scarce. Therefore, further studies are needed to compare and understand the nutritional value and health effects of krill oil versus other sources of n-3 FA.

\subsubsection{Cholesterol content in extracted krill oils}

The extraction procedures yielding oil with the highest $(\mathrm{P}<0.05)$ content of polar non-PL (one-step extractions in Figure 4) did not have high cholesterol content (Figure 6). The one-step procedures with krill:solvent ratios $\geq 1$ :9 had lower $(\mathrm{P}<0.05)$ cholesterol content than acetone extract of the 2 -step procedure. Cholesterol content of the 2-step, Folch, and Soxhlet extractions mimicked content of the polar non-PL (Figure 4), suggesting that the cholesterol content contributed more to the content of polar non-PL in these procedures than the onestep procedures.

In general, cholesterol content of krill is lower than shrimp, and slightly higher than fish [39]. Importantly, not only are sterols in krill composed of 
cholesterol, but they also contain $\sim 30 \%$ non-cholesterol sterols [44]. Noncholesterol sterols from both shellfish and plant sources have been shown to reduce cholesterol absorption in experimental studies [38]. Krill oil resulted in $18 \%$ reduction in total serum cholesterol compared to $6 \%$ with fish oil in hyperlipidemic patients [19]. The hypolipidemic effects of seafood oils are not fully understood, but are significantly influenced by $\omega-3$ PUFA. Since krill oil is rich in $\omega-3$ PUFA and contains non-cholesterol sterols, the hypolipidemic effects of krill oil could be additive.

\subsubsection{Antioxidant capacity (trolox equivalents - TE) of extracted krill oils}

The red color of krill oil is due to the carotenoid astaxanthin, a potent antioxidant. Frozen krill contains 3-4 mg of carotenoids/100 $\mathrm{g}$ and astaxanthin is $>80 \%$ of the total carotenoids [18]. Aside from measuring the total antioxidant capacity of each extraction procedure as an indirect indicator of astaxanthin content, it is also useful information in terms of human health benefits. It has been shown that astaxanthin decreases induced membrane oxidative injury to a

greater degree than $\alpha$-tocopherol, an antioxidant commonly used in food products.

Oils extracted with the one-step procedure using 1:9 and 1:30 krill:solvent ratios as well as the ethanol extract of the two-step procedure had the highest $(\mathrm{P}<0.05)$ antioxidant capacity (Figure 7). Despite the highest $(\mathrm{P}<0.05)$ content of polar non-PL (Figure 4), the acetone extract of the 2-step procedure had the lowest $(\mathrm{P}<0.05)$ antioxidant capacity. Therefore, the polar non-PL of the acetone extract may be predominately cholesterol. The Folch extraction also yielded oil 
with the lowest $(\mathrm{P}<0.05)$ antioxidant capacity. The antioxidant capacities of oils extracted with one-step procedures mimicked their respective contents of polar non-PL (Figure 4), suggesting that astaxanthin was the primary component of the polar non-PL in the oils extracted with one-step procedures.

\subsubsection{Crude protein, total fat, and ash content of the residual spent krill following oil extraction}

Proximate analysis performed on the residual spent krill that was recovered from the sediment following oil extraction and centrifugation (Figure 1) shows that the sediment was primarily composed of protein $(\sim 74 \mathrm{~g} / 100 \mathrm{~g}$, dry weight, Table 1). The amount of protein in the residual spent krill was not $(\mathrm{P}>0.05)$ affected by oil extraction procedure. The lipid content decreased $(\mathrm{P}<0.05)$ as the krill:solvent ratio increased from 1:9 to 1:30 in the one-step extraction. The two-step extraction and one-step extraction using 1:12 and 1:30 krill:solvent ratios resulted in the lowest $(\mathrm{P}<0.05)$ lipid content in the residual spent krill. Likewise, the one-step extraction using 1:30 krill:solvent ratio and two-step procedure also resulted in the lowest $(\mathrm{P}<0.05)$ mineral content. However, the ash content in the residual spent krill was comparable to the ash content in whole krill prior to extraction (ash $17.4 \mathrm{~g} / 100 \mathrm{~g}$, dry basis, [45]). Therefore, the fluoride $(\mathrm{F})$ content was likely high and would need to be reduced if the protein in the residual spent krill were to be recovered and used for human/animal consumption. 
The proximate data clearly shows that there is high protein content in the residual spent krill; though ash (and likely F) is also high. The protein could be recovered with the isoelectric solubilization/precipitation (ISP), while ISP also significantly reduces ash content $[27,45]$. It has been shown that the proteins recovered from whole krill using ISP result in good quality heat-set gels [27]. Therefore, a fuller utilization of krill as a human food would be possible by extracting oil as shown in the present study, followed by protein recovery by ISP for subsequent inclusion in human food products. 


\subsection{References}

1. Zhang X, and Beynen A (1992) Increasing intake of soybean protein or casein, but not cod meal, reduces nephrocalcinosis in femals rats. J.Nutr 122: 2218-2225.

2. Gigliotti, J. C., Smith, A. L., Jaczynski, J., \& Tou, J. C. (2010).

Consumption of krill protein concentrate prevents early renal injury and nephrocalcinosis in female Sprague-Dawley rats. Urological Research, in press.

3. Schmiedl, A., Schwille, P.O., Bonucci, E., Erben, R.G., Grayczyk, A., and Sharma, V. (2000). Nephrocalcinosis and hyperlipidemia in rats fed a cholesterol- and fat-rich diet: association with hyperoxaluria, altered kidney and bone minerals, and renal tissue phospholipid-calcium interaction. Urol Res, 28, 404-415.

4. Schlemmer, C.K., Coetzer, H., Claassen, N., Kruger, M.C., Rademeyer, C., van Jaarsveld, L., \& Smuts, C.M. (1998). Ectopic calcification of rat aortas and kidneys is reduced with n-3 fatty acid supplementation.

Prostaglandins Leukot Essent Fatty Acids, 59, 221-227.

5. Bottino, N. R. (1975). Lipid composition of two species of Antarctic krill: Euphausia superba and E. crystallorophias. Comparative Biochemistry and Physiology B, 50, 479-484.

6. Nicol, S., James, A., \& Pitcher, G. (1987). A first record of daytime surface swarming by Euphausia lucens in the Southern Benguela region. Marine Biology, 94, 7-10. 
7. Suzuki, T., \& Shibata, N. (1990). The utilization of Antarctic krill for human food. Food Reviews International, 6(1), 119-147.

8. Food and Agriculture Organization of the United Nations. (2007). The state of world fisheries and aquaculture 2006. Rome, Italy: FAO Fisheries and Aquaculture Department.

9. Smetacek, V., \& Nicol, S. (2005). Polar ocean ecosystem in a changing world. Nature, 437, 362-368.

10. Nicol, S., \& Foster, J. (2003). Recent trends in the fishery for Antarctic krill. Aquatic Living Resources, 16(1), 42-45.

11. Everson, I. (2000). Krill: Biology, ecology and fisheries. Oxford: Blackwell Science. pp. 384.

12. Laws, R. M. (1985). The ecology of southern ocean. Amercican Scintist, 73(1), 26-40.

13. Hureau, J. C. (1985). Interaction between Antarctic and sub-Antarctic marine, freshwater and terrestrial organisms. In W. R. Siegfried, P. R. Condy, R. M. Laws, Antarctic Nutrient Cycles and Food Web. (pp. 626629). Berlin: Springer-Verlag.

14. Grantham, G. J. (1977). The Southern Ocean: The utilization of krill. Southern Ocean Fisheries Survey Programme GLO/SO/7/3 (pp. 1-61). Rome (Italy): Food and Agriculture Organization.

15. Gigliotti, J. C., Jaczynski, J., \& Tou, J. C. (2008). Determination of the nutritional value, protein quality and safety of krill protein concentrate 
isolated using an isoelectric solubilization / precipitation technique. Food Chemistry, 111(1), 209-214.

16. Kolakowska, A., Kolakowski, E., \& Szczygielski, M. (1994). Winter season krill (Euphausia superba Dana) as a source of n-3 polyunsaturated fatty acids. Die Nahrung, 38, 128-134.

17. Harris, W.S., Kris-Etherton, P.M., and Harris, K.A. (2008). Intakes of long-chain omega-3 fatty acid associated with reduced risk for death from coronary heart disease in healthy adults. Current Athereosclerosis Reports, 10 .

18. Yamaguchi, K., Miki, W., Toriu, W., Kondo, Y., Murakami, M., Konosu, S., Satake, M., Fujita, T. 1983. The composition of carotenoid pigments in the Antarctic krill Euphausia superba. Nippon Suisan Gakkaishi, 49(9), $1411-1415$.

19. Bunea, R., El Farrah, K., \& Deutsch, L. (2004). Evaluation of the effects of Neptune krill oil on the clinical course of hyperlipidemia. Alternative Medicine Review, 9(4), 420-428.

20. Sampalis, F., Bunea, R., Pelland, M. F., Kowalski, O., Duguet, N., \& Dupuis, S. (2003). Evaluation of the effects of Neptune krill oil on the management of premenstrual syndrome and dysmenorrhea. Alternative Medicine Review, 8(2), 171-179.

21. Sampalis, T. (2007). Krill and/or marine extracts for prevention and/or treatment of cardiovascular diseases arthritis, skin cancer diabetes, 
premenstrual syndrome and transdermal transport. U.S. patent application number 20070098808. U.S. Patent and Trademark Office.

22. Beaudoin, A., \& Martin, G. (2004). Method of extracting lipids from marine and aquatic animal tissues. U.S. patent 6,800,299. U.S. Patent and Trademark Office.

23. Anheller, J. E., Hellgren, L., Karlstam, B., \& Vincent, J. (1989).

Biochemical and biological profile of a new enzyme preparation from Antarctic krill Euphausia superba Dana suitable for debridement of ulcerative lesions. Archives of Dermatological Research, 281, 105-110.

24. Dunford, N. T., Temelli, F., \& LeBlanc, E. (1997). Supercritical CO $\mathrm{CO}_{2}$ extraction of oil and residual proteins from Atlantic mackerel (Scomber scombrus) as affected by moisture content. Journal of Food Science, 62(2), 289-294.

25. Bruheim, I., Griinari, M., Tilseth, S., Banni, S., Cohn, J. S., \& Mancinelli, D. (2008). Bioeffective krill oil compositions. U.S. patent application number 20080274203. U.S. Patent and Trademark Office.

26. Carvajal, P. A., Lanier, T. C., \& Macdonald, G. A. (2005). Stabilization of proteins in surimi. In J. W. Park, Surimi and Surimi Seafood, $2^{\text {nd }}$ ed. (pp. 163225). Boca Raton (FL): Taylor and Francis Group.

27. Chen, Y. C., \& Jaczynski, J. (2007a). Gelation of protein recovered from whole Antarctic krill (Euphausia superba) by isoelectric solubilization / precipitation as affected by functional additives. Journal of Agricultural and Food Chemistry, 55, 1814-1822. 
28. Jaczynski, J. (2007). Industrial bioreactor and method of use in continuous protein and lipid recovery system. U.S. patent application number 20070281349. U.S. Patent and Trademark Office.

29. Torres, J. A., Chen, Y. C., Rodrigo-Garcia, J., \& Jaczynski, J. (2007). Recovery of by-products from seafood processing streams. In F. Shahidi, Maximizing the Value of Marine By-products. (pp. 65-90). Boca Raton (FL): CRC Press.

30. Folch, J., Lees, M., \& Sloane, S. (1957). A simple method for isolation and purification of total lipids from animal tissues. Journal of Biological Chemistry, 226, 497-509.

31. Association of Official Analytical Chemists. (1995). Official Methods of Analysis. 16th ed., Gaithersburg, MD: Association of Official Analytical Chemists International.

32. Chen, Y. C., Nguyen, J., Semmens, K., Beamer, S., \& Jaczynski, J. (2006). Enhancement of omega-3 fatty acid content in rainbow trout (Oncorhynchus mykiss) fillets. Journal of Food Science, 71(7), C383-389.

33. Chen, Y. C., Nguyen, J., Semmens, K., Beamer, S., \& Jaczynski, J. (2007). Physicochemical changes in omega-3-enhanced farmed rainbow trout (Oncorhynchus mykiss) muscle during refrigerated storage. Food Chemistry, 104(3), 1143-1152.

34. Chen, Y. C., Nguyen, J., Semmens, K., Beamer, S., \& Jaczynski, J. (2008a). Effects of dietary alpha-tocopheryl acetate on lipid oxidation and alpha-tocopherol content of novel omega-3-enhanced farmed rainbow 
trout (Oncorhynchus mykiss) fillets. LWT - Food Science and Technology, 41(2), 244-253.

35. Chen, Y. C., Nguyen, J., Semmens, K., Beamer, S., \& Jaczynski, J. (2008b). Chemical changes in omega-3-enhanced farmed rainbow trout (Oncorhynchus mykiss) fillets during abusive-temperature storage. Food Control, 19(6), 599-608.

36. Taskaya, L., Chen, Y. C., Beamer, S., Tou, J. C., \& Jaczynski, J. (2009a). Compositional characteristics of materials recovered from whole gutted silver carp (Hypophthalmichthys molitrix) using isoelectric solubilization / precipitation. Journal of Agricultural and Food Chemistry, 57(10), 42594266.

37. Feeley, R. M., Criner, P. E., \& Watt, B. K. (1972). Cholesterol content of foods. Journal of the American Dietetic Association, 61, 134-149.

38. Vahouny, G. V., Connor, W. E., Roy, T., Lin, D. S., \& Gallo, L. (1981). Lymphatic absorption of shellfish sterols and their effects on cholesterol absorption. American Journal of Clinical Nutrition, 34, 507-513.

39. Tou, J. C., Jaczynski, J., \& Chen, Y. C. (2007). Krill for human consumption: nutritional value and potential health benefits. Nutrition Reviews, 65(2), 63-77.

40. Kolakowska, A. (1991). The influence of sex and maturity stage of krill (Euphausia superba Dana) upon the content and composition of its lipids. Polish Polar Research, 12, 73-78. 
41. Amate, L., Gil, A., \& Ramirez, M. (2002). Dietary long-chain PUFA in the form of TAG or phospholipids influence lymph lipoprotein size and composition in piglets. Lipids, 37(10), 975-980.

42. Matthews, S. A., Oliver, W. T., Phillips, O. T., Odle, J., Diersen-Schade, D. A., \& Harrell, R. J. (2002). Comparison of triglycerides and phospholipids as supplemental sources of dietary long-chain

43. Saether, O., Ellingsen, T. E., \& Mohr, V. (1986). Lipids of North Atlantic krill. Journal of Lipid Research, 27, 274-285.

44. Fricke, H., Gercken, G., Schreiber, W., Oehlenschlaeger, J. (1984). Lipid, sterol and fatty acid composition of Antarctic krill (Euphausia superba Dana). Lipids, 19(11), 821-827.

45. Chen, Y. C., Tou, J. C., \& Jaczynski, J. (2009). Amino acid and mineral composition of protein and other components and their recovery yields from whole Antarctic krill (Euphausia superba) using isoelectric solubilization / precipitation. Journal of Food Science, 74(2), H31-39. 
Figure 1.

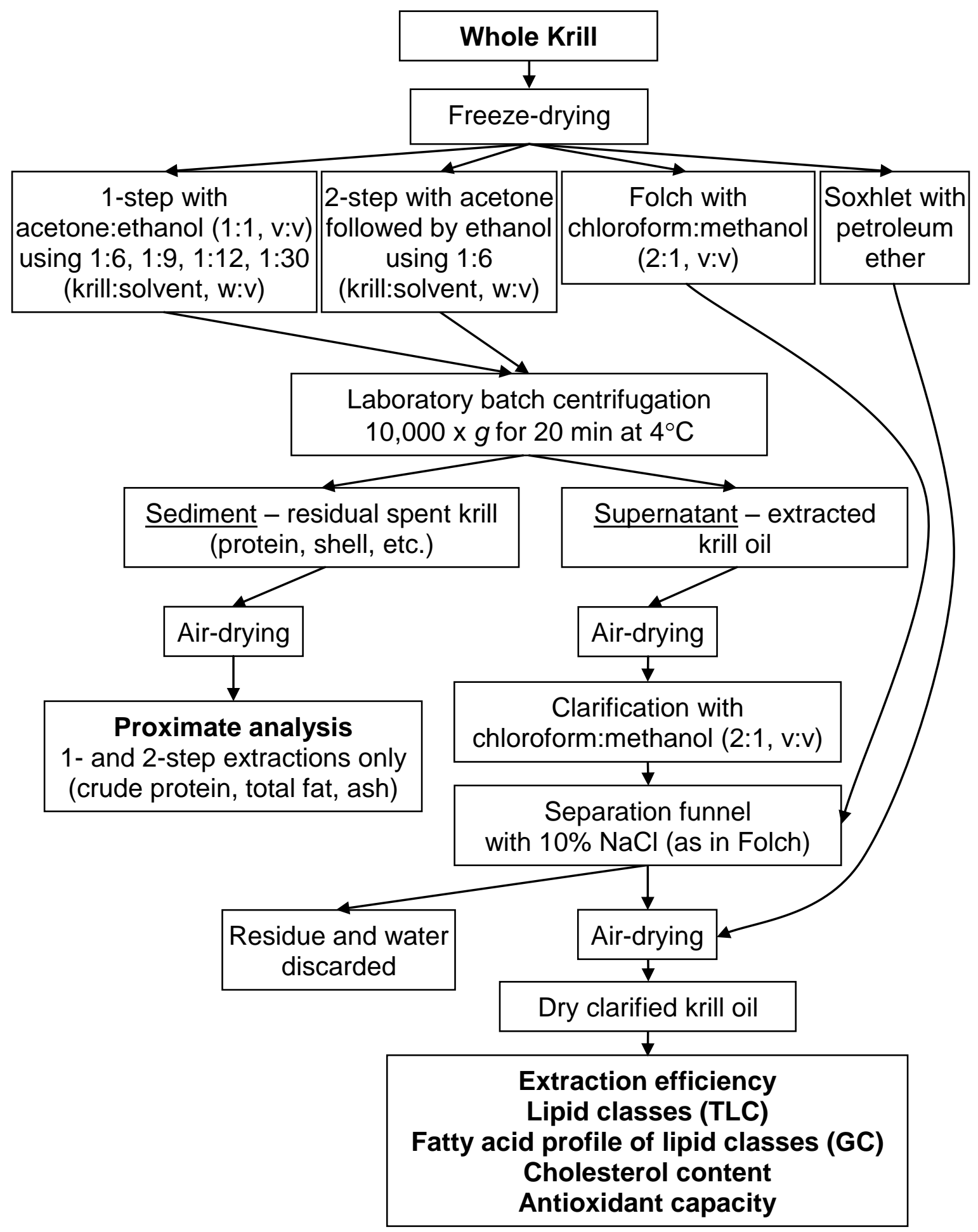


Figure 2.

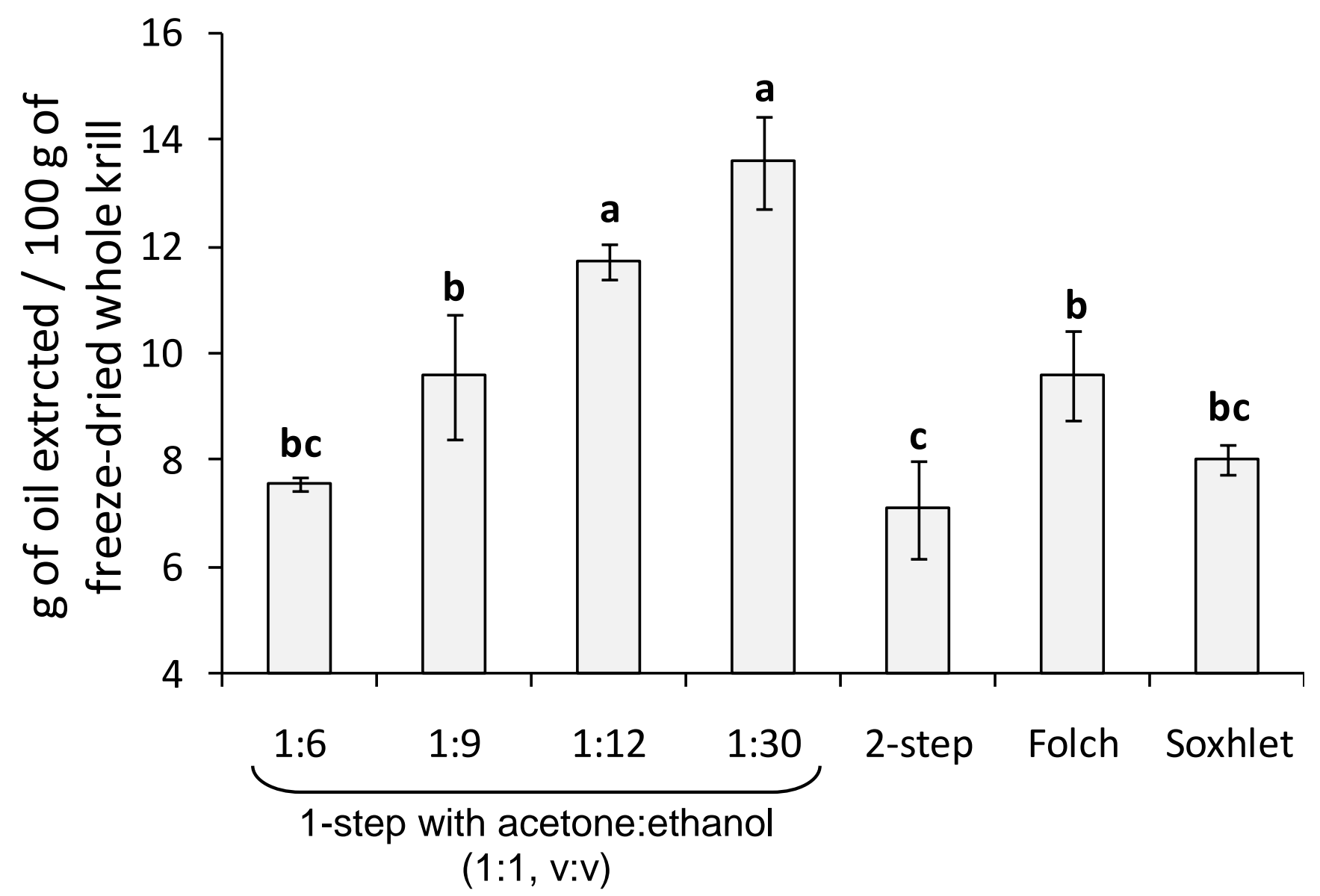


Figure 3.

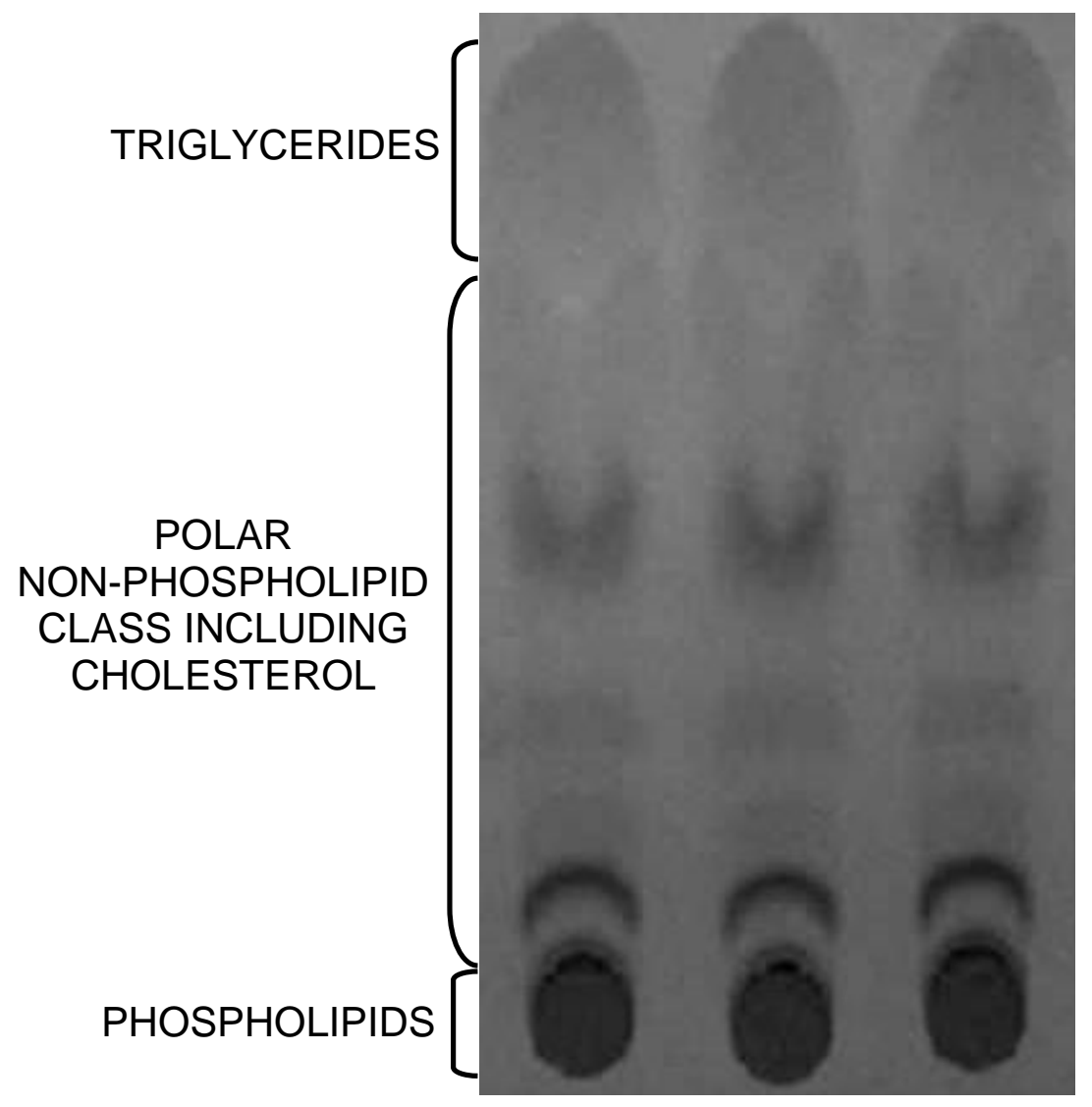


Figure 4.

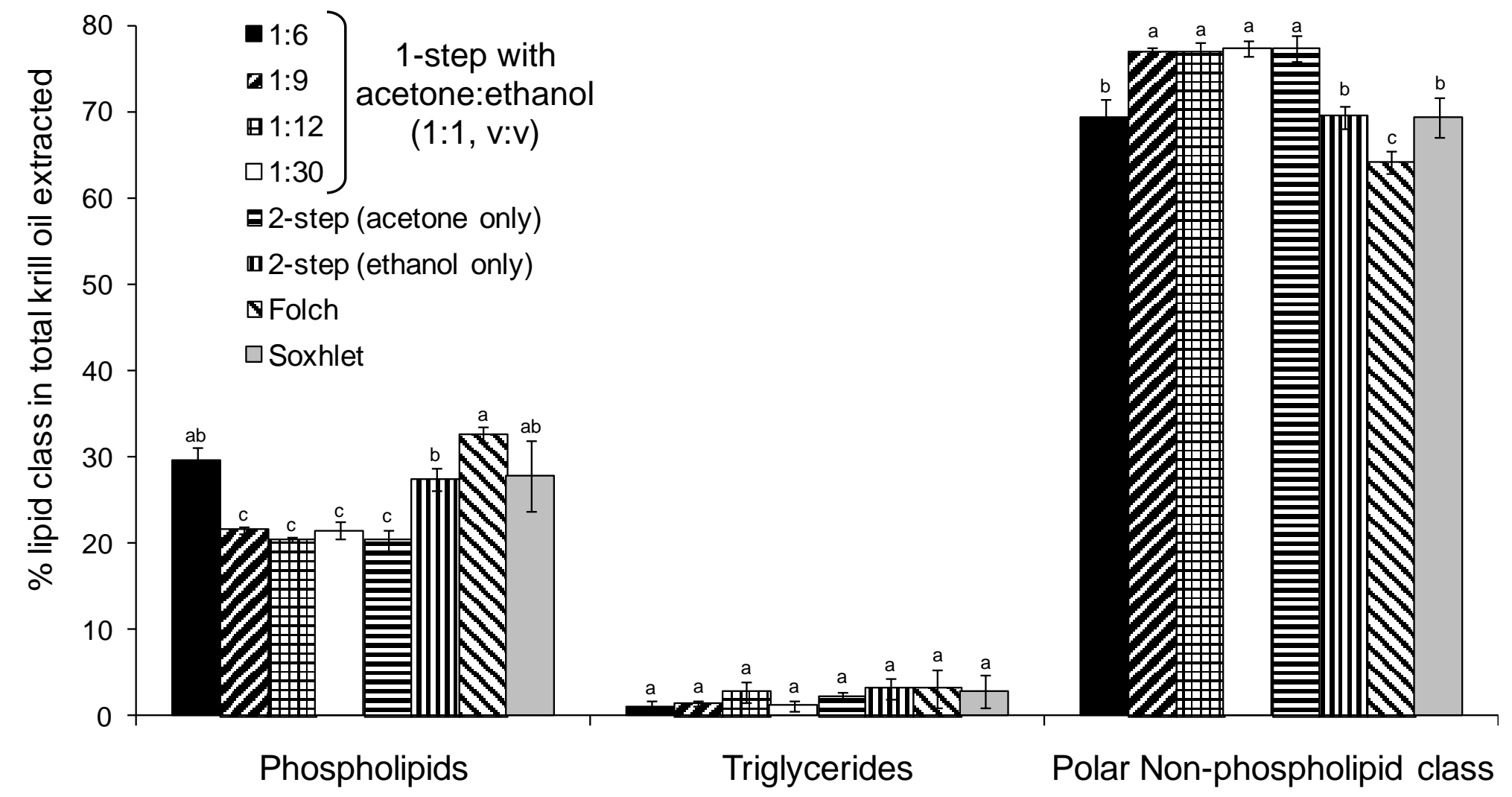


Figure 5.
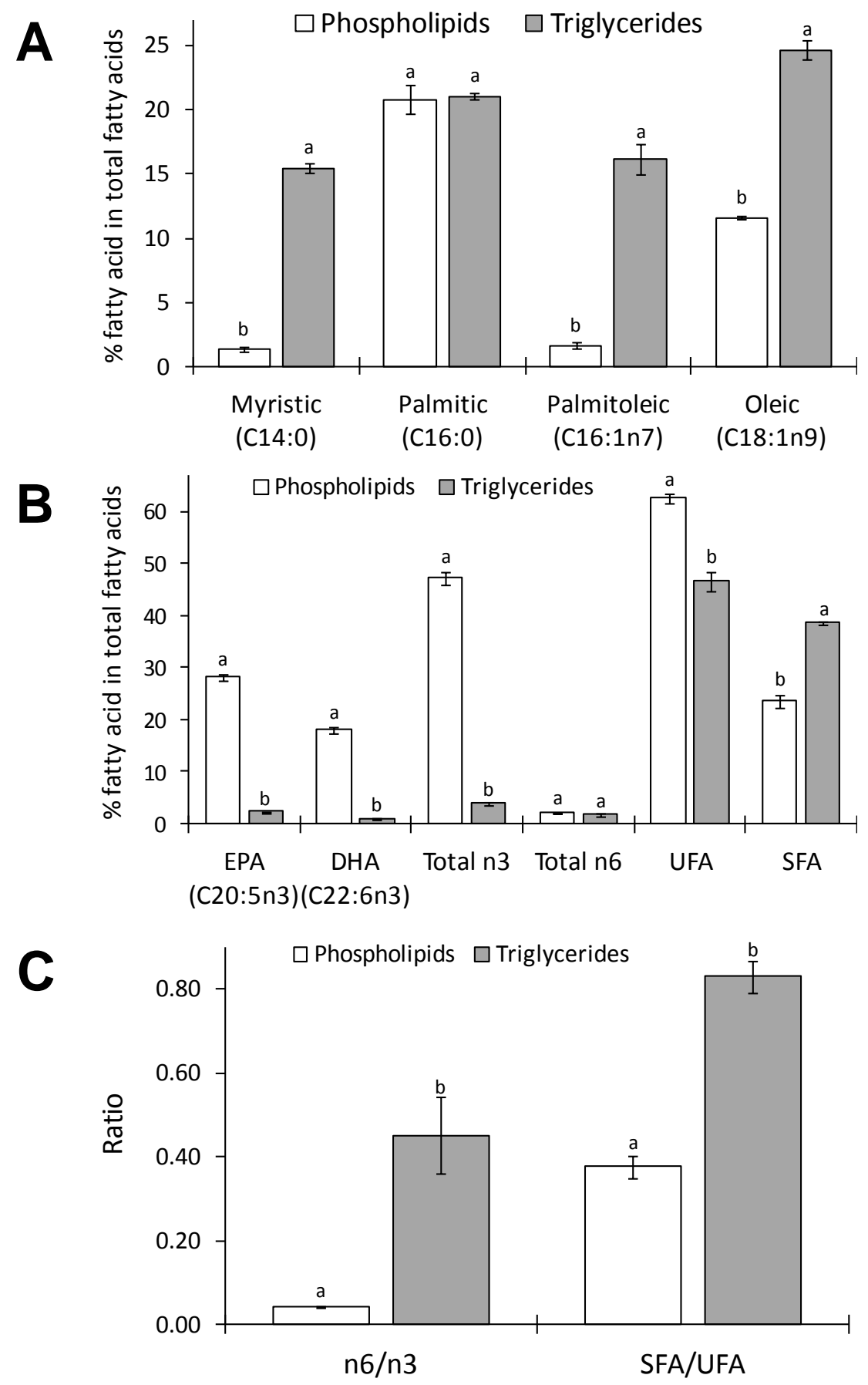
Figure 6.

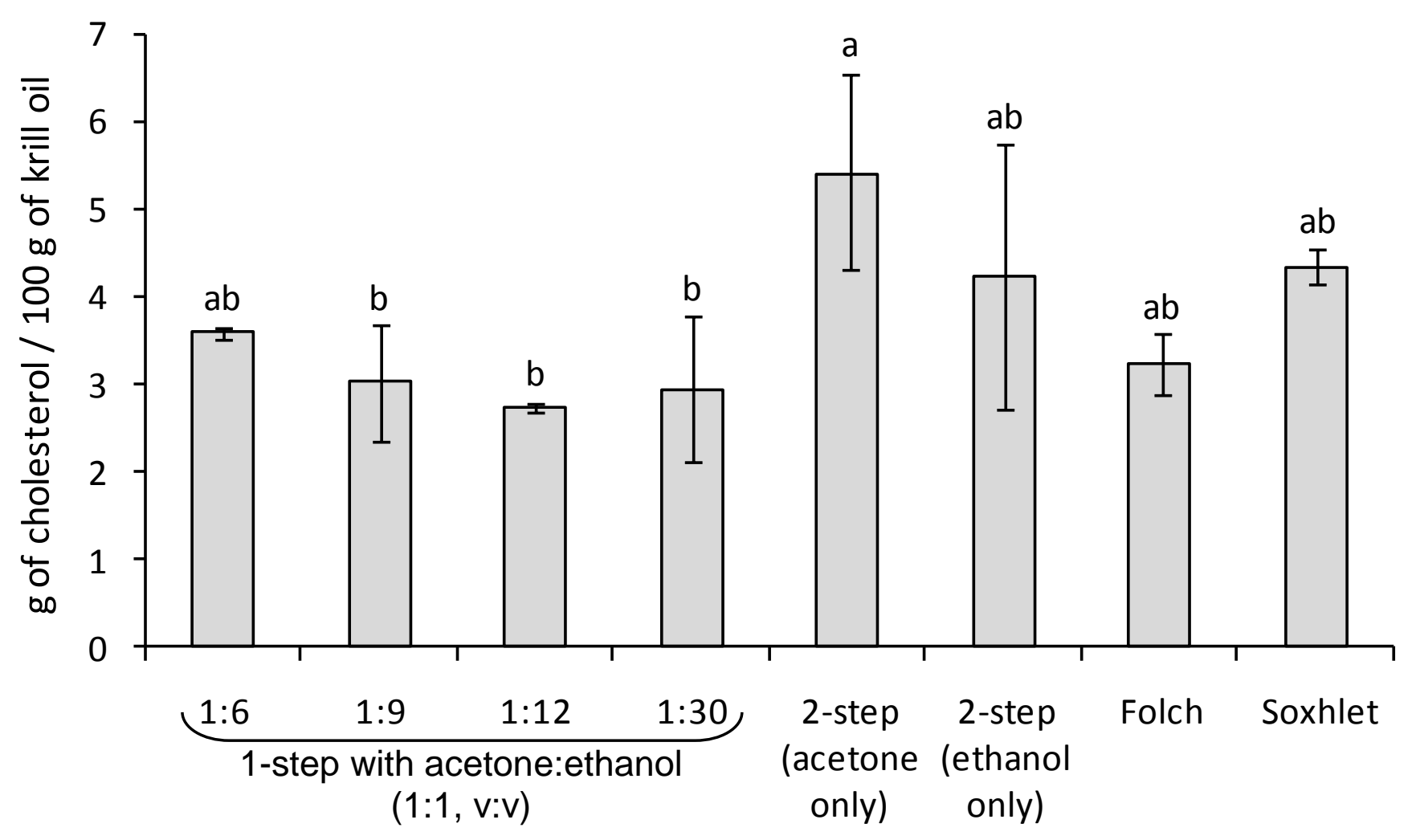


Figure 7.

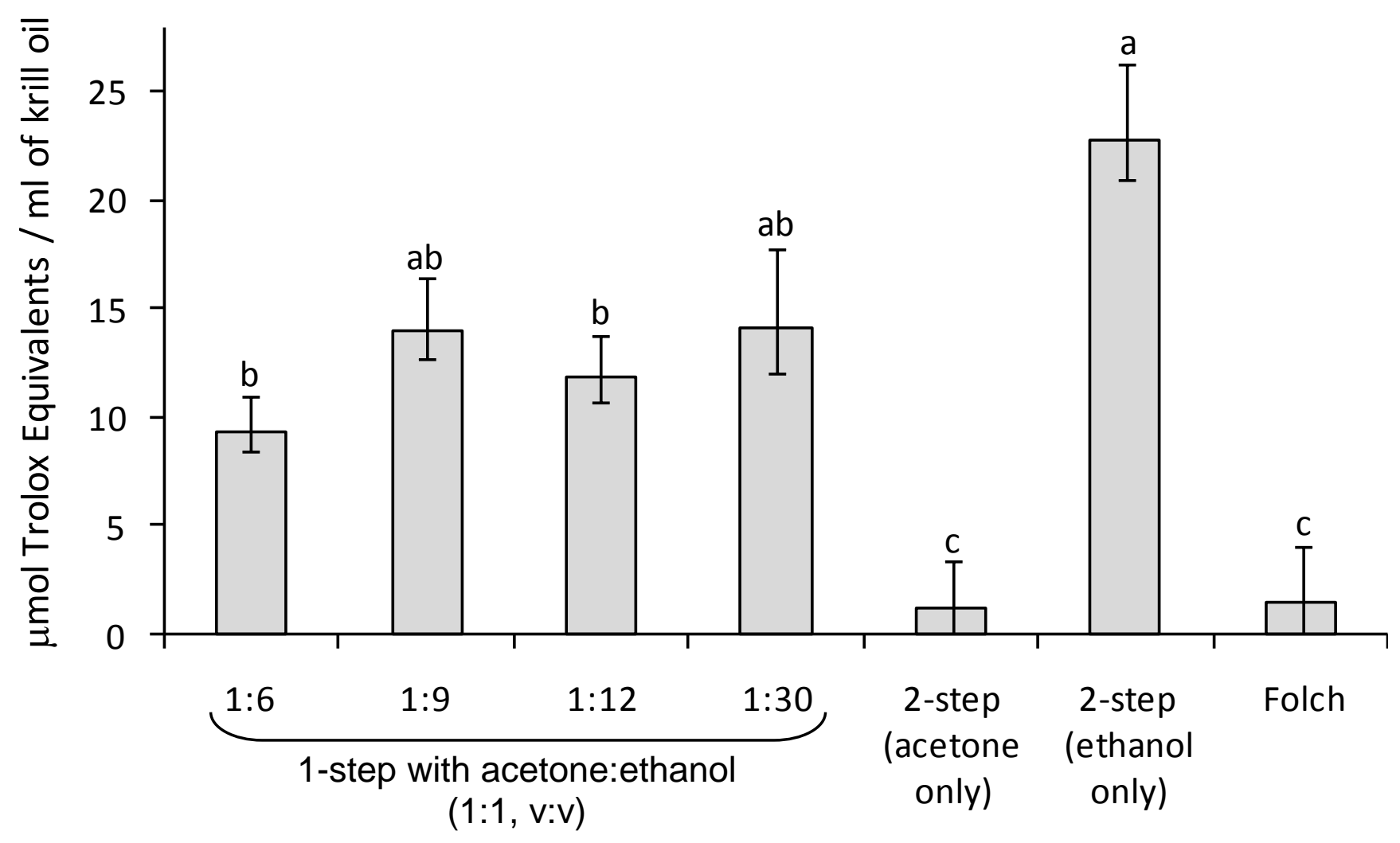


Figure 1. A flow diagram for oil extraction from krill and subsequent analyses of the extracted oil and residual spent krill.

Figure 2. Extraction efficiency* of different solvent systems for extraction of oil from freeze-dried whole krill.

* Different letters on the top of data bars indicate significant differences (Tukey’s test, $\mathrm{P}<0.05)$ between mean values $( \pm \mathrm{SD}, \mathrm{n}=3)$.

Figure 3. An example plate showing lipid classes resolved with thin layer chromatography (TLC) for krill oil extracted with one-step extraction using 1:12 krill:solvent ratio (w:v) (triplicate). TLC plates for krill oils extracted with different solvent systems were analyzed quantitatively with densitometry (Figure 4). Lipid classes were isolated from TLC plates and analyzed for fatty acid profile (FAP) using gas chromatography (GC) shown in Figure 5.

Figure 4. Densitometry analysis* of TLC plates (an example of TLC plate is shown in Figure 3). For two-step extraction, TLC plates with acetone and ethanol extracts were analyzed separately.

* Different letters on the top of data bars indicate significant differences (Tukey's test, $\mathrm{P}<0.05)$ between mean values $( \pm \mathrm{SD}, \mathrm{n}=3)$ within a lipid class.

Figure 5. Major FA* in phospholipids (PL) and triglycerides (TRIG) of oil extracted from krill with one-step extraction using 1:12 krill:solvent ratio (w:v). The PL, TRIG, and polar non-PL class were resolved with TLC (Figures 3 and 4). The polar non-PL 
class showed no detectable FA. This class likely contained antioxidants including asthaxantin. EPA - eicosapentaenoic acid (20:5n3), DHA - docosahexaenoic acid (22:6n3), n3 - $\omega-3$ FA, n6 - $\omega-6$ FA, UFA - total unsaturated FA, and SFA - total saturated FA.

* Different letters on the top of data bars indicate significant differences (Student's t-test, $\mathrm{P}<0.05)$ between mean values $( \pm \mathrm{SD}, \mathrm{n}=3)$ within the FA.

Figure 6. Cholesterol content in oil extracted from freeze-dried whole krill using different solvent systems.

* Different letters on the top of data bars indicate significant differences (Tukey's test, $\mathrm{P}<0.05)$ between mean values $( \pm \mathrm{SD}, \mathrm{n}=3)$.

Figure 7. Antioxidant capacity of oil extracted from freeze-dried whole krill using different solvent systems.

* Different letters on the top of data bars indicate significant differences (Tukey's test, $\mathrm{P}<0.05)$ between mean values $( \pm \mathrm{SD}, \mathrm{n}=3)$. 
Table 1. Crude protein*, total fat*, and ash content* of the residual spent krill following oil extraction with one- and two-step extraction.

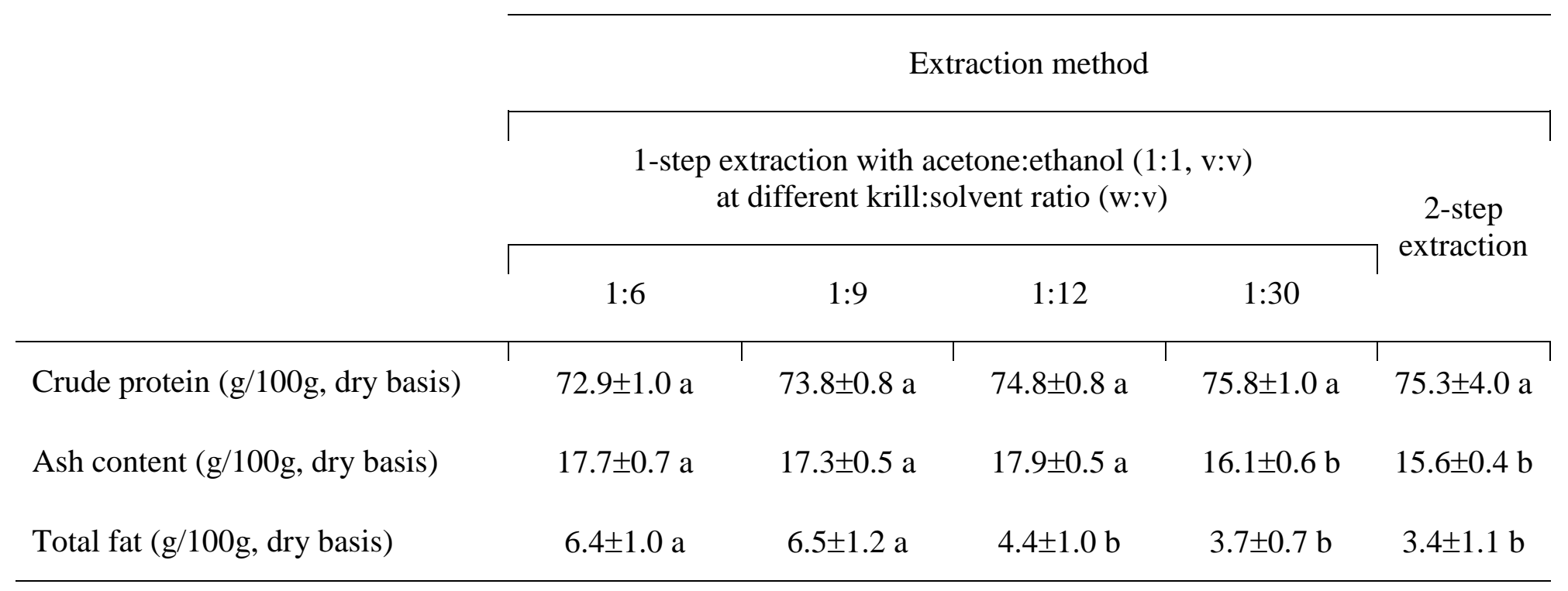

* Different letters indicate significant differences (Tukey’s test, $\mathrm{P}<0.05)$ between mean values $( \pm \mathrm{SD}, \mathrm{n}=3$ ) within the same row. 
Gigliotti, J.C., Turk, P., Livengood, R., Benedito, V., \& Tou, J.C. (2012)

The Influence of Different Dietary Sources of Omega-3 Polyunsaturated Fatty Acids on Renal Health in Female Rats 


\section{$5.1 \quad$ Background}

Results from Section 4 concluded that krill oil is rich in $\omega-3$ PUFAs, and is a complex lipid composed of phospholipids and other lipid soluble pigments. This unique lipid content has been the focus of advertisement for krill oil supplementation. While research supports a benefit of krill oil supplementation in regards to various aspects of health, it is unclear how krill oil and other $\omega$-PUFA sources may influence kidney health. In addition, residual $\omega-3$ PUFA content may explain why certain protein sources (i.e soybean, KPC, codmeal, flaxseed, etc.) benefit renal health.

\subsection{Introduction}

Nephrocalcinosis (NC) is a form of renal disease characterized by increased deposition of Ca within kidney tissue. The progression of NC is associated with detrimental changes in renal morphology and subsequent renal failure [1]. While NC affects various animal species (including humans), it is a serious issue in rodents where dietary components and gender impact its occurrence $[2,3]$. The occurrence of NC in rats was a major consideration during the formulation of the current American Institute of Nutrition (AIN) rodent diet (AIN-93). For the AIN-93 diet formulation, the occurrence of diet induced $\mathrm{NC}$ in rats was addressed through alterations in the dietary $\mathrm{Ca}$ and $\mathrm{P}$ content $[3,4]$. While there is a clear relationship between the dietary mineral content and $\mathrm{NC}$ in rats $[5,6,7)$, research suggests that changes in other dietary components can also influence NC. Mayer et al. [8] found that changing the dietary protein source has a greater influence on NC than the dietary mineral content. Further research has suggested that casein, which is commonly used in rodent diets, is more nephrocalcigenic $[9,10]$. 
Aside from $\mathrm{NC}$, changing the dietary protein source has been associated with benefits in other forms of renal disease as well $[11,12]$.

The mechanism for how dietary protein can modulate renal health is still unclear. Some of the protein sources used in previous studies contained residual lipids from known sources of omega-3 polyunsaturated fatty acids ( $\omega-3$ PUFAs) $[9,10]$. While the role of $\omega-3$ PUFAs in human renal diseases in unclear [13], $\omega-3$ PUFA supplementation has been reported to benefit rodent models of renal calcification [14, 15], 5/6 nephrectomy [16, 17], diabetic renal disease [18], and polycystic kidney disease [19]. Furthermore, corn oil was replaced with soybean in reformulation of the AIN-93 diet [20] and may also be responsible for the reduction in observed NC. Soybean oil contains both essential fatty acids, the omega-6 polyunsaturated fatty acid ( $\omega-6$ PUFA) LA and the omega-3 ( $\omega-3)$ PUFA ALA. Corn oil is predominately the $\omega-6$ PUFA LA, which provides a dietary $\omega-6$ PUFA content suggested to be proinflammatory [21, 22]. Inflammation and cellular damage are involved in the etiology of several renal diseases including NC $[23,24]$. Therefore, increasing the consumption of the anti-inflammatory

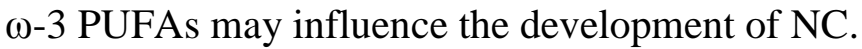

In the current study, we determined the lipid class, and fatty acid composition of corn oil and different dietary sources of $\omega-3$ PUFAs. The characterized oils were then fed to young (28d), healthy female rats. To our knowledge, this is the first study to compare the influence of different dietary sources of $\omega-3$ PUFAs on renal health using non-diseased animals. A primary aim of this study was to determine if changing the PUFA content of a casein-based diet can influence the development of NC in female rats. In turn, changing the dietary lipid content can also influence prostaglandin production [25-28], the activity of the proinflammatory transcription factor NFKB [21, 22, 28, 29], 
and the expression of the proinflammatory, profibrotic chemokine transforming growth factor-beta 1 (TGF- $\beta 1$ ) [30]. Aside from NC, inflammation and fibrosis are key components to the etiology of several renal diseases. Therefore, the objectives of this study were:

1. to determine if diets differing in $\omega-3$ PUFA content influence the development of $\mathrm{NC}$ in healthy female rats fed a casein-based diet,

2. to determine if diets differing in $\omega-3$ PUFA content influence systemic prostaglandin production and the renal expression of $\mathrm{COX}-\mathrm{II}$,

3. to determine if providing $\omega-3$ PUFAs can influence the activity of NF $\kappa B$ and the expression of TGF- $\beta$ in renal tissue.

\subsection{Materials and methods}

\subsubsection{Selection of dietary oils}

Dietary sources of $\omega$-3 PUFAs used in this study were flaxseed (FO), menhaden (MO), krill (KO), salmon (SO), and tuna oils (TO). FO is considered the richest source of the essential $\omega$-3 PUFA, ALA (Cunnane SC). MO and SO are common sources of EPA and DHA in commercial fish oils supplements. KO is a novel $\omega-3$ PUFA source and has a similar fatty acid profile as MO. However, KO has been suggested to be a rich source of phospholipid [10] as compared to most dietary oils which are presumed to be predominately triglycerides. TO was chosen because it is considered a rich source of DHA, whereas other seafood $\omega-3$ PUFA sources are generally higher in EPA. CO was included because it is rich in the essential $\omega-6$ PUFA, linoleic acid (LA, 18:2 $\omega-3$ ). Additionally, the inclusion of an oil rich in $\omega-6$ PUFAs allows the comparison between the physiological effects of $\omega-6$ and $\omega-3$ PUFA rich oils. FO, SO, and TO were 
generously provided by Jedwards International (Quincy, MA). MO was purchased from Omega Protein Inc. (Houston, TX), and the KO was purchased from Enzymotec USA Inc. (Morristown, NJ). All oils were of commercial feed grade, and were kept at $4{ }^{\circ} \mathrm{C}$ in the dark.

\subsubsection{Lipid analysis of dietary oils}

Quantifying lipid classes

Thin-layer chromatography (TLC) was performed to identify and quantify the different lipid classes. Approximately $1 \mathrm{mg}$ of each oil was dissolved in chloroform:methanol $(1: 1 ; \mathrm{v}: \mathrm{v})$ and spotted onto Whatman K6F Silica plates with $60 \AA$ pore sizes, (Cobert Associates, MO). Silica plates were developed in a hexane:ether:acetic acid (80:20:1.5; v:v:v) solvent. Following development, plates were air-dried for $5 \mathrm{~min}$ and visualized using a Fluorchem 8000 densitometer using transluminating white light (Alpha Innotech Corp, CA). Plate images were captured using a camera interfaced to PC and the lipid classes were quantified using the spot densitometer tab in the Fluorchem (version 1.0) computer program. Total glycerophospholipid (PL) and triacylglyceride (TAG) lipid classes were identified using $\mathrm{R}_{\mathrm{F}}$ values obtained by comparison to the standards soybean lecithin (Fisher Scientific, PA) and triolein (Sigma-Aldrich, MO), respectively. Due to the pigmentation of KO, which is presumably astaxanthin, lipid classes located between the PL and TAG spots were quantified and summed together collectively as polar, non-phospholipids (representative image in Figure 1). Data from the TLC plates are presented as a percentage of the total pixel count of the lane. 


\section{Determining fatty acid composition}

Fatty acid methyl esters (FAMEs) were prepared from the dietary oils using the procedure described by Fritsche and Johnston [31]. Briefly, $4 \mathrm{ml}$ of a $4 \%$ $\mathrm{H}_{2} \mathrm{SO}_{4} /$ methanol solution was added to $20-30 \mathrm{mg}$ of oil. The methylation reaction was carried out by heating at $90^{\circ} \mathrm{C}$ for $1 \mathrm{~h}$ and was terminated by the addition of water. FAMEs were then isolated in chloroform, dried under nitrogen gas, and resuspended to a known concentration $(2-5 \mathrm{mg} / \mathrm{ml})$ in isooctane. FAMEs were analyzed by gas chromatography (GC, CP-3800 Varian), using nitrogen as the carrier gas. GC setting consisted of an initial temperature of $140^{\circ} \mathrm{C}$ for $5 \mathrm{~min}$ followed by an increase of $1{ }^{\circ} \mathrm{C}$ per min to a final temperature of $220^{\circ} \mathrm{C}$. Fatty acids were identified as FAMEs by comparing retention times to a FAME 37 standard (Supelco, PA) and presented as percent of total peak area counts corrected for isooctane.

\subsubsection{Diet formulation}

Experimental diets (Table 1) were based on the standard semi-purified AIN-93G formulation. Diets were formulated to be $12 \%$ (by weight), high fat diets with the lipid source supplied as either $\mathrm{CO}, \mathrm{FO}, \mathrm{MO}, \mathrm{KO}, \mathrm{SO}$, or TO. $\mathrm{MO}$ and $\mathrm{KO}$ diets consisted of a blend of $11.8 \%$ test oil $+0.2 \% \mathrm{CO}$ in order to meet the recommendation for LA in growing rats [32]. The lipid dose (12\% by wt) is based on levels of oil achievable in the human diet (approximately 27\% caloric intake); whereas much higher lipid inclusions have been used previously. Diets were flushed with nitrogen gas, vacuum sealed in $1 \mathrm{~kg}$ packages, and stored in the dark at $-20^{\circ} \mathrm{C}$ until fed. 


\subsubsection{Animal Study}

All animal procedures were conducted in accordance with the guidelines set forth by the National Research Council for the Care and Use of Laboratory Animals and approved by the Animal Care and Use Committee at West Virginia University.

Young (28 d), female Sprague-Dawley rats were obtained from Hilltop Lab Animals Inc. (Scottdale, PA). Female Sprague-Dawley rats were chosen due to their susceptibility to diet induced renal damage [2]. Upon arrival, rats were individually housed in metabolic cages, and maintained in a room at $21^{\circ} \mathrm{C}$ with a $12 \mathrm{~h}$ light/dark cycle. During a $7 \mathrm{~d}$ acclimation period, animals were given ad libitum access to deionized distilled water $\left(\mathrm{ddH}_{2} \mathrm{O}\right)$ and $\mathrm{AIN}-93 \mathrm{G}$ diet (Harklan Teklad, IN). Following the $7 \mathrm{~d}$ acclimation period, rats were then randomly assigned ( $n=10$ rats) to one of the six experimental diets. The rats were provided $(14.75 \pm 0.75 \mathrm{~g})$, to prevent variation in total caloric intake, and fresh diets were supplied daily throughout the 8 week study. Body weights and diet and $\mathrm{ddH}_{2} \mathrm{O}$ consumption was recorded throughout the study.

\subsubsection{Determining kidney mineral content}

At the end of the 8 week feeding study, rats were euthanized by $\mathrm{CO}_{2}$ inhalation. Both kidneys were excised, trimmed, decapsulated, and weighed separately. After no bilateral difference in left and right kidney weights was determined, the left kidney was divided transversely and both halves were frozen at $-80^{\circ} \mathrm{C}$ until analyzed.

To determine kidney mineral content, half of the left kidney was ashed in a muffle furnace (Lindberg $515 \mathrm{~A} 2, \mathrm{WI}$ ) at $550^{\circ} \mathrm{C}$ for $24 \mathrm{~h}$. Ashed samples were dissolved in 2 $\mathrm{mL}$ of $70 \%$ nitric acid, filtered through Whatman no. 1 paper, and diluted to a final volume of $25 \mathrm{~mL}$ in $\mathrm{ddH}_{2} \mathrm{O}$. The $\mathrm{Ca}$ and $\mathrm{P}$ content of the kidney samples $(\mathrm{mg} / \mathrm{g}$ kidney 
tissue) were determined using inductively coupled plasma spectrometry (ICP) (model P400, Perkin Elmer, Shelton, CN).

\subsubsection{Kidney histology}

A center sagittal section was removed from the right kidney and immediately fixed in $10 \%$ formalin solution (VWR, PA) for histological evaluation. Tissues were dehydrated through a series of increasing ethanol concentrations in $\mathrm{ddH}_{2} \mathrm{O}$ to xylene and embedded in paraffin. $3 \mu \mathrm{m}$ sections from each block were stained with hematoxylin and eosin with appropriate staining control tissue. Histologic parameters evaluated included glomerular hypercellularity and matrix deposition, arteriolosclerosis, tubular dilation, tubulointerstitial fibrosis, interstitial inflammation, and interstitial matrix deposition or calcification. All slides were analyzed under a Nikon TE 2000-S light microscope (Nikon Instruments, NY) by two trained individuals who were blinded to the treatments. Representative images presented were captured using a PC interfaced with Q-Capture imaging software (Quantitative Imaging Corporation, BC, Canada).

\subsubsection{Kidney fatty acid composition}

To determine the fatty acid composition of the kidneys, total lipid was extracted from the remaining half of the left frozen kidney following a modified method of Bligh and Dyer [33]. Briefly, 400 mg of frozen renal tissue was homogenized in Tris/EDTA buffer and mixed with a chloroform:methanol:acetic acid (2:1:0.15 v/v/v) solution. After centrifugation at $900 \times \mathrm{g}$ for 10 minutes at $10^{\circ} \mathrm{C}$, the bottom chloroform layer was collected. The collected chloroform was filtered through 1-phase separation filters, dried 
under $\mathrm{N}_{2}$ gas, and the extracted lipid samples were then methylated and quantified as described above for the fatty acid analysis of dietary oils.

\subsubsection{RNA isolation and real-time PCR analysis}

A portion of the right kidney was frozen in liquid nitrogen and stored at $-80^{\circ} \mathrm{C}$ until processed for RNA isolation. Total renal RNA was extracted from $~ 100 \mathrm{mg}$ of frozen tissue following the Total RNA Isolation procedure of the mirVana miRNA Isolation Kit (Ambion, TX). Isolated RNA integrity was visualized on a $1.5 \%$ agarose gel, and isolate RNA concentration was quantified by spectrophotometry (Thermo Scientific, DE). After DNase treatment of the isolated RNA (Applied Biosystems, CA), total mRNA was amplified using the Superscript III First Strand Synthesis assay with oligo dT primers (Invitrogen, CA).

Primers were designed for rat COX-II (Ptgs2, NM_017232), TGF- $\beta$ (Tgfb1, NM_021578), and the housekeeping gene GAPDH (Gapdh, NM_017008.3) using the Primer3 program [34] and respective mRNA sequences obtained from NCBI. Forward and reverse primers for COX-II (PTGS2) were 5' CGGAGGAGAAGTGGGTTTTAG 3', and 5' TGAAAGAGGCAAAGGGACAC 3' respectively. Forward and reverse primers for TGF- $\beta$ (Tgfb1) were 5' GCCTGAGTGGCTGTCTTTTG 3' and 5'

CCCTGTATTCCGTCTCCTTG 3' respectively. Primer efficiencies were determined on pooled RNA samples serially diluted in $\mathrm{ddH}_{2} \mathrm{O}$ up to $1: 10000$.

PCRs consisted of $2.5 \mu 1$ of SYBR ${ }^{\circledR}$ Green Master Mix (Applied Biosystems, CA), $1 \mu \mathrm{l}$ of cDNA, $1 \mu \mathrm{l}$ of respective forward and reverse primers, and $0.5 \mu 1$ of $\mathrm{ddH}_{2} \mathrm{O}$ for a total reaction volume of $5 \mu \mathrm{l}$. The thermal profile consisted of $50^{\circ} \mathrm{C}$ for 2 minutes, $95^{\circ} \mathrm{C}$ for 10 minutes, and then 40 cycles of $95^{\circ} \mathrm{C}$ for 15 seconds and $60^{\circ} \mathrm{C}$ for 1 minute. Data 
was analyzed as described by Pfaffl [35], and normalized to GAPDH expression. Data is presented as relative expression compared to rats fed $(\mathrm{CO})$.

\subsubsection{Isolation of nuclear proteins and measurement of NFkB activation}

A portion of the right kidney ( $300 \mathrm{mg})$ was processed for isolation of nuclear proteins using a commercially available nuclear protein extraction kit (Active Motif, Ca). The protein content of the nuclear extract was determined using a commercially available protein determination assay based on the Bradford method (Cayman Chemical, MI). The activation of NFאB was determined using the TransAM NFKB p65 transcription factor assay kit (Active Motif, CA). Nuclear protein $(10 \mu \mathrm{g})$ was used for the assay, and results were calculated as a percentage of NFKB activity seen in rats fed $\mathrm{CO}$.

\subsubsection{Serum and urinary measures of renal function and health}

At the end of the 8 week feeding study, rats were euthanized by $\mathrm{CO}_{2}$ inhalation and trunk blood was collected. Blood samples were maintained at $4^{\circ} \mathrm{C}$ for $15 \mathrm{~min}$, and then centrifuged for $10 \mathrm{~min}$ at $1500 \mathrm{X} \mathrm{g}$ for serum isolation. Serum measures of kidney function included: total protein, albumin, blood urea nitrogen (BUN), creatinine, Ca, and P. Serum measures of kidney function were determined by colorimetric assays using a commercially available Vet-16 rotor quantified by a Hemagen Analyst automated spectrophotometer (Hemagen Diagnostics Inc., MD).

Urinary volume was recorded and collected throughout the study. Urinary measures of kidney function were performed on pooled urine samples collected during the final week of the study and included urinary: Ca and P content, creatinine, albumin, $\mathrm{PGE}_{2}$ and $\mathrm{pH}$. Urinary $\mathrm{Ca}$ and $\mathrm{P}$ content was determined by diluting the urine 1:40 in 
$\mathrm{ddH}_{2} \mathrm{O}$, and then analyzed by ICP. Urinary creatinine was determined using a colorimetric assay (Cayman Chemical, MI). Urinary albumin (Alpco, NH) and $\mathrm{PGE}_{2}$ metabolite content (Cayman Chemical, MI) was determined using commercially available assays. Urinary $\mathrm{pH}$ was determined using a standard $\mathrm{pH}$ meter (Beckman, $\mathrm{CA}$ ). Glomerular filtration rate (GFR) was estimated by measuring creatinine clearance (CrC) determined as: $\mathrm{CrC}=(\mathrm{UC} / \mathrm{SC}) \mathrm{X} \mathrm{V}$, where $\mathrm{UC}$ is urinary creatinine concentration, $\mathrm{SC}$ is serum creatinine concentration, and $\mathrm{V}$ is the volume of urine excreted per minute.

\subsubsection{Statistical analysis}

The animal feeding study was analyzed as a completely randomized design, with $\mathrm{n}=10$ rats per diet treatment. One-way analysis of variance (ANOVA) was used to determine differences among rats fed the different diets, while a nonparametric rank analysis was performed on data not normally distributed. Post-hoc analysis was performed using Tukey's test, and all statistical analysis was performed using Sigma Stat 3.1 (Systat Software Inc., San Jose, CA). Differences were considered significant at $P<0.05$.

\section{$5.4 \quad$ Results}

\subsubsection{Lipid Analysis of Dietary Oils}

All dietary oils used in the study were predominately TAG $(>65 \%)$ with the exception of $\mathrm{KO}$. The lipid content of $\mathrm{KO}$ was unique in that it was primarily composed of PLs and polar, non-phospholipid classes (Figure 1). The plant oils were abundant in the essential fatty acids LA and ALA, and devoid of the long chain PUFAs AA, EPA and DHA. The seafood sources of $\omega-3$ PUFAs all contained EPA and DHA, and had $\omega-6: \omega-3$ 
of at least 1:10. However, absolute amounts and ratios of EPA and DHA varied among sources. KO and SO had the highest EPA content, while and TO had the highest DHA content (Table 2).

\subsubsection{Kidney mineral content}

Rats fed KO had heavier $(P<0.001)$ relative kidney weights compared to rats fed FO or MO (Table 3). Rats fed KO had the highest kidney Ca content $(P<0.001)$ and higher kidney $\mathrm{P}$ content compared to rats fed $\mathrm{MO}(P=0.03)$.

\subsubsection{Kidney histology}

All rats fed KO displayed tubular calcification, dilation, tubulointerstitial changes (specifically fibrosis), and interstitial inflammation (Figure 2). Sparse fibrosis and interstitial inflammation was observed among all treatment groups. However, rats fed FO also displayed a higher occurrence of these two conditions compared to the other dietary groups. No differences in glomerular morphology or arteriolosclerosis were observed among the treatment groups.

\subsubsection{Kidney fatty acid composition}

No differences were found in total lipid content among treatment groups $(P=0.4)$. The fatty acid content of the kidneys was similar to the fatty acid composition of the diet. Rats fed CO had a tissue $\omega-6: \omega-3$ ratio greater than $30: 1$, the highest tissue $\omega-6$ content, and the lowest EPA and DHA content. All rats provided $\omega-3$ PUFA sources had an $\omega-$ 6: $\omega-3$ ratio less than 3:1. Among $\omega-3$ PUFA sources, renal tissue from rats fed FO had a 
similar LA content as found in rats fed $\mathrm{CO}$, the lower renal EPA and DHA content, and the highest total $\omega-6$ content as compared to rats fed the marine $\omega-3$ PUFA oils (Table 4 ).

\subsubsection{Real-time PCR analysis}

COX-II expression was lower in all rats provided $\omega-3$ PUFAs as compared to rats fed CO (Figure 3). The expression of COX-II was the lowest in rats fed SO or TO diets, which was 45 and $16 \%$ lower than in rats fed $\mathrm{CO}$, respectively. COX-II expression in rats fed $\mathrm{KO}$ was approximately half (55\%) of that of $\mathrm{CO}$ fed rats, while $\mathrm{MO}$ and $\mathrm{FO}$ fed rats expressed COX-II at 85 and $78 \%$ of that in rats fed $\mathrm{CO}$, respectively.

Feeding $\omega$-3 PUFAs also resulted in reduced expression of TGF- $\beta$ (Figure 4). Rats fed KO, SO, and TO had the lowest TGF- $\beta$ expression, which as approximately 45\% of that in rats fed CO. Rats fed FO and MO had TGF- $\beta$ expression at 84 and $80 \%$ compared to rats fed $\mathrm{CO}$, respectively.

\subsubsection{NFкB activation}

$\mathrm{NF} \kappa \mathrm{B}$ activity in rats fed SO and TO was approximately 17 and $11 \%$ of that found in rats fed $\mathrm{CO}$. The measured $\mathrm{NF \kappa B}$ activity appeared similar in rats fed $\mathrm{CO}, \mathrm{MO}$ and KO. Rats fed FO had the highest apparent $\mathrm{NF \kappa B}$ activity, which was at $30 \%$ higher than all other groups (Figure 5).

\subsubsection{Serum and urinary measures of renal function and health}

There were no differences in serum measures of kidney function of creatinine, phosphorus, $\mathrm{Ca}$, and total protein between rats fed the different diets. Rat fed SO had 
higher $(P=0.04)$ BUN content compared to rats fed $\mathrm{CO}$, however this difference was absent when BUN was corrected for creatinine (Table 5).

There were significant differences in the urinary measures of kidney health and function. Rats fed MO and FO had greater $(P=0.009)$ urinary excretion of Ca compared to rats fed TO, while rats fed $\mathrm{KO}$ had the highest $(P<0.001)$ urinary excretion of $\mathrm{P}$ and greatest reduction in urinary $\mathrm{pH}(P<0.001)$. These results occurred in the absence of differences in urinary volume $(P=0.9)$ and albuminuria $(P=0.4)$ (Table 6).

There was also an apparent differences in urinary excretion of $\mathrm{PGE}_{2}$ during the final week of the study (Figure 6). Rats provided seafood sources of $\omega$-3 PUFAs (MO, $\mathrm{KO}, \mathrm{SO}$, and TO) had $<50 \%$ lower excretion of urinary $\mathrm{PGE}_{2}$ compared to rats fed $\mathrm{FO}$ or CO.

\subsection{Discussion}

\subsubsection{Nephrocalcinosis and associated damage}

A major objective of this study was to determine if changing the PUFA content of casein-based diets influences the development of NC in female rats. Differences in kidney weights provided initial evidence for the presence of NC. Previous studies have found that heavier kidney weights were positively correlated with the kidney Ca content $[5,36]$. Unexpectedly, the heaviest kidney weights were observed in rats fed a source of $\omega-3$ PUFAs (KO), but not in rats fed the $\omega-6$ PUFA rich CO. The presence of NC in rats fed $\mathrm{KO}$ was confirmed by elevated renal $\mathrm{Ca}$ content and histological identification of mineral deposits. In addition, histological evaluation showed tubular dilation, tubulointerstitial changes (namely fibrosis), and/or interstitial inflammation in all rats fed KO. These structural changes are common with advanced renal mineralization $[37,38]$. 
Fibrosis and interstitial inflammation are common in a numerous forms of advanced renal diseases, and supports the involvement of $\mathrm{NC}$ in the initiation of renal failure [1].

$\mathrm{NC}$, and its associated renal disease, can be generated experimentally by increasing dietary $\mathrm{P}$ content $[5,37,38]$. In the current study, the same basal diet was used for all diets fed and therefore contained equal amounts of inorganic $\mathrm{P}(0.03 \%$ by weight). However, rats fed $\mathrm{KO}$ had elevated urinary $\mathrm{P}$ content and acidity, a urinary composition typically associated with increased $\mathrm{P}$ intake $[5,6]$. Further analysis revealed that the $\mathrm{KO}$ diets had an increased $\mathrm{P}$ content $(0.46 \%$ vs $0.3 \%)$. Characterization of the oils showed that KO had a high PL content. Therefore, we concluded that the observed $\mathrm{NC}$ in rats fed $\mathrm{KO}$ was due to elevated $\mathrm{P}$ intake in the form of PLs. This conclusion was supported by a previous study, where rats fed diets high in $\mathrm{P}(0.4-0.6 \%)$ had similar renal Ca content [36].

It was unexpected that rats fed the EPA rich $\mathrm{KO}$, and not the $\omega-6$ PUFA rich $\mathrm{CO}$, developed NC. This contradicts previous findings where EPA retarded calcium gluconate induced renal mineralization in both male and female rats $[14,15]$. However, calcium gluconate induces NC through hypercalcemia and hypercalciuria; a form of NC that likely differs in etiology as compared to P induced NC [39]. Therefore, the results presented here suggest that $\omega-3$ PUFA supplementation does not influence $\mathrm{P}$ induced NC.

\subsubsection{Renal fatty acid composition and prostaglandin production}

Another aim of this study was to determine if changing the PUFA content of the tissue can influence inflammatory gene expression in non-diseased induced animals. To our knowledge, this is the first study comparing the influence of multiple dietary sources of PUFAs on renal fatty acid composition and health in non-diseased animals. Our diets 
were high fat (12\% vs. $7 \%$ ), but remained lower than high fat diets used in other studies. The increased lipid content was chosen to amplify effects while maintaining a physiologically relevant dose.

In general, the fatty acid composition of renal tissue was similar to the fatty acid composition of the diet. Rats fed $\omega-3$ PUFAs had a renal $\omega-6: \omega-3$ ratio ten times lower than that found in rats fed CO. Among rats fed $\omega-3$ PUFA rich oils, rats fed FO had the highest renal $\omega-6$ PUFA content and renal $\omega-6: \omega-3$ ratio. Ogborn et al., [19] reported that rats fed a chow based diet with a $10 \%$ inclusion of whole flaxseed had reduced renal $\mathrm{Ca}$ content. In our study, rats fed FO had a higher renal EPA and DHA content than rats fed CO. However, these levels were less than half that found in rats fed seafood based $\omega-3$ oils. Mammalian conversion of ALA to EPA and DHA is considered an inefficient process, and is the basis for recommendation for increased fatty fish consumption. Based on our results, providing $\omega-3$ PUFAs as ALA was inefficient at saturating renal tissue EPA and DHA as compared to feeding rats seafood based oils rich in EPA and DHA.

The PUFA content of renal tissue is important given the role of PUFAs as substrates for prostaglandin production. $\mathrm{PGE}_{2}$ is crucial for renal homeostasis [40] and therefore, the changes in tissue PUFA observed in our study may influence prostaglandin production and renal health. Rats provided the seafood sources of $\omega-3$ PUFAs (MO, KO, $\mathrm{SO}$, and TO) had over $50 \%$ reduction of urinary $\mathrm{PGE}_{2}$ excretion compared to rats fed $\mathrm{CO}$ and FO. Increased tissue EPA content can compete with AA for membrane incorporation, and this can affect substrate availability for COX mediated prostaglandin production. This is supported by previous studies, where feeding rats a mixture of MO and $\mathrm{CO}$ led to a reduction in $\mathrm{PGE}_{2}$ production [23] and increase in $\mathrm{PGE}_{3}$ [41] production 
by renal medullary tissue. Therefore, the decreased $\mathrm{PGE}_{2}$ excretion in these rats could be the result of altered substrate availability and increased $\mathrm{PGE}_{3}$ production.

\subsubsection{Renal molecular analysis}

The lower $\mathrm{PGE}_{2}$ excretion in rats provided $\omega-3$ PUFAs could also be a consequence of reduced renal COX-II expression. In vitro studies suggest that $\omega-3$ PUFAs can influence COX-II expression, and this occurs through mediating the activity of the NFאB transcription factor [29]. In the current study, rats provided $\omega-3$ PUFAs had reduced renal COX-II expression and NFKB activity as compared to rats fed CO. This difference was most pronounced in rats fed $\mathrm{SO}$ and TO. In vitro studies suggest that NFkB activation is sensitive to $\omega-3$ PUFAcontent, especially DHA [29, 42]. In our study, TO had the highest DHA content which may explain the reduced NFkB activation. Rats fed SO also had lower renal NFאB activity, despite having a lower oil and tissue DHA content. Preliminary studies suggest that DHA bioavailability is higher in rats fed SO, which may partly explain these results (unpublished data). We expected the NFKB activity in rats fed $\mathrm{FO}$ and $\mathrm{KO}$ to be elevated, due to the occurrence of inflammation in these animals. In agreement, rats fed FO had greater than a $30 \%$ increase in NFאB activity compared to all other rats. $\mathrm{NF \kappa B}$ is considered a master regulator of the inflammatory response $[43,44]$, and may explain the mild morphological changes observed in rats fed FO. However, there was no apparent increase in NFkB activity in rats fed KO. As previously discussed, the damage observed in rats fed KO was likely due to the $\mathrm{P}$ induced NC. An in vitro study suggested that the inflammatory signaling induced by calcium-phosphate crystals is mediated by transcription factors other than NFкB [39]. 
The renal expression of TGF- $\beta$ was also of interest, since it is considered a key signaling molecule in renal fibrosis [45]. Furthermore, previous research has shown that renal TGF- $\beta$ expression is decreased with $\omega-3$ PUFA supplementation in rodent models of lupus [30]. In our study, rats fed $\mathrm{KO}, \mathrm{SO}$, and TO had a $45 \%$ reduction in TGF- $\beta$ expression compared to rats fed CO. However, this reduction in TGF-B expression did not reflect the occurrence of observed renal tubulointerstitial fibrosis. Fibrotic processes are complex, and consist of various cell types and signaling molecules. Therefore, it is unlikely that the degree of interstitial fibrosis observed here is due to variations in TGF- $\beta$ expression alone.

In summary, feeding high fat diets differing in PUFA content appears to influence renal composition and health in non-diseased female rats. All diets rich $\omega-3$ PUFAs led to an increase in renal $\omega-3$ PUFA content; however, the absolute amount varied among sources. Rats fed the seafood sources of $\omega-3$ PUFAs excreted $>50 \%$ less $\mathrm{PGE}_{2}$ than rats fed $\mathrm{CO}$ and FO, which could be related to the lower tissue $\omega-6: \omega-3$ ratio and suppressed renal COX-II expression in these animals. Additionally, altered NFאB activity and renal expression of COX-II and TGF- $\beta$ suggests that the potential anti-inflammatory activities differ between dietary $\omega$-3 PUFA sources. However, increased tissue $\omega$-3 PUFA content did not prevent the development of $\mathrm{P}$ induced $\mathrm{NC}$ and associated renal damage in rats fed KO. Therefore, we conclude that changing the dietary PUFA content can have profound influence on renal health in rats. This, and other data, suggests that the kidneys are heavily influenced by dietary composition, and that renal health could become compromised with the consumption of an improper diet. 


\subsection{References}

1. Jara A, Chacon C, Ibaceta M, Valdivieso A, and Felsenfeld A (2004) Effect of ammonium chloride and dietary phosphorus in the azotaemic rat. Part II-kidney hypertrophy and calcium deposition. Nephrol Dial Transpl 19: 1993-1998.

2. Cousins, F.B., \& Geary, C.P.M. (1966). A sex-determined renal calcification in rats. Nature, 211, 980-981.

3. Reevesn P.G., Rossow, K.L., and Lindlauf, J. (1993). Development and testing of the AIN-93 purified diets for rodents: results on growth, kidney calcification and bone mineralization in rats and mice. $J$ Nutr, 123, 1923-1931.

4. Reeves, P.G. (1997). Components of the AIN-93 diets as improvements in the AIN-76A diet. J Nutr, 127, S838-S841.

5. Haut, L.L., Alfrey, A.C., Guggenheim, S., Buddington, B., \& Schrier, N. (1980). Renal toxicity of phosphate in rats. Kidney Int, 17, 722-731.

6. Ritkes-Hoitinga, J., Mathot, J.N.J.J., Danse, L.H.J.C., \& Beynen, A.C. (1991). Commercial rodent diets and nephrocalcinosis in weanling female rats.

Laboratory Animals, 25, 126-132.

7. Cockell, K.A., Abbe, M.R., and Belonje, B. (2002). The concentration and ratio of dietary calcium and phosphorus influence development of nephrocalcinosis in female rats. $J$ Nutr, 132, 252-256.

8. Meyer, O., Blom, L., and Sondergaard, D. (1982). The influence of minerals and protein on the nephrocalcinosis potential for rats of semisynthetic diets. $L a b$ Anim, 16, 271-273. 
9. Zhang, X., \& Beynen, A. (1992). Increasing intake of soybean protein or casein, but not cod meal, reduces nephrocalcinosis in female rats. J Nutr, 122, 22182225 .

10. Gigliotti, J. C., Smith, A. L., Jaczynski, J., \& Tou, J. C. (2010). Consumption of krill protein concentrate prevents early renal injury and nephrocalcinosis in female Sprague-Dawley rats. Urol Res, 39, 59-67.

11. Mattson RL, Kunert MP, Kaldunski ML, Greene AS, Roman RJ, Jacob HJ, and Cowley Jr. AW (2004) Influence of diet and genetics on hypertension and renal disease in Dahl salt-sensitive rats. Physiol Genomics 16: 194-203.

12. Trujillo, J., Ramirez, V., Perez, J., Torre-Villavazo, I., Torres, N., Tovar, A.R., Munoz, R.M., Uribe, N., Gamba, G., and Bobadilla, N.A. (2005). Renal protection by a soy diet in obese Zucker rats is associated with restoration of nitric oxide generation. Am J Physiol Renal Physiol, 288, F108-F116.

13. Fassett, R.G. (2010). Omega-3 polyunsaturated fatty acids in the treatment of kidney disease. American Journal of Kidney Diseases, 56, 728-742.

14. Burgess, S.A., Reynolds, T.M., Williams, A.P., and Smith, S. (1995). Evaluation of four animal models of intrarenal calcium deposition and assessment of the influence of dietary supplementation with essential fatty acids on calcification. Urol Res, 23, 239-242.

15. Schlemmer, C.K., Coetzer, H., Claassen, N., Kruger, M.C., Rademeyer, C., van Jaarsveld, L., \& Smuts, C.M. (1998). Ectopic calcification of rat aortas and kidneys is reduced with n-3 fatty acid supplementation. Prostaglandins Leukot Essent Fatty Acids, 59, 221-227. 
16. Clark, W.F., Parbtani, A., Philbrick, D.J., Holub, B.J., and Huff, M.W. (1991). Chronic effects of $\omega-3$ fatty acids (fish oil) in a rat 5/6 renal ablation model. $J A m$ Soc Nephrol, 1, 1343-2353.

17. An, W.S., Kim, H.J., Cho, K-H., and Vaziri, N.D. (2009). Omega-3 fatty acid supplementation attenuates oxidative stress, inflammation, and tubulointerstitial fibrosis in the remnant kidney. Am J Physiol Renal Physiol, 297, F895-F903.

18. Garman, J.H., Mulroney, S., Manigrasso, M., Flynn, E., and Maric, C. (2009). Omega-3 fatty acid rich diet prevents diabetic renal disease. Am J Physiol Renal Physiol, 296, F306-F316.

19. Ogborn, M.R., Nitschmann, H.W., Leswick, D., and Bankovic-Calic, N. (1999). Flaxseed ameliorates interstitial nephritis in rat polycystic kidney disease. Kidney Int $, 55,417-423$.

20. Reeves, P.G., Nielsen, F.H., and Fahey, G.C. (1993). AIN-93 purified diets for laboratory rodents: final report of the American Institute of Nutrition ad hoc writing committee on the reformulation of the AIN-76A rodent diet. J Nutr, 123, $1939-1951$.

21. Hennig, B., Toborek, M., Joshi-Barve, S., Barger, S.W., Barve, S., Mattson, M.P., and McClain, C.J. (1996). Linoleic acid activates nucler transcription factor- $\kappa \mathrm{B}$ $(\mathrm{NF}-\kappa \mathrm{B})$ and induces NF- $\mathrm{B}-$ dependent transcription in cultured endothelial cells. Am J Clin Nutr, 63, 322-328.

22. Camandola, S., Leonarduzzi, G., Musso, T., Varesio, L., Carini, R., Scavazza, A., Chiarpottto, E., Baeuerle, P.A., and Poli, G. (1996). Nuclear factor $\kappa B$ is activated by arachidonic acid but not by eicosapentaenoic acid. Biochem Biophys Res Commun, 229, 643-647. 
23. Umekawa, T., Chegini, N., \& Khan, S.R. (2003). Increased expression of monocyte chemoattractant protein-1 (MCP-1) by renal epithelial cell in culture on exposure to calcium oxalate, phosphate and uric acid crystals. Nephrol Dial Transplant, 18, 664-669.

24. Verkoelen, C.F., \& Herhulst, A. (2007). Proposed mechanism in renal tubular crystal retention. Kidney International, 72, 13-18.

25. Schoene, N.W., Ferretti, A., and Fiore, D. (1981). Production of prostaglandins in homogenates of kidney medullae and cortices of spontaneously hypertensive rats fed menhaden oil. Lipids, 16, 866-869.

26. Coffman, T.M., Yohay, D., Carr, D.R., Brazy, P.C., Yarger, W.E., and Klotman, P.E. (1988). Effect of dietary fish oil supplementation on eicosanoid production by rat renal allografts. Transplantation, 45, 470-474.

27. Bagga, D., Wang, L., Farias-Eisner, R., Glaspy, J.A., amd Reddy, S.T. (2003). Differential effects of prostaglandin derived from $\omega-6$ and $\omega-3$ polyunsaturated fatty acids on COX-2 expression and IL-6 secretion. PNAS, 100, 1751-1756.

28. De Caterina, R. and Massaro, M. (2005). Omega-3 fatty acids and the regulation of endothelial pro-atherogenic and pro-inflammatory genes. J Membrane Biol, 206, 103-116.

29. Massaro, M., Habib, A., Lubrano, L., Del Turco, S., Lazzerini, G., Bourcier, T., Weksler, B.B., and De Caterina, R. (2006). The omega-3 fatty acid docosahexaenoate attenuates endothelial cyclooxygenase- induction through both NADP(H) oxidase and PKCE inhibition. PNAS, 103, 15184-15189.

30. Chandrasekar, B., Troyer, D.A., Venkatraman, J.T., and Fernandes, G. (1995). Dietary omega-3 lipids delay the onset and progression of autoimmune lupus 
nephritis by inhibiting transforming growth factor $\beta$ mRNA and protein expression. J Autoimmun, 8, 381-393.

31. Fritsche, K.L. and Johnston, P.V. (1990). Effect of dietary omega-3 fatty acids on cell-mediated cytotoxic activity in BALB/c mice. Nutr Res, 10, 577-588.

32. National Research Council. (1995). Nutrient requirements of laboratory animals, $4^{\text {th }}$ edition. National Academy Press, Washington, D.C.

33. Bligh, E.G. and Dyer, W.J. (1959). A rapid method of total lipid extraction and purification. Can J Physiol Pharmacol, 37, 911-917.

34. Rozen, S. and Skaletsky, H.J. (2000). Primer3 on the WWW for general users and for biologist programmers. In: Krawetz S, Misener S (eds) Bioinformatics Methods and Protocols: Methods in Molecular Biology. Humana Press, Totowa, NJ, pp 365-386

35. Pfaffl, M.W. (2001). A new mathematical model for relative quantification in real-time RT-PCR. Nucleic Acids Rec, 29, 2002-2007.

36. Ritkes-Hoitinga, J., Lemmens, A.G., Danse, L.H.J.C., \& Beynen, A.C. (1989). Phosphorus induced nephrocalcinosis and kidney function in female rats. J Nutr, $119,1423-1431$.

37. Woodard, J.C. (1971). A morphologic and biochemical study of nutritional nephrocalcinosis in female rats fed semipurified diets. Amer J Path, 65, 253-268.

38. Schmidt, R.E., Hubbard, G.B., Booker, J.L., \& Gleiser, C.A. (1980). Dietary induction of renal mineralization in dogs. Can. J. comp. Med., 44, 459-465.

39. Khan, S.R. (2004). Crystal-induced inflammation of the kidneys: results from human studies, animal models, and tissue-culture studies. Clin Exp Nephrol, 8, $75-88$. 
40. Hao, C.M. and Breyer, M.D. (2008). Physiological regulation of prostaglandins in the kidney. Annu Rev Physiol, 70, 357-377.

41. Ferretti, A., Schoene, N.W., and Flanagan, V.P. (1981). Identification and quantification of prostaglandin $\mathrm{E}_{3}$ in renal medullary tissue of three strains of rats fed fish oil. Lipids, 16, 800-804.

42. De Caterina, R., Cybulsky, M.I., Clinton, S.K., Gimbrone Jr., M.A., and Libby, P. (1994). The omega-3 fatty acid docosahexaenoate reduces cytokine-induced expression of proatherogenic and proinflammatory proteins in human endothelial cells. Arterioscler Thromb, 14, 1829-1836.

43. Katzung, B.G. (2007). Basic and clinical pharmacology. McGraw-Hill, NY.

44. Simmonds, R.E. and Foxwell, B.M. (2008). NF- $\kappa B$ and its relevance to arthritis and inflammation. Rheumatology, 47, 584-590.

45. Border, W.A. and Noble, N.A. (1997). TGF- $\beta$ in kidney fibrosis: a target for gene therapy. Kidney Int, 51, 1388-1396. 
Figure 1. Lipid Class Diagram

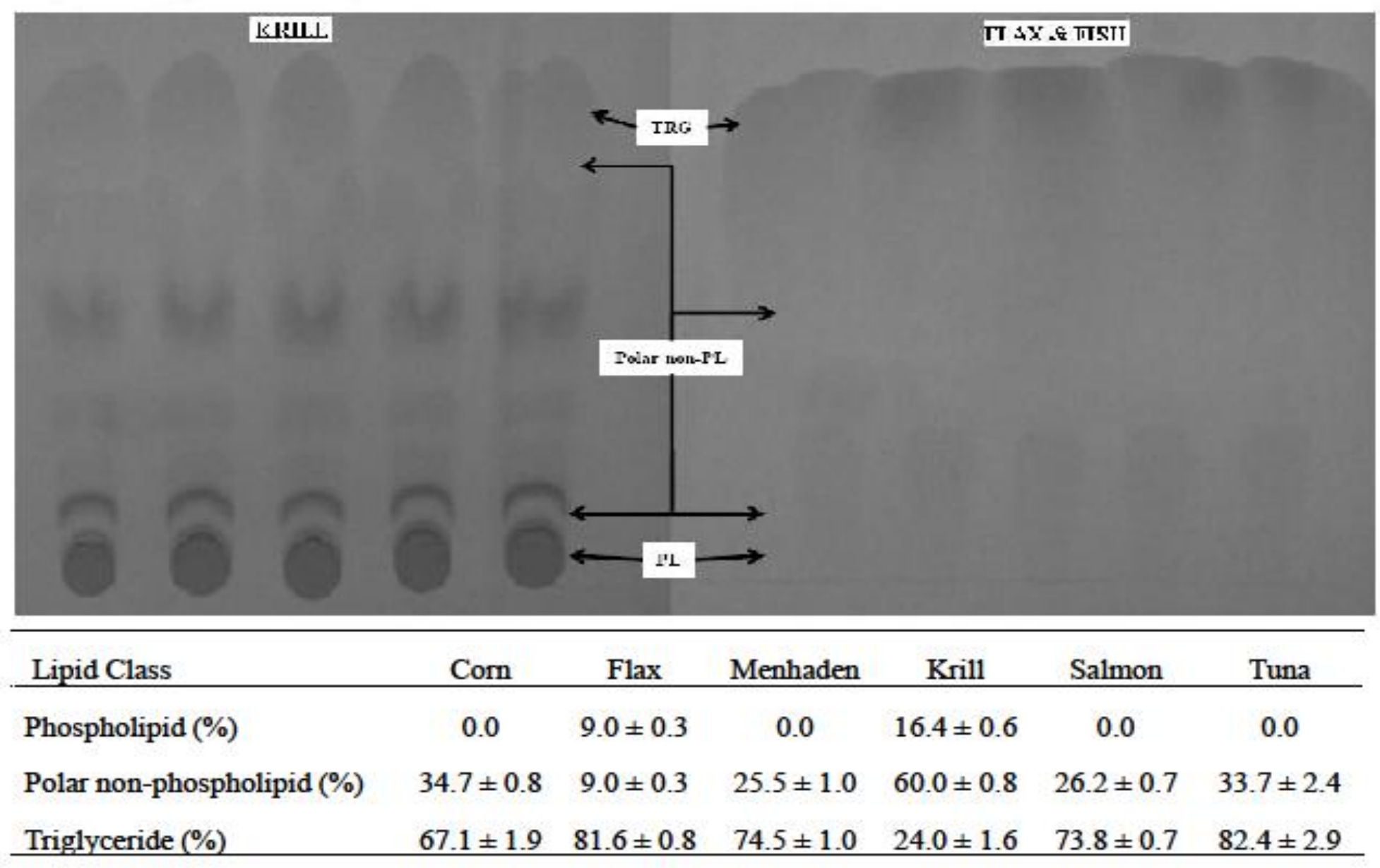


Figure 2. Histological Observations
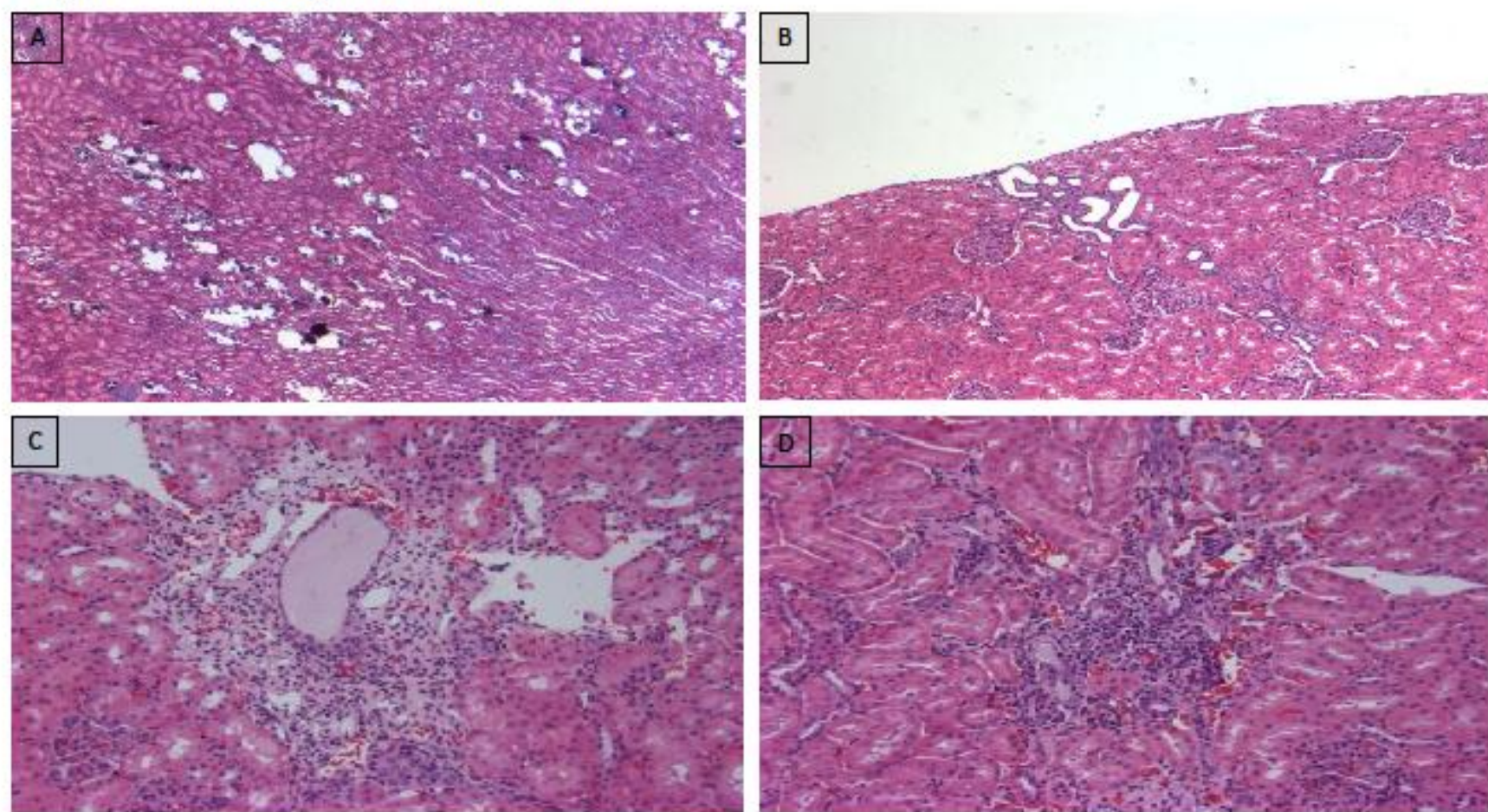

\begin{tabular}{cllllll} 
& Corn & Flaxseed & Menhaden & Krill & Salmon & Tuma \\
\hline Tubular Calcification (A) & $0 / 10$ & $1 / 10$ & $1 / 10$ & $10 / 10$ & $0 / 10$ & $1 / 10$ \\
Tubular Dilation (B) & $0 / 10$ & $0 / 10$ & $0 / 10$ & $10 / 10$ & $0 / 10$ & $1 / 10$ \\
Tubulointerstitial Changes (C) & $1 / 10$ & $6 / 10$ & $2 / 10$ & $8 / 10$ & $2 / 10$ & $1 / 10$ \\
Interstitial Inflammation (D) & $4 / 10$ & $5 / 10$ & $1 / 10$ & $10 / 10$ & $4 / 10$ & $2 / 10$ \\
\hline
\end{tabular}


Figure 3. Renal COX-II (PTGS-2) expression

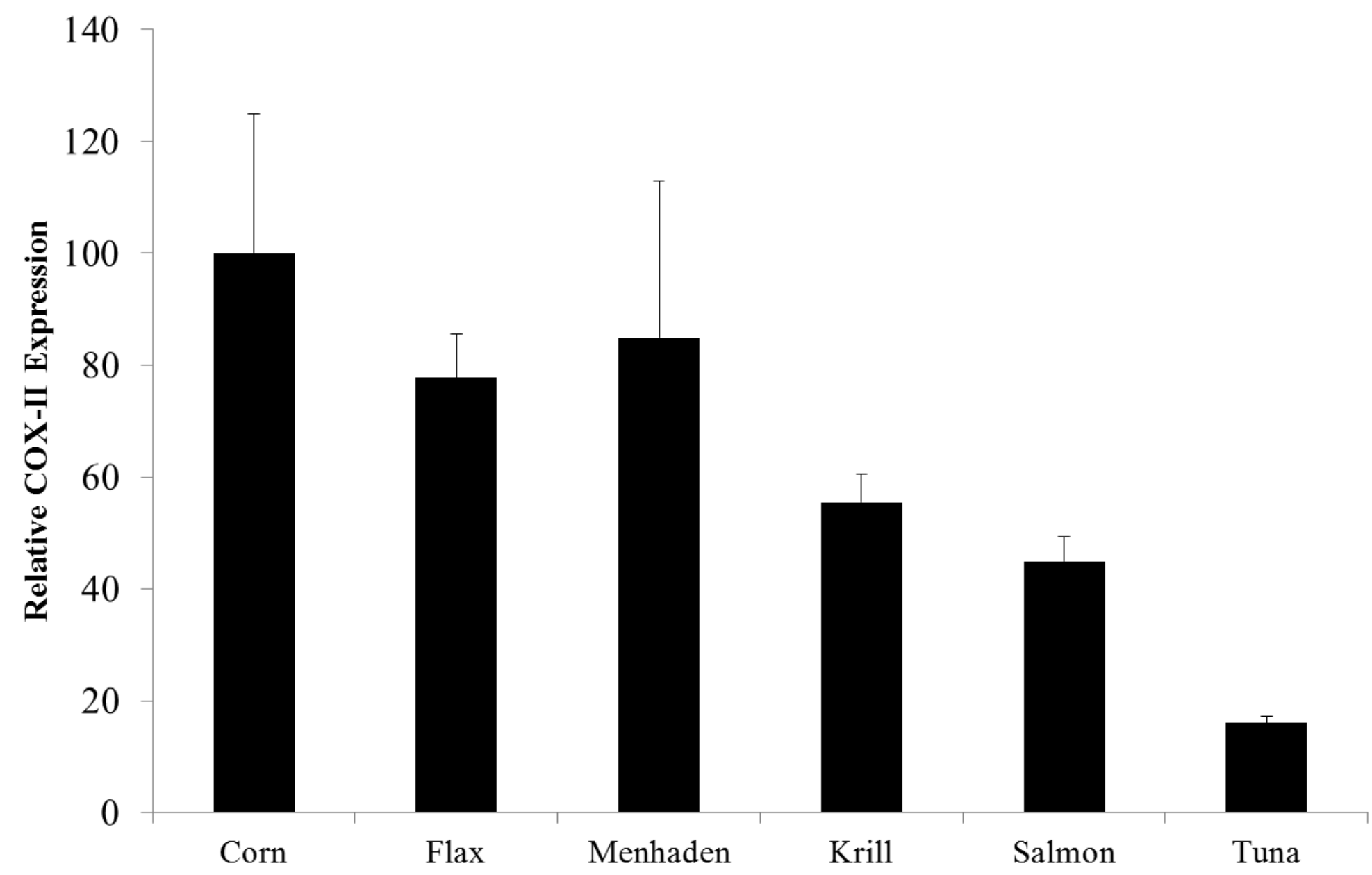


Figure 4. Renal TGF- $\beta$ expression

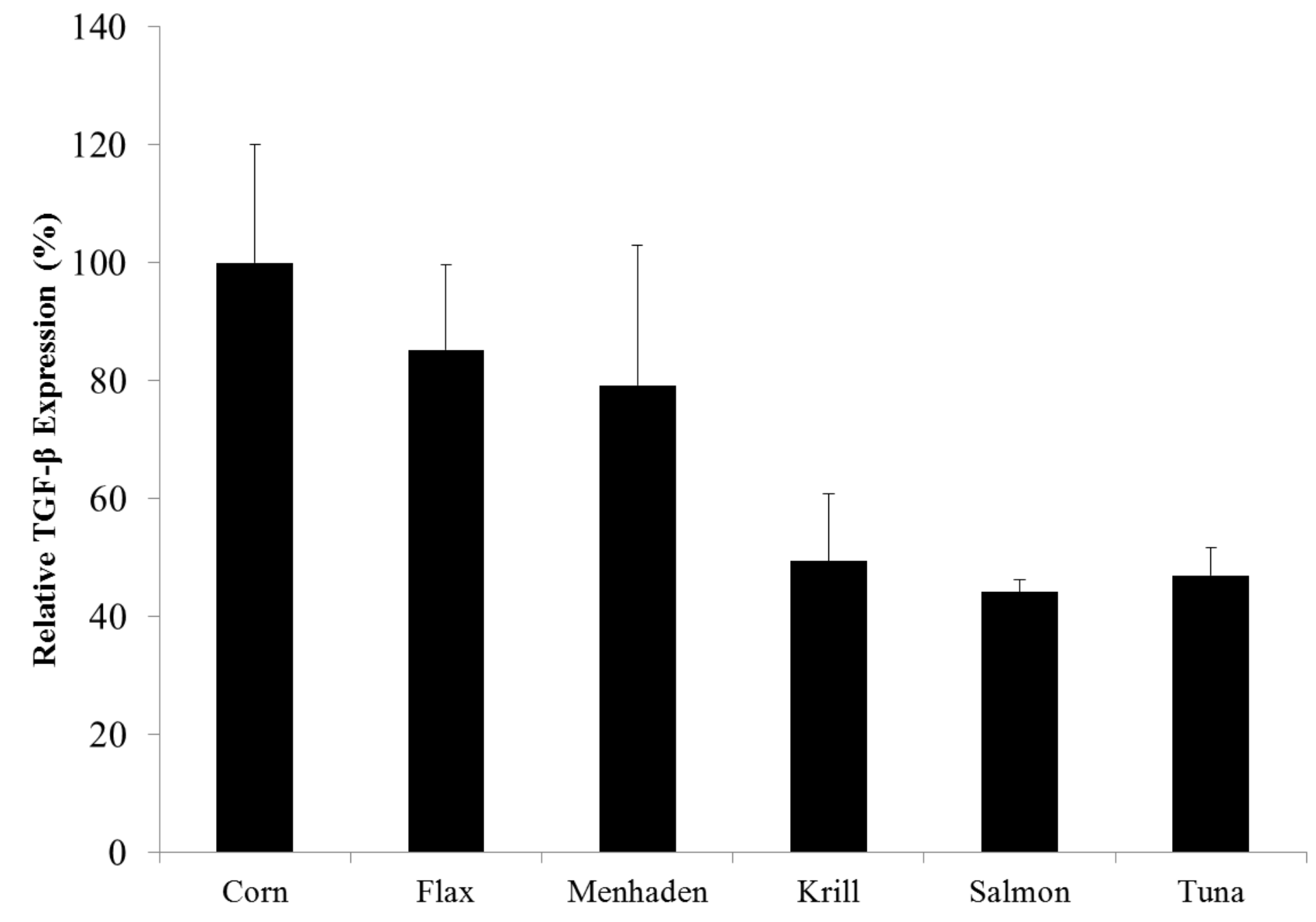


Figure 5. Renal NFkB activity.

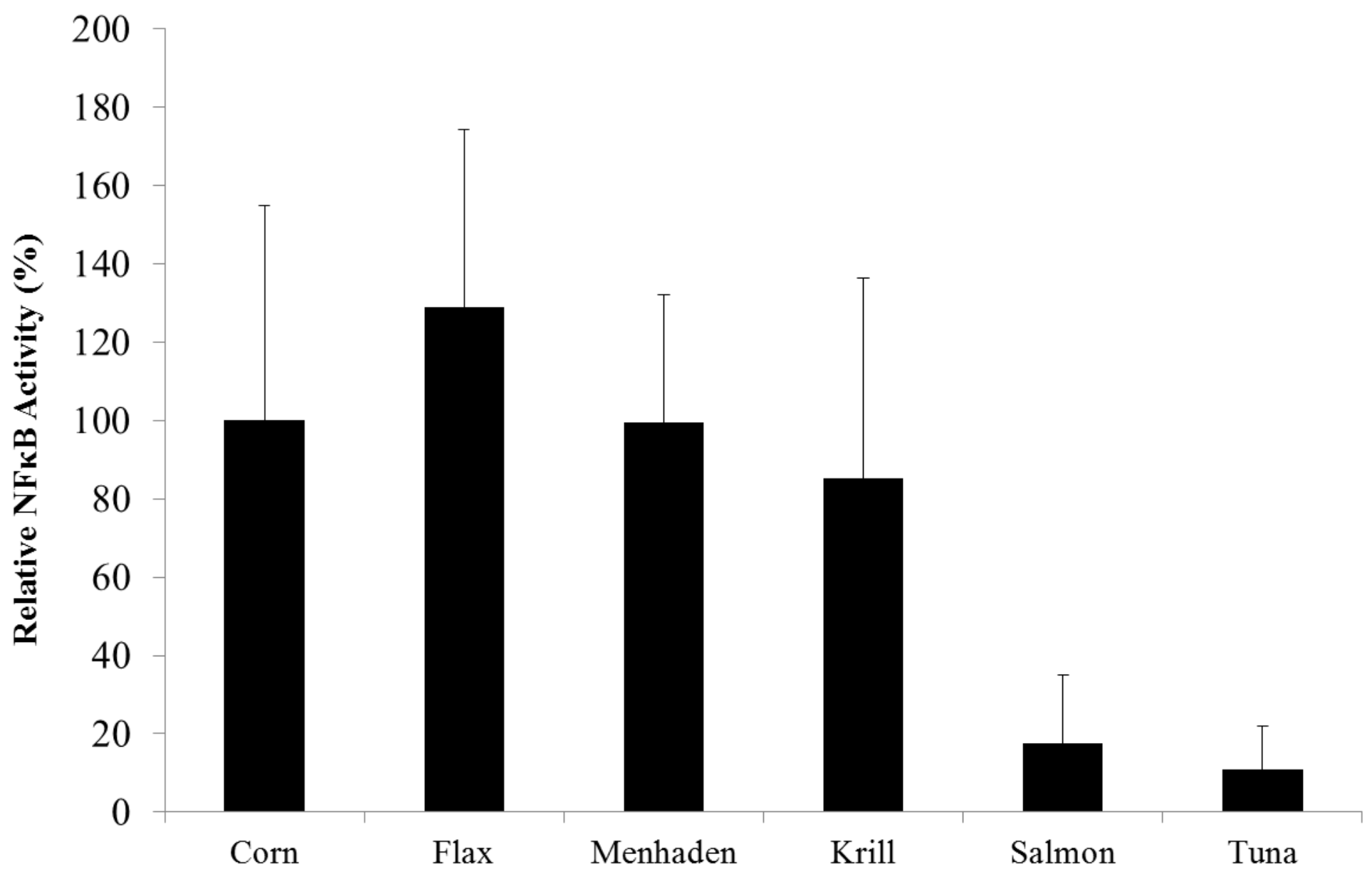


Figure 6. Urinary excretion of $\mathrm{PGE}_{2}$

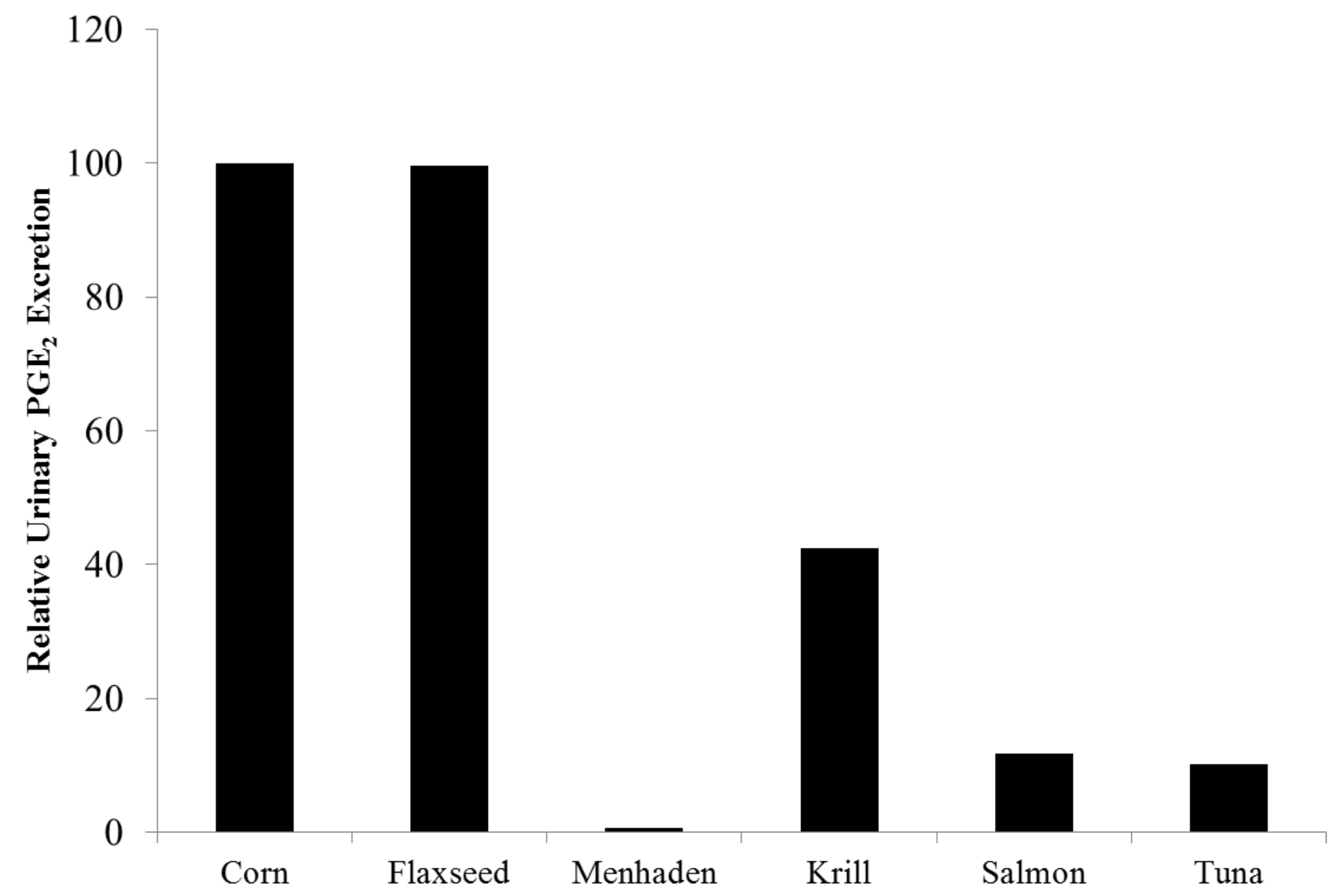


Figure 1. Representative image and quantification of lipid classes in PUFA oils of interest. Spots were quantified by densitometry and data expressed as \% of total lipid detected on TLC plate. Data presented as mean \pm SEM.

$\mathrm{TRG}=$ triglyceride, $\mathrm{PL}=$ phospholipid.

Figure 2. Representative images of identified changes in renal morphology. Data is represented as proportion of animals displaying morphological changes $(n=10)$.

Figure 3. Expression of PTGS-2 (COX-II) in renal tissue of rats fed diets varying in PUFA content. Data is reported as a percentage of expression found in rats fed corn oil.

Figure 4. Expression of TGF- $\beta$ in renal tissue of rats fed diets varying in PUFA content. Data is reported as a percentage of expression found in rats fed corn oil.

Figure 5. Activation of $\mathrm{NF} \kappa \mathrm{B}$ in renal tissue nuclear extracts of rats fed diets varying in PUFA content. Data is reported as a percentage of expression found in rats fed corn oil.

Figure 6. Urinary excretion of $\mathrm{PGE}_{2}$ in rats fed diets varying in PUFA content. Data is reported as a percentage of expression found in rats fed corn oil. 
Table 1. Experimental Diet Compositions

\begin{tabular}{lccccccc}
\hline Ingredients (g/kg diet) & AIN-93G & Corn & Flax & Menhaden $^{\text {b }}$ & Krill $^{\text {b }}$ & Salmon & Tuna $^{\prime}$ \\
\hline Soybean Oil & 70.0 & - & - & - & - & - & - \\
Corn Oil & - & 120.0 & - & 2.0 & 2.0 & - & - \\
Flaxseed Oil & - & - & 120.0 & - & - & - & - \\
Salmon Oil & - & - & - & - & - & 120.0 & - \\
Menhaden Oil & - & - & - & 118.0 & - & - & - \\
Tuna Oil & - & - & - & - & - & - & 120.0 \\
Krill Oil & - & - & - & - & 118.0 & - & - \\
Casein & 200.0 & 200.0 & 200.0 & 200.0 & 200.0 & 200.0 & 200.0 \\
L-Cysteine & 3.0 & 3.0 & 3.0 & 3.0 & 3.0 & 3.0 & 3.0 \\
Corn Starch & 397.5 & 347.5 & 347.5 & 347.5 & 347.5 & 347.5 & 347.5 \\
Maltodextrin & 132.0 & 132.0 & 132.0 & 132.0 & 132.0 & 132.0 & 132.0 \\
Sucrose & 100.0 & 100.0 & 100.0 & 100.0 & 100.0 & 100.0 & 100.0 \\
Cellulose & 50 & 50 & 50 & 50 & 50 & 50 & 50 \\
Mineral Mix & & 35 & 35 & 35 & 35 & 35 & 35
\end{tabular}




\begin{tabular}{lccccccc} 
Vitamin Mix & 10 & 10 & 10 & 10 & 10 & 10 & 10 \\
Choline Bitartrate & 2.5 & 2.5 & 2.5 & 2.5 & 2.5 & 2.5 & 2.5 \\
Antioxidant (TBHQ) & 0.014 & - & - & - & - & - & - \\
\hline
\end{tabular}

${ }^{a}$ Based on the AIN-93G vitamin and mineral mixes [7].

${ }^{\mathrm{b}}$ Diets formulated for $118 \mathrm{~g}$ of test oil $+2 \mathrm{~g}$ corn oil to meet LA requirements. 
Table 2. Fatty acid composition of experimental oils

\begin{tabular}{|c|c|c|c|c|c|c|}
\hline Fatty Acid (\%) & Corn & Flax & Menhaden & Krill & Salmon & Tuna \\
\hline $14: 0$ & - & - & 12.3 & 5.1 & 10.3 & 3.7 \\
\hline $16: 0$ & 10.5 & 4.9 & 24.3 & 31.4 & 21.9 & 16.7 \\
\hline $16: 1$ & - & - & 17.6 & 3.8 & 12.7 & 5.2 \\
\hline 18:0 & 1.6 & 2.96 & 3.1 & 1.9 & 2.9 & 4.4 \\
\hline $18: 1$ & 26.8 & 18.7 & 12.1 & 16.7 & 16.8 & 14.4 \\
\hline $18: 2(\omega 6)$ & 57.8 & 15.5 & 0.7 & 1.9 & 4.0 & 1.7 \\
\hline $18: 3(\omega 3)$ & 1.0 & 55.9 & 3.1 & 1.3 & 1.4 & 0.7 \\
\hline $20: 4(\omega 6)$ & - & - & - & - & - & 1.9 \\
\hline $20: 5(\omega 3)$ & - & - & 3.9 & 20.3 & 14.4 & 8.6 \\
\hline $22: 6(\omega 3)$ & - & - & 3.3 & 5.9 & 3.5 & 24.8 \\
\hline EPA:DHA & ND & ND & $3: 1$ & $3: 1$ & $4: 1$ & $1: 3$ \\
\hline Total $\omega 6$ & 58 & 16 & 0.7 & 2 & 4 & 3.6 \\
\hline Total $\omega 3$ & 1 & 56 & 15 & 27 & 19 & 34 \\
\hline$\omega 6: \omega 3$ & $59: 1$ & $1: 4$ & $1: 23$ & $1: 14$ & $1: 5$ & $1: 10$ \\
\hline
\end{tabular}


Table 3. Relative kidney weights, and renal $\mathrm{Ca}$ and $\mathrm{P}$ content

\begin{tabular}{|c|c|c|c|c|c|c|c|}
\hline & Corn & Flaxseed & Menhaden & Krill & Salmon & Tuna & $P$ \\
\hline Kidney weight (mg/100g BW) & $837.2 \pm 24.5^{\mathrm{ab}}$ & $749.1 \pm 16.6^{b}$ & $785.3 \pm 37.9^{b}$ & $918.7 \pm 18.3^{\mathrm{a}}$ & $823.7 \pm 22.1^{\mathrm{ab}}$ & $830.7 \pm 12.7^{\mathrm{ab}}$ & $<0.001$ \\
\hline Kidney Ca content (mg/g) & $0.21 \pm 0.02^{b}$ & $0.21 \pm 0.02^{b}$ & $0.21 \pm 0.02^{b}$ & $0.58 \pm 0.12^{\mathrm{a}}$ & $0.18 \pm 0.02^{b}$ & $0.18 \pm 0.02^{b}$ & $<0.001$ \\
\hline Kidney P content (mg/g) & $2.40 \pm 0.06^{\mathrm{ab}}$ & $2.43 \pm 0.05^{\mathrm{ab}}$ & $2.31 \pm 0.09^{b}$ & $2.88 \pm 0.27^{\mathrm{a}}$ & $2.47 \pm 0.03^{\mathrm{ab}}$ & $2.49 \pm 0.03^{\mathrm{ab}}$ & 0.03 \\
\hline
\end{tabular}


Table 4. Total lipid and fatty acid content of kidney tissue

\begin{tabular}{|c|c|c|c|c|c|c|}
\hline & Corn & Flax & Menhaden & Krill & Salmon & Tuna \\
\hline Kidney lipid content (mg/g) & $43.3 \pm 8.8$ & $44.6 \pm 4.6$ & $42.7 \pm 2.7$ & $36.2 \pm 5.3$ & $31.8 \pm 3.5$ & $35.0 \pm 5.1$ \\
\hline \multicolumn{7}{|l|}{ Fatty Acid (\%) } \\
\hline $16: 0$ & $23.53 \pm 0.24$ & $22.42 \pm 0.25$ & $25.30 \pm 0.44$ & $25.05 \pm 0.56$ & $26.64 \pm 0.57$ & $28.06 \pm 0.55$ \\
\hline $16: 1$ & - & $1.10 \pm 0.07$ & $2.23 \pm 0.16$ & $1.58 \pm 0.10$ & $2.16 \pm 0.14$ & $2.05 \pm 0.21$ \\
\hline 18:0 & $13.51 \pm 0.41$ & $13.93 \pm 0.33$ & $13.81 \pm 0.45$ & $14.81 \pm 0.20$ & $15.80 \pm 0.43$ & $15.20 \pm 0.57$ \\
\hline $18: 1$ & $11.93 \pm 1.19$ & $13.80 \pm 0.54$ & $11.86 \pm 0.65$ & $11.83 \pm 0.45$ & $13.39 \pm 0.63$ & $13.92 \pm 0.80$ \\
\hline $18: 2(\omega 6)$ & $11.85 \pm 0.89$ & $11.68 \pm 0.28$ & $3.18 \pm 0.23$ & $2.77 \pm 0.12$ & $2.39 \pm 0.19$ & $2.17 \pm 0.13$ \\
\hline $18: 3(\omega 3)$ & - & $4.01 \pm 0.24$ & - & - & - & - \\
\hline $20: 4(\omega 6)$ & $20.95 \pm 1.04$ & $10.83 \pm 0.32$ & $13.11 \pm 0.36$ & $9.90 \pm 0.48$ & $11.96 \pm 0.58$ & $14.57 \pm 1.09$ \\
\hline $20: 5(\omega 3)$ & - & $4.52 \pm 0.26$ & $6.73 \pm 0.36$ & $9.69 \pm 0.54$ & $8.86 \pm 0.32$ & $5.08 \pm 0.27$ \\
\hline $22: 6(\omega 3)$ & $1.05 \pm 0.08$ & $1.81 \pm 0.06$ & $6.54 \pm 0.36$ & $6.16 \pm 0.37$ & $4.71 \pm 0.15$ & $5.56 \pm 0.15$ \\
\hline EPA:DHA & $0: 1$ & $3: 1$ & $1: 1$ & $2: 1$ & $2: 1$ & $1: 1$ \\
\hline Total $\omega 6$ & 33 & 23 & 16 & 13 & 14 & 17 \\
\hline Total $\omega 3$ & 1 & 10 & 13 & 16 & 13 & 11 \\
\hline
\end{tabular}


Table 5. Serum measures of kidney function

\begin{tabular}{|c|c|c|c|c|c|c|c|}
\hline Measurement & Corn & Flax & Menhaden & Krill & Salmon & Tuna & $\boldsymbol{P}$ \\
\hline BUN (mg/dL) & $10.7 \pm 1.3^{b}$ & $10.7 \pm 1.3^{\mathrm{ab}}$ & $13.6 \pm 0.9^{\mathrm{ab}}$ & $12.2 \pm 0.7^{\mathrm{ab}}$ & $15.2 \pm 0.9^{\mathrm{a}}$ & $13.1 \pm 0.6^{\mathrm{ab}}$ & 0.04 \\
\hline Serum creatinine (mg/dL) & $0.5 \pm 0.04$ & $0.5 \pm 0.02$ & $0.5 \pm 0.04$ & $0.4 \pm 0.05$ & $0.7 \pm 0.09$ & $0.6 \pm 0.08$ & 0.2 \\
\hline BUN/Creatinine & $22.7 \pm 1.7$ & $26.1 \pm 2.6$ & $33.5 \pm 5.4$ & $30.6 \pm 3.8$ & $23.4 \pm 4.3$ & $27.7 \pm 4.7$ & 0.5 \\
\hline Serum phosphorus(mg/dL) & $9.4 \pm 0.7$ & $10.1 \pm 0.3$ & $10.4 \pm 0.6$ & $9.7 \pm 0.4$ & $9.8 \pm 0.5$ & $10.1 \pm 0.2$ & 0.8 \\
\hline Serum calcium (mg/dL) & $13.4 \pm 1.0$ & $13.6 \pm 0.5$ & $13.9 \pm 1.0$ & $14.6 \pm 1.3$ & $13.0 \pm 0.5$ & $12.6 \pm 0.3$ & 0.7 \\
\hline Serum protein $(\mathrm{g} / \mathrm{dL})$ & $5.8 \pm 0.4$ & $6.1 \pm 0.3$ & $6.3 \pm 0.1$ & $6.2 \pm 0.3$ & $6.3 \pm 0.2$ & $6.0 \pm 0.2$ & 0.7 \\
\hline $\mathrm{CrC}(\mathrm{ml} / \mathrm{min})$ & $0.65 \pm 0.1$ & $0.59 \pm 0.1$ & $0.71 \pm 0.08$ & $0.80 \pm 0.2$ & $0.48 \pm 0.2$ & $0.99 \pm 0.2$ & 0.3 \\
\hline
\end{tabular}


Table 6. Urinary measures of kidney health and function during the final week of the study

\begin{tabular}{|c|c|c|c|c|c|c|c|}
\hline Measurement & Corn & Flax & Menhaden & Krill & Salmon & Tuna & $\boldsymbol{P}$ \\
\hline Urinary output $(\mathrm{ml} / \mathrm{d})$ & $4.3 \pm 0.7$ & $4.0 \pm 0.6$ & $4.2 \pm 0.6$ & $3.5 \pm 0.7$ & $4.0 \pm 0.6$ & $4.6 \pm 1.0$ & 0.9 \\
\hline Urinary albumin $(\mathrm{mg} / 7 \mathrm{~d})$ & $3.3 \pm 1.4$ & $4.3 \pm 1.2$ & $2.1 \pm 0.5$ & $6.6 \pm 3.1$ & $3.0 \pm 1.0$ & $2.5 \pm 0.7$ & 0.4 \\
\hline Urinary $\mathrm{Ca}$ (final) $(\mathrm{mg} / 7 \mathrm{~d})$ & $4.7 \pm 2.1^{\mathrm{ab}}$ & $4.0 \pm 0.9^{\mathrm{a}}$ & $4.7 \pm 1.5^{\mathrm{a}}$ & $3.6 \pm 1.5^{\mathrm{ab}}$ & $1.5 \pm 0.3^{\mathrm{ab}}$ & $0.9 \pm 0.2^{b}$ & 0.009 \\
\hline Urinary P (final) (mg/7d) & $30.3 \pm 13.05^{b}$ & $52.7 \pm 12.2^{b}$ & $29.2 \pm 9.2^{b}$ & $149.2 \pm 14.5^{\mathrm{a}}$ & $18.5 \pm 2.3^{b}$ & $22.38 \pm 4.5^{\mathrm{b}}$ & $<0.001$ \\
\hline Change in urinary $\mathrm{pH}(\%)$ & $-1.28 \pm 0.7^{b}$ & $0.48 \pm 0.4^{\mathrm{b}}$ & $-4.07 \pm 4.3^{b}$ & $-9.79 \pm 4.7^{\mathrm{a}}$ & $-0.06 \pm 0.07^{\mathrm{b}}$ & $-0.29 \pm 0.33^{b}$ & $<0.001$ \\
\hline
\end{tabular}




\subsection{Results and conclusion}

Results presented here suggest that dietary components can have profound influence on renal health in female rats. We found that changing the protein source (from casein to KPC) led to reduced NC and associated renal damage. KPC contained residual lipid, which we described as being a unique $\omega$-3 PUFA source in regards to lipid content. To determine if the residual $\omega-3$ PUFA content was responsible for the observed benefits of KPC, we formulated casein-based diets that contained variable PUFA content. To our surprise, the diet rich in the "proinflammatory" $\omega-6$ PUFAs did not result in NC. Female rats fed krill oil developed NC, and this appeared to be due to the high PL (and subsequent high dietary P) content of the krill oil. Aside from NC, changing the dietary PUFA content resulted in extreme variations in renal tissue PUFA composition. In vitro studies have suggested that manipulating the PUFA content can modulate the activity of proinflammatory mediators such as $\mathrm{PGE}_{2}$, as well as proinflammatory signaling. Providing $\omega$-3 PUFAs lead to reduced excretion of $\mathrm{PGE}_{2}$ and reduced expression of proinflammatory mediators. Differences were also found among the dietary sources of $\omega-3$ PUFAs, in regards to both tissue PUFA content and elicited physiological responses.

Therefore, we conclude that:

1.) diet has a profound influence on renal health in non-diseased female rats,

2.) changing the source of protein from casein to KPC influenced the development of $\mathrm{NC}$ in female rats,

3.) krill oil has a unique lipid composition that is sensitive to processing methods,

4.) PUFAs do not appear to modulate diet induced NC in female rats,

5.) consumption of $\omega-3$ PUFAs influences inflammatory signaling in non-diseased female rats, and 
6.) lipid content and physiological responses varies among dietary $\omega-3$ PUFA sources.

The results presented here provide valuable information to the fields of nutrition, agriculture, physiology, and cell biology. By understanding the interaction of diet and physiology, we can develop preventative measures to help decrease the prevalence of morbid diseases. 